University of Louisville

ThinkIR: The University of Louisville's Institutional Repository

8-2007

\title{
Creativity and economic development : exploring the relationship between index rank, index components and economic development context.
}

Stephen Dennis Rausch

University of Louisville

Follow this and additional works at: https://ir.library.louisville.edu/etd

\section{Recommended Citation}

Rausch, Stephen Dennis, "Creativity and economic development : exploring the relationship between index rank, index components and economic development context." (2007). Electronic Theses and

Dissertations. Paper 1186.

https://doi.org/10.18297/etd/1186

This Doctoral Dissertation is brought to you for free and open access by ThinkIR: The University of Louisville's Institutional Repository. It has been accepted for inclusion in Electronic Theses and Dissertations by an authorized administrator of ThinkIR: The University of Louisville's Institutional Repository. This title appears here courtesy of the author, who has retained all other copyrights. For more information, please contact thinkir@louisville.edu. 


\title{
CREATIVITY AND ECONOMIC DEVELOPMENT: EXPLORING THE RELATIONSHIP BETWEEN INDEX RANK, INDEX COMPONENTS AND ECONOMIC DEVELOPMENT CONTEXT
}

\author{
By \\ Stephen Dennis Rausch
}

\author{
A Dissertation \\ Submitted to the Faculty of the \\ Graduate School of the University of Louisville \\ in Partial Fulfillment of the Requirements \\ for the Degree of
}

Doctor of Philosophy

Department of Urban and Public Affairs

University of Louisville

Louisville, KY

August 2007 
Copyright 2007 by Stephen D. Rausch

All rights reserved 


\title{
CREATIVITY AND ECONOMIC DEVELOPMENT: EXPLORING THE RELATIONSHIP BETWEEN INDEX RANK, INDEX COMPONENTS AND ECONOMIC DEVELOPMENT CONTEXT
}

\author{
By \\ Stephen D. Rausch \\ B.A., Bellarmine College, 1971 \\ M.B.A., Indiana University Southeast, 1996
}

A Dissertation Approved on

July 23, 2007

By the following Dissertation Committee:

Dissertation Director 


\section{DEDICATION}

This dissertation is dedicated to my children who continually inspire me to raise my expectations. 


\section{ACKNOWLEDGMENTS}

I would like to thank my dissertation advisor, Dr. Cynthia Negrey, for her guidance, patience, support and direction throughout my Ph.D. studies. I also appreciate the guidance and contribution of my other committee members, Dr. Hank Savitch, Dr. Peter B. Meyer, Dr. Steven Koven, and Dr. Wei-Bin Zeng. In addition, I would like to thank the professors in the Departments of Sociology, Urban and Public Affairs, and Political Science whose instruction was invaluable in the completion of this work, particularly Dr. Wayne Usui, Dr. Thomas Lyons, and Dr. David Imbroscio.

I would also like to express my thanks to my classmates in the Department of Urban and Public Affairs, Dr. Anar Valiyev, Dr. Jian Sun, and Ming Yin without whose assistance the completion of this effort would have been impossible. A special thanks to Dr. Susan Opp for her review of material in this document. 


\begin{abstract}
CREATIVITY AND ECONOMIC DEVELOPMENT: EXPLORING THE RELATIONSHIP BETWEEN INDEX RANK, INDEX COMPONENTS AND ECONOMIC DEVELOPMENT CONTEXT
\end{abstract}

\author{
Stephen D. Rausch
}

July 23, 2007

Richard Florida's (2002a and b) work ranks 276 U. S. Metropolitan Statistical Areas (MSA) according to a creativity index. This dissertation explores whether the creativity index or its subcomponents are related to the economic strength or growth in MSAs. The dissertation initially explores the relationship between the creativity index or the proportion of the creative class in an MSA with measures of per capita income and mean earnings adjusted for cost-of-living and region. It further tests the relationship between the creativity index or the proportion of the creative class in an MSA and economic strength and growth where economic strength is operationalized using Gross Metropolitan Product (GMP) per capita for the year 2000 and economic growth is operationalized by the percent change in GMP from 2000 to 2004 and from 2000 to 2005. These economic measures are tested against the components of the creativity index for the year 2000 as defined in the softcover edition (Florida 2002b).

In addition, this dissertation explores whether "creative" metropolitan areas are in fact "better," from a quality of life perspective, as a result of "creativity." I test the relationship between the proportion of the creative class in an MSA in 2000 and measures 
of poverty, homelessness, and crime in all the MSAs for which data are available. Using only the 49 largest MSAs, I conduct an exploratory factor analysis of the creativity components and several measures of culture and economic development context to determine if the three components of the creativity index - technology, talent and tolerance - emerge as reasonable dimensions. The gender wage gap is an element of culture. I test whether this wage gap is smaller in MSAs with high creativity indices than in MSAs with lower creativity indices. Using backward regression analysis I test for significant economic context variables against GMP percent change and then test whether the inclusion of the culturally related subcomponents of the creativity index in the independent variable set adds any explanatory power to the regression models. Finally, I present the results of qualitative research for four specific MSAs - Louisville, Nashville, Indianapolis and Raleigh-Durham.

The results raise questions as to the whether the concentration of the creative class in an MSA acts as an economic engine, or as a positive influence, on quality of life. These conclusions are based on the analysis of correlations, various linear regression models, and qualitative analysis in selected MSAs and therefore do not constitute causal arguments. 


\section{TABLE OF CONTENTS}

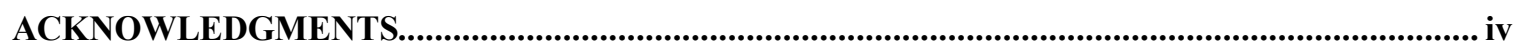

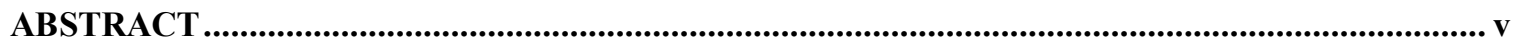

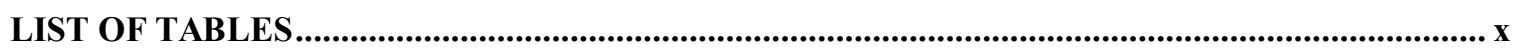

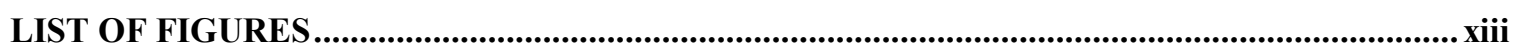

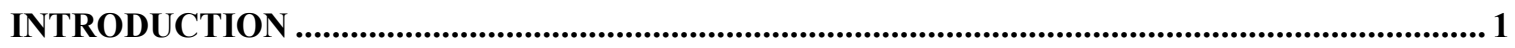

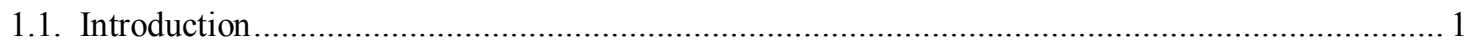

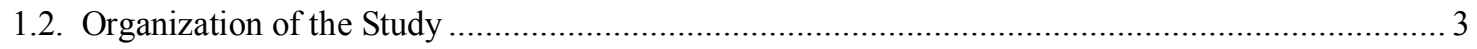

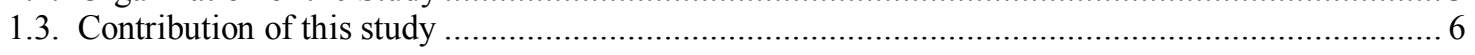

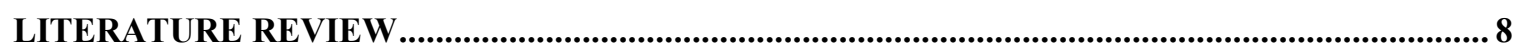

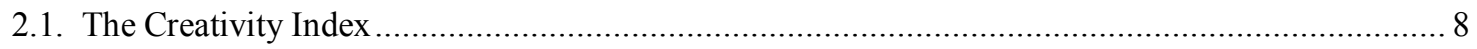

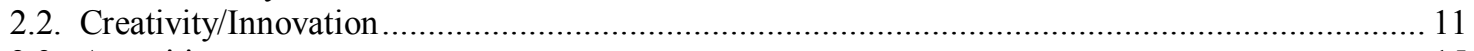

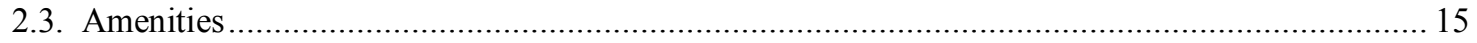

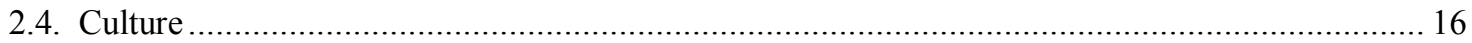

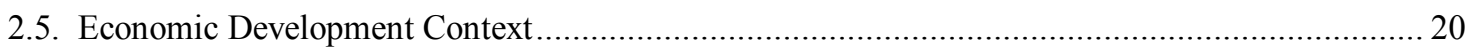

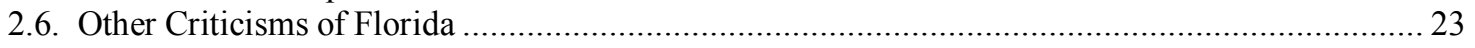

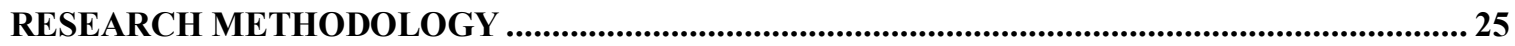

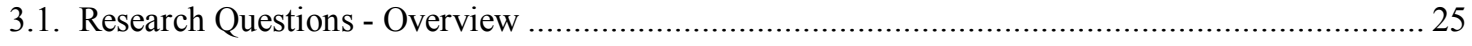

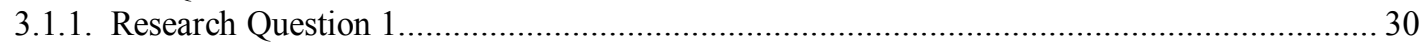

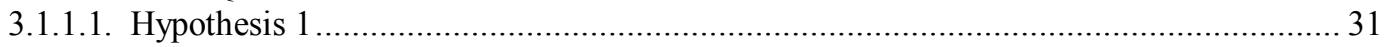

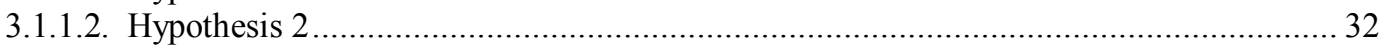

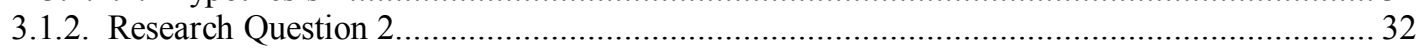

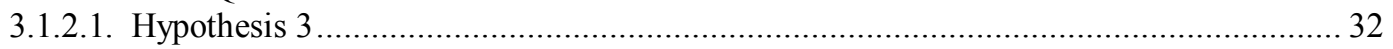

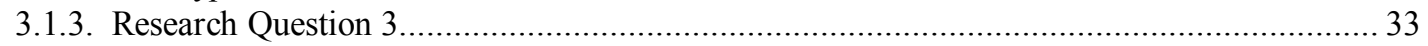

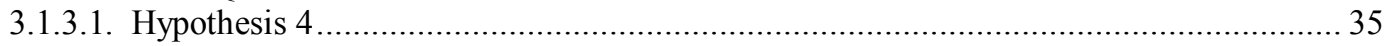

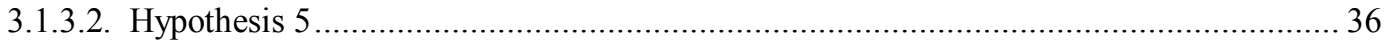

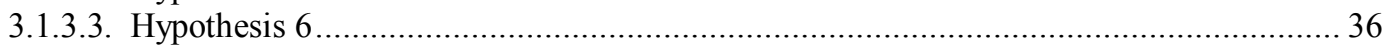

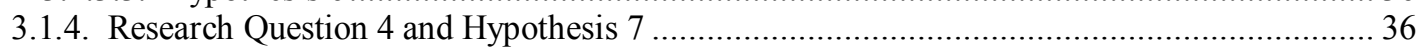

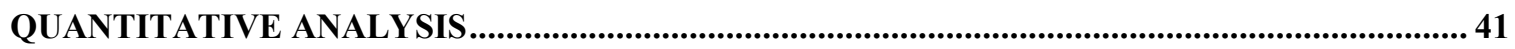

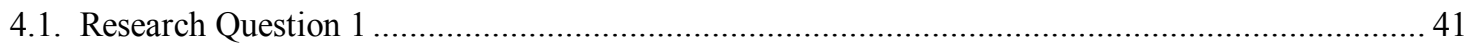

4.1.1. Hypothesis 1: Creativity Index vs. Income and Earnings .................................................... 41

4.1.2. Hypothesis 2: Creative class percentage vs. GMP measures ................................................. 49

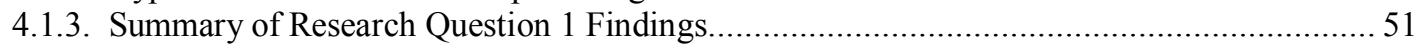

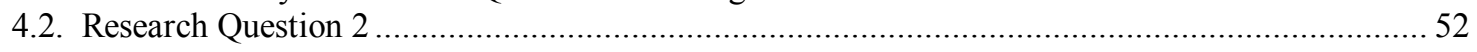

4.2.1. Hypothesis 3: Creativity index components vs. GMP measures...................................... 52

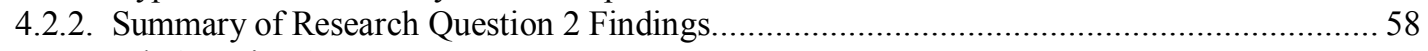

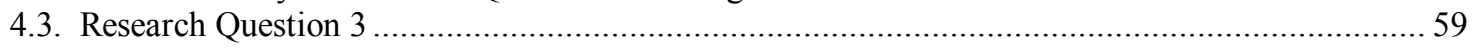

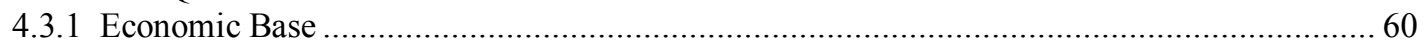




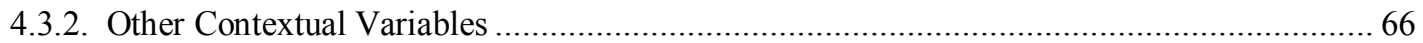

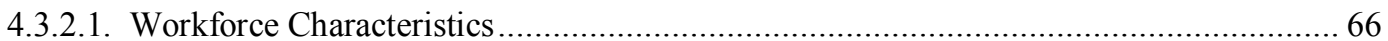

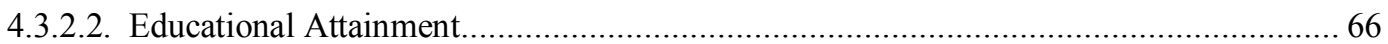

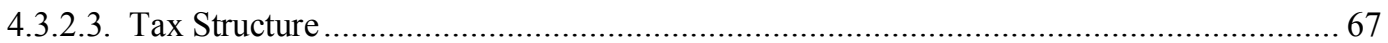

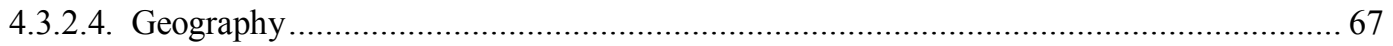

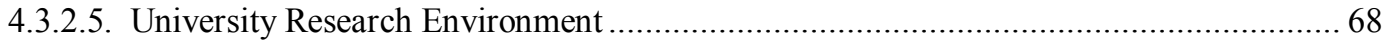

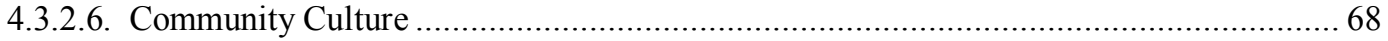

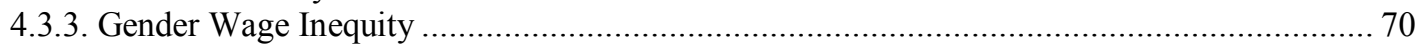

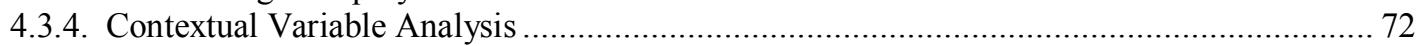

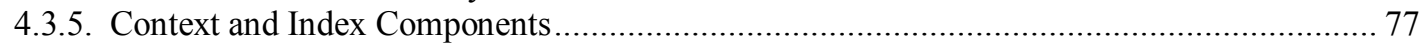

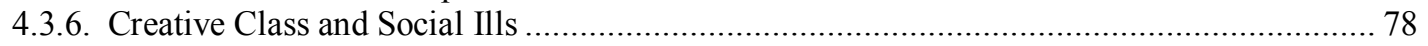

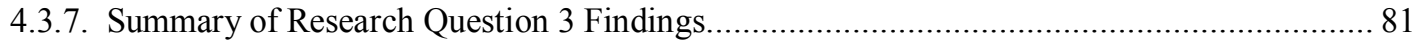

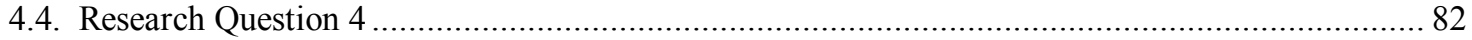

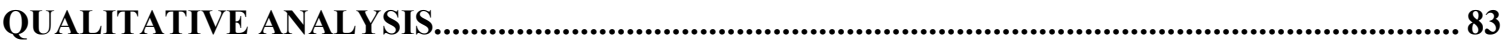

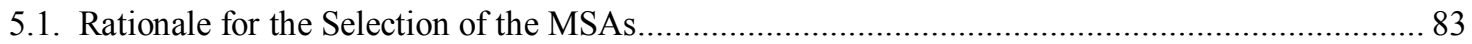

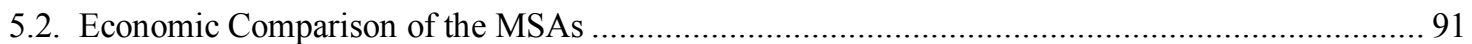

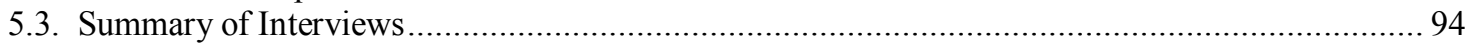

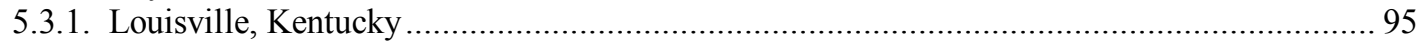

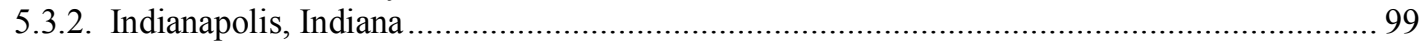

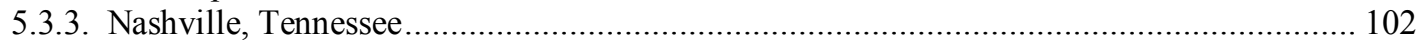

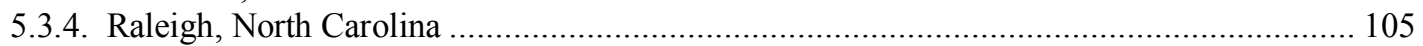

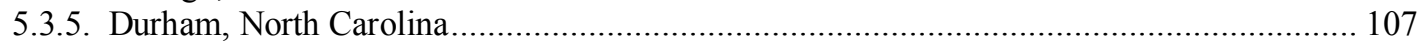

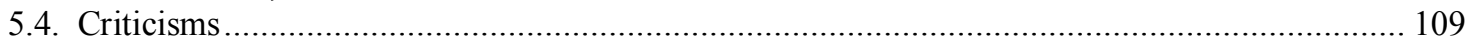

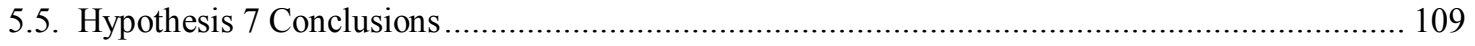

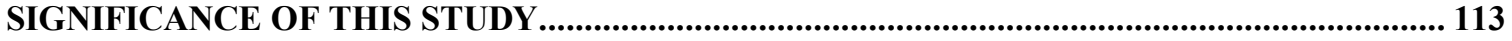

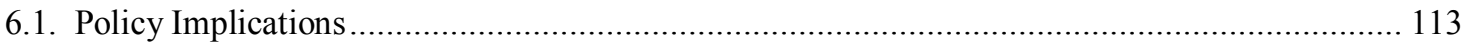

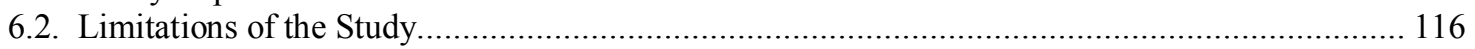

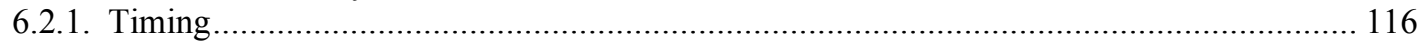

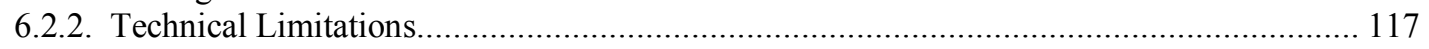

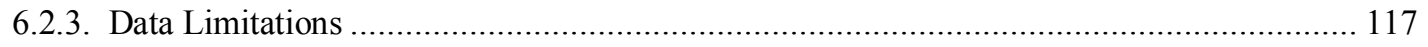

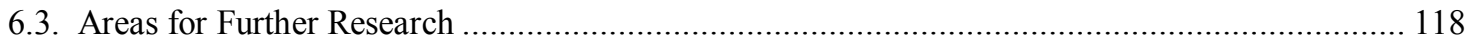

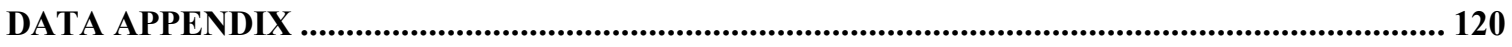

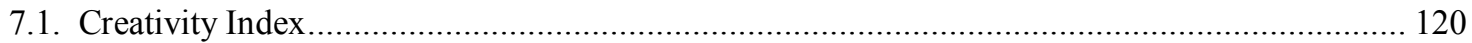

7.1.1. Reconstruction of Creativity Index Components ............................................................ 122

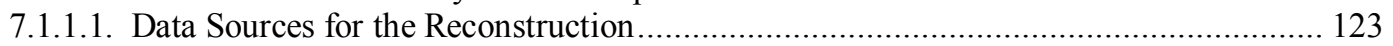

7.1.1.1.1. The Occupational Employment Survey ……....................................................... 123

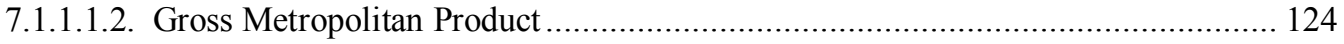

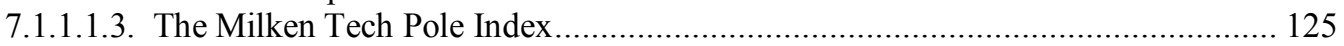

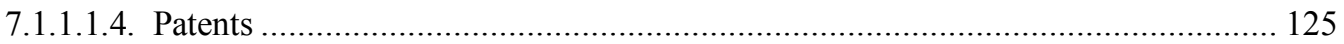

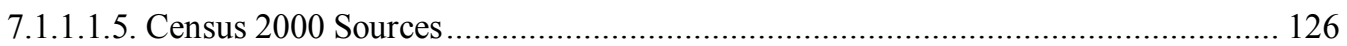

7.1.1.2. New Haven and Boston Special Considerations.......................................................... 128

7.1.2. Comparison of Reconstruction to Original Data ........................................................... 128

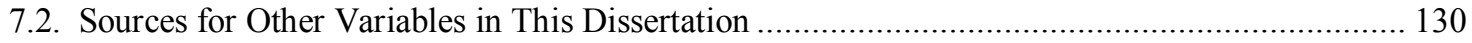

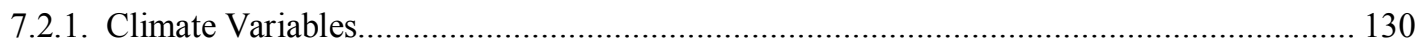

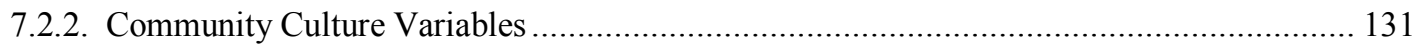

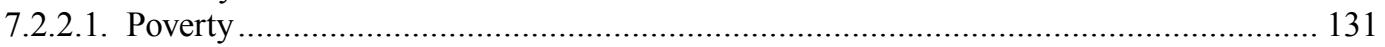

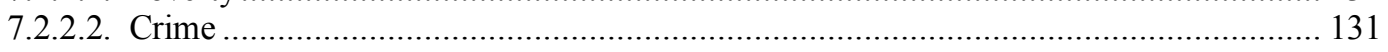

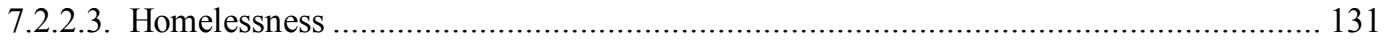

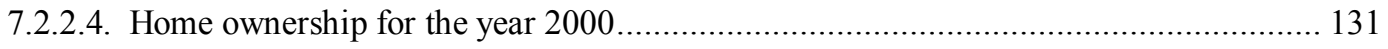

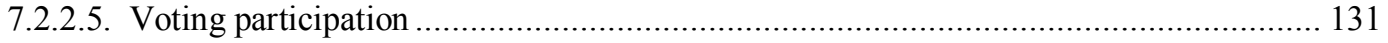

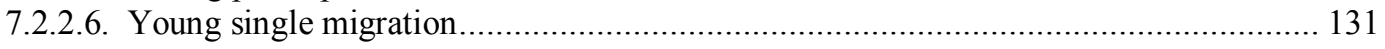

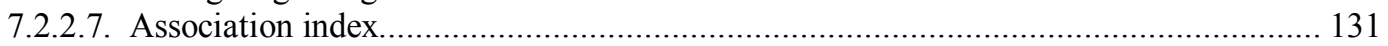


7.3. Correlation Matrices for the Linear Regressions in Research Question 2 ................................. 131

7.3.1. Data Checks for Regressions in Research Question 2 ................................................. 131

7.3.2. Correlation Matrix for Context Variables..................................................................... 132

7.3.3. Regression Results for Contextual Variables with Creativity Index Subcomponents ........... 140

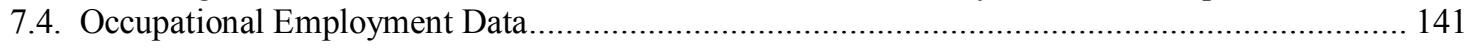

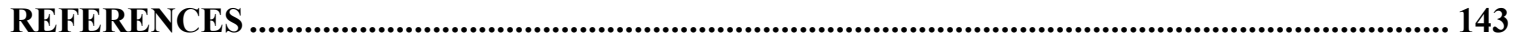

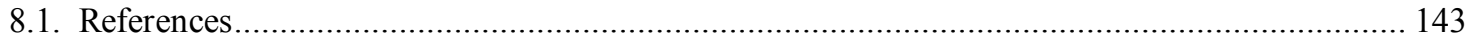

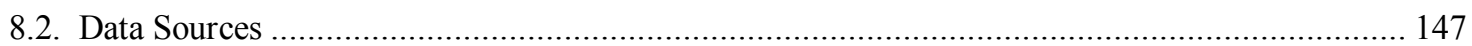

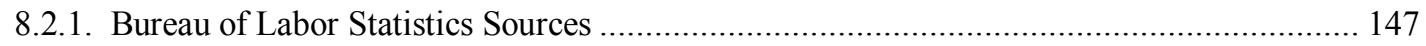

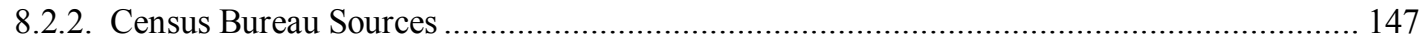

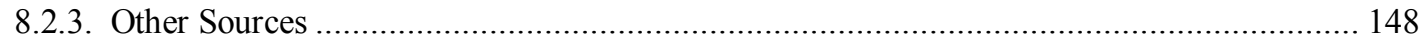

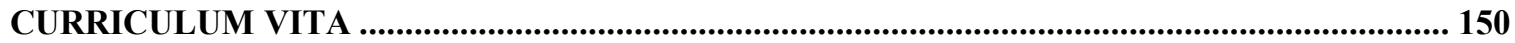




\section{LIST OF TABLES}

TABLE 1: CREATIVITY INDEX RANKINGS For STUDIED MSAs........................................................... 38

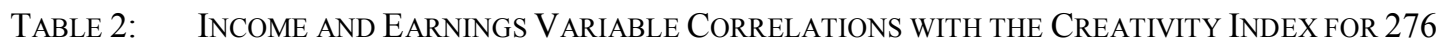

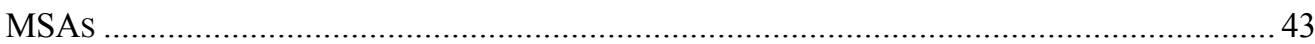

Table 3: Income and Earnings Variable Correlations with the Percentage of the

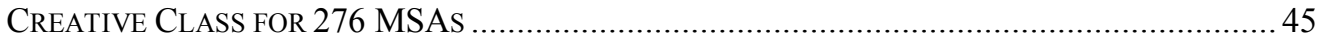

Table 4: Regression Results for Per Capita Income and Creative Class Mean Earnings WITH REGIONAL CONTROLS AT THE MSA/CMSA LEVEL ....................................................... 47

Table 5: Regression Results for Per Capita Income and Creative Class Mean Earnings WITH REgIONAL CONTROLS AT THE MSA/PMSA LEVEL ..................................................... 48

TABLE 6: CORRELATIONS OF GMP WITH INCOME DATA FOR 276 MSA/CMSAS AND 318

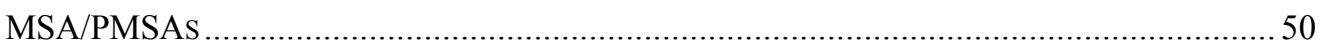

Table 7: Correlations of the Creativity IndeX and Percentage of the Creative Class with Year 2000GMP and Percent Change IN GMP From 00-04 AND 00-05 .................... 51

TABLE 8: REgRESSION RESUlts FOR GMP PER CAPITA (2000) WITH INDEPENDENT VARIABLES IN

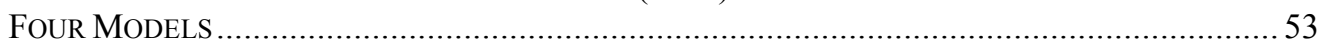

TABLE 9: REgRESSION RESUlts FOR GMP PER CAPITA (2000) WITH INDEPENDENT VARIABLES IN FOUR MODELS (8 OUTLIERS REMOVED)

TABle 10: Regression Results For GMP Percent Change From 2000 to 2004 With

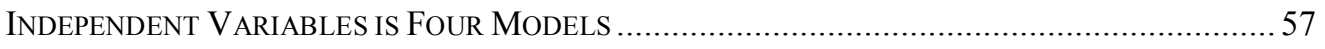

TABle 11: Regression Results For GMP PerCent ChANGe From 2000 to 2005 With INDEPENDENT VARIABLES IS FOUR MODELS ................................................................... 58

TABLE 12: SPSS Total VARIANCE EXPLAINED TABLE For LoCAL INDUSTRY FACtORS ........................ 62

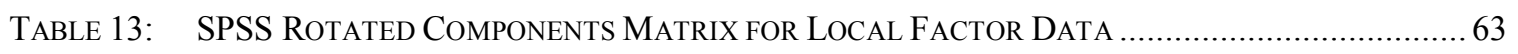

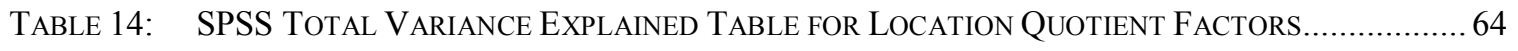

TABLE 15: SPSS RotATEd COMPONENTS MatriX For LoCAL FACTOR DATA …….................................. 65

Table 16: Differences in Creative Class Mean Earnings for Top 10 and Bottom 10 Large

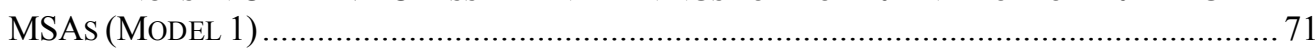


Table 17: Differences in Male/Female Creative Class Mean Earnings in Top 10 and BOTTOM 10 LARGE MSAS (MODEL 2).

Table 18: Differences in Creative Class Mean Earnings for Top 16 And Bottom 16 Large MSAS (MODEL 3)..... 71

Table 19: Differences in Male/Female Creative Class Mean Earnings in Top 16 And BotTom 16 LARGE MSAs (Model 4) .................................................................... 72

TABlE 20: REgRESSION RESUlts OF GMP PER CAPITA WITH CONTEXTUAL VARIABLES ........................ 73

Table 21: Regression of Percent Change in GMP from 2000 to 2004 with Contextual VARIABLES.

Table 22: Regression of Percent Change in GMP from 2000 to 2005 with ConteXtual VARIABLES.

Table 23: Regressions of Context Variables Adding Percentage of the Creative Class....... 76

Table 24: Regression of Percent Change In GMP From 2000 to 2005 With CONTEXTUAL VARIABLES AND CREATIVITY INDEX SUBCOMPONENTS .............................................. 77

Table 25: Regression Results of Percent Poverty (DV) Against Creative Class PERCENTAGE 79

Table 26: Regression Results of Percent Homelessness (DV) against Creative Class PERCENTAGE 80

Table 27: Regression Results of Crime Rate Per 100,000 (DV) Against Creative Class PERCENTAGE

TABLE 28: $\quad$ POPULATION 2000 AND 2005 FOR FoUR MSAS ....................................................... 91

TABle 29: EMPLOYMENT BY MAJOR OCCUPATION FOR 2006 FOR FOUR MSAS

Table 30: Location Quotient Percent Change From 2000 to 2006 AND Basic Industries For 2006 Based on EMPloyment by Major OCCUPATIONAL CATEgORY FOR Four MSAs ...... 93

Table 31: Gross Metropolitan Product 2000, 2005 and Percent Change 00-05 for four MSAS IN \$BILLIONS

Table 32: Creative Class Variable Correlations ..... 121

TABle 33: Descriptive Statistics for the Creative Class Percent ages 129

TABle 34: CORRELATIONS MATRIX FOR GMP PER CAPITA (2000) WITH INDEPENDENT VARIABLES (PART 1 OF 2)

TABle 35: CORRELATIONS MATRIX FOR GMP PER CAPITA (2000) WITH INDEPENDENT VARIABLES (PART 2 OF 2)

Table 36: Correlations Matrix For GMP Percent Change 2000 TO 2004 With IndePENDENT VARIABLES (PART 1 OF 2) 
Table 37: Correlations Matrix for GMP Percent Change 2000 to 2004 with IndePendent

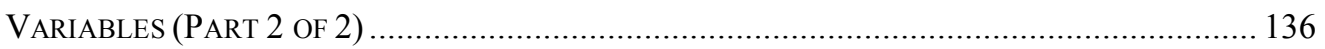

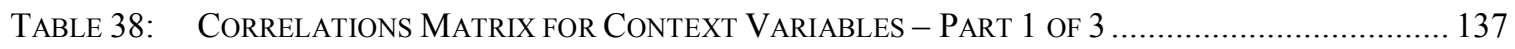

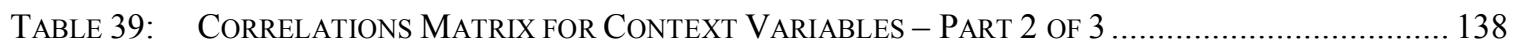

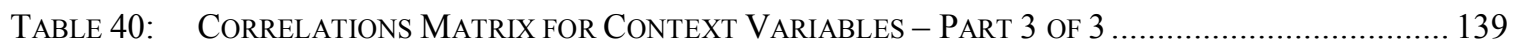

TABle 41: Regression Results For GMP PER CAPITA In 2000 vs. Significant ConteXt

VARIABLES AND CREATIVITY INDEX TOLERANCE SUBCOMPONENTS................................... 140

TABle 42: Regression Results For GMP Percent Change From 2000 to 2004 vs. Significant CONTEXT VARIABLES AND CREATIVITY INDEX TOLERANCE SUBCOMPONENTS ...................... 140

TABLE 43: Location QuOtIENTS For MANAGEMENT OCCUPATIONS For Four MSAs ........................ 141

Table 44: Location Quotients for HealthCARE Practitioner Occupations in Four MSAs .... 142 


\section{LIST OF FIGURES}

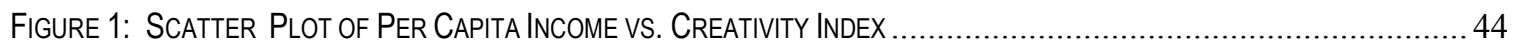

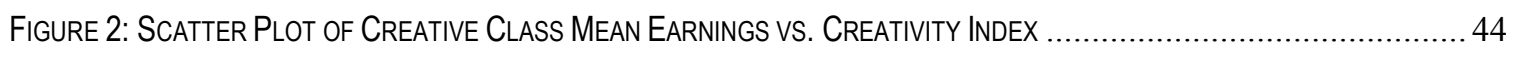

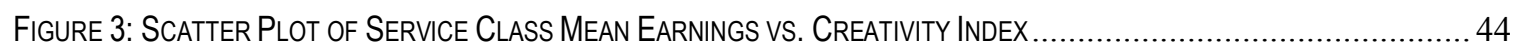

Figure 4: Scatter Plot of Per Capita Income Adjusted for cost of Living vs. Creativity IndeX ....................... 44

Figure 5: Scatter Plot of Creative Class Mean Earnings Adjusted for Cost of Living vs. Creativity IndeX..... 44

Figure 6: Scatter Plot of Service Class Mean Earnings Adjusted for Cost of Living vs. Creativity IndeX ...... 44

Figure 7: Scatter Plot of Working Class Mean Earnings vs. Creativity IndeX........................................... 45

Figure 8: Scatter Plot of Working Class Mean Earnings Adjusted for Cost of Living vs. Creativity IndeX ..... 45

Figure 9: Map Showing Relative Geographic Size and Location of Studied MSAs ..................... 85

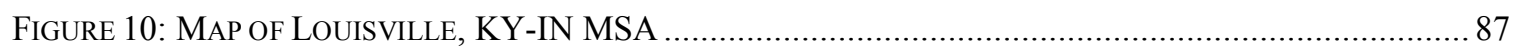

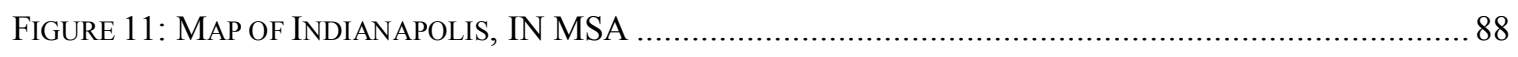

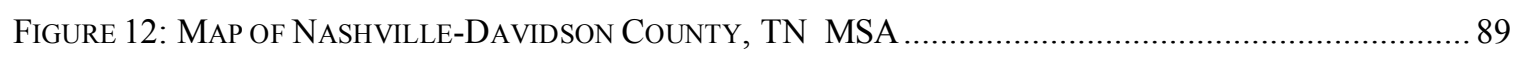

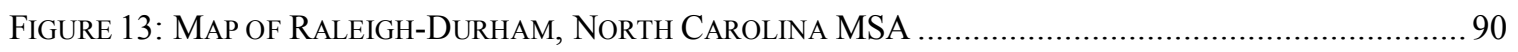




\section{CHAPTER 1}

\section{INTRODUCTION}

\subsection{Introduction}

Richard Florida (2002a and b) ${ }^{1}$ argues plausibly that creativity is the major force driving the U.S. economy and that occupations in the "creative class" constitute today's economic engine. By redirecting local economic development efforts toward education, research and development, and appropriate amenities, regions can enlarge their creative class resulting in economic growth. However, I would argue that cities and regions have cultures arising from their history and location and, while culture is not immutable, regions that attempt to improve their economies by pursuing a "creative class" strategy may not, in fact, do so. Further, the relative proportion of the creative class in an MSA may not be a panacea for entrenched social ills such as poverty, homelessness, and crime.

In this dissertation I investigate the relationship between creativity and economic development by examining various aspects of creativity as measured by Florida and regional economic strength as measured by the Gross Metropolitan Product (GMP). According to Florida (2002b), economic development expenditure intended to lure

\footnotetext{
${ }^{1}$ Florida (2002b, Appendix B) describes the differences from Florida (2002a) in the development of the creativity index components and the creativity index itself. Other than Appendix B, the volumes are the same and page references apply to both volumes. I will use (2002b) in references throughout the remainder of this dissertation.
} 
companies, even high-tech companies, to an area is misdirected. Economic development expenditures should build creative capital. Therefore investment should be redirected to educate the populace, increase expenditure in research and development, and purchase or enhance those amenities that cultivate a tolerant environment to support cultural diversity. Florida argues that his "creative capital" theory trumps classical firm location theories, as well as clustering and agglomeration theories, because in the new economy firms follow talent and his theory studies where people locate not where firms locate. Florida further argues that social capital theory is less powerful than creative capital theory because the creative class no longer seeks the close knit relationships that underpin the social capital theory. Glaeser (2004) posits that Florida's creative capital theory is no different than traditional human capital theory. Florida argues that creative capital theory is distinguished from human capital theory in two respects:

It identifies a type of human capital, creative people (emphasis mine), as being key to economic growth; and it identifies the underlying factors that shape the location decisions of these people, instead of merely saying that regions are blessed with certain endowments of them (Florida 2002b, p. 223).

Florida (2004) agrees with Glaeser that human capital development is important but that an environment open to various sorts of human difference--tolerance--is what attracts human capital to a place. The tolerance dimension of his theory is what essentially distinguishes creative capital from human capital. Openness attracts the creative class and the concentration of this class in a Metropolitan Statistical Area (MSA) drives its economy. My fundamental research question in this dissertation is whether the relationship between creative class concentration and economic health or growth holds when subjected to various quantitative and qualitative analyses. I agree with Glaeser 
(2004) that creative capital as defined by Florida is essentially human capital by another name.

There are certain nagging definitional issues with the notion of "creative class." Is the "creative class" sufficiently homogeneous to be defined as a class? Is the creative class geographically concentrated in the urban core of an MSA, or a suburban, or exurban, phenomenon? I do not specifically test these questions in this research. If, however, for analysis purposes, one assumes that the creative class is, in fact, an urban class, then one can reasonably ask whether their concentration has a positive impact on urban culture and urban problems. Even if there is no particular relationship with economic performance, is this class concerned with their own economic improvement, or an equitable distribution of economic benefits? In my opinion, the "openness" of a city is an element of its culture and while culture is not immutable, it seems to me that creative class attraction strategies are merely surface treatments that are unlikely to change a city's culture. Admittedly culture can change over time. The question is whether the creative class is the impetus of such change. Therefore, in addition to studying the economic impact of the creative class, this research explores the relationship between the concentration of the creative class in an MSA and various aspects of economic development context and culture to determine whether such a concentration results in desirable contextual or cultural improvements.

\subsection{Organization of the Study}

Chapter 2 summarizes Florida's theory, previous critical literature regarding Florida's theory, and relevant literature on creativity, innovation, amenities, culture, and economic development context. 
Chapter 3 presents the details of my research questions, hypotheses and the general methodology I used to test the hypotheses. Methodological details and findings are provided in Chapter 4. The following is a broad summary of the questions explored:

1. Does the creativity index predict economic growth?

2. Does one or more of the subcomponents of the creativity index predominate as a predictor of economic growth when human capital and geographical control variables are introduced?

3. Do economic development context and cultural variables separate into interpretable dimensions under factor analysis?

4. Do the subelements of the creativity index add in any significant way to the power of other contextual variables in predicting GMP per capita or GMP growth?

5. Are poverty, homelessness, crime or gender wage inequity ameliorated in creative MSAs?

6. Have the creativity indices of specific MSAs influenced the behavior of economic development professionals in those MSAs?

My specific hypotheses are presented in Chapter 3. In general they are as follows:

1. No positive relationship exists between the creativity index, or the percentage of the creative class with per capita income or class mean earnings after adjusting for cost-of- living. 
2. No positive relationship exists between the creativity index, or the percentage of the creative class with GMP in 2000 or with percent change in GMP from 2000 to 2004 or 2000 to 2005 .

3. When economic growth is operationalized using GMP and the creativity index is separated into its subcomponents, elements other than creative class percentage will emerge as most important.

4. Economic development context variables will not split into three recognizable dimensions--technology, talent and tolerance

5. Creativity index subcomponents will not add to the explanatory power of economic development context variables.

6. Creative MSAs are not better in terms of fewer or less severe social inequities, and...

7. Economic development professionals in selected MSAs, one with a high creativity index rank and three with relatively low ranks, do not modify entrenched economic development practices as a result of creativity ranks.

Chapter 4 provides a detailed discussion of the data used in the study, the specific quantitative methods employed to test the various hypotheses, and the results of the quantitative analysis.

Chapter 5 relates to research question 6 and hypothesis 6 . A number of personal interviews were conducted in selected MSAs to explore this question. The chapter presents the rationale for selecting the MSAs, a general economic comparison of those MSAs, and the results of the interviews. 
Chapter 6 summarizes the quantitative and qualitative results, draws conclusions from those results with respect to the policy implications of this study, discusses the limitations of this study, and suggests areas for further research.

\subsection{Contribution of this study}

Florida's books are national best sellers. Engaging a broader audience in the consideration of what constitutes effective economic development is welcome and necessary. It seems that there are things that cities can do to "attract the creative class." They can provide incentives for the construction of urban housing. They can provide incentives for the development of upscale urban amenities. They can pass fairness ordinances. However, by subjecting the subcomponents of the creativity index to quantitative analysis and by adding variables to capture economic development context, this study raises questions as to whether creative class concentrations are really significant in terms of improving the economy of an MSA or its cultural milieu. The various linear regression models utilized in this study to test selected variables for specific purposes are not intended to establish causality. Nevertheless, this study's conclusions reemphasize existing economic development literature by highlighting higher education, racial tolerance, and immigration as important factors in economic development. From a policy perspective it highlights why Florida's books are perhaps so successful - cities can take action on creative class attraction via amenities - while at the same time it finds more fundamental and important economic development drivers where, in fact, city actions may be limited. Cities can only indirectly influence policy with respect to higher education (where states have control) and immigration (where geographical location and federal policies are important). In addition, MSAs, not cities, 
are the unit of analysis in Florida's as well as this study. The lack of consistent policies across entire MSAs may influence the results of both studies with implications for further research on a smaller-than-MSA geographical scale. Nevertheless, this study highlights the importance of exerting whatever influence cities can muster in these areas and raises policy questions ripe for additional research analysis. 


\section{CHAPTER 2}

\section{LITERATURE REVIEW}

This chapter contains a review of relevant literature. It is organized into six topics: the creativity index, creativity and innovation, amenities, culture, economic development context, and a review of other literature critical of Florida's work.

\subsection{The Creativity Index}

Florida (2002b, Appendix B) develops a creativity index for MSAs. This index comprises three categories and four equally weighted components, as follows:

1. Technology as measured by the Milken Institute's Tech Pole (2000) and by the Average Annual Patent Growth from 1990 to 1999 from the U. S. Patent Office. Each of these components has equal weight.

2. Talent as measured by the percentage of the workforce in the creative class. In Florida's (2002b, p. 44) view, creativity is the key driver of today's economy. Knowledge and information are the tools and materials of creativity; innovation is creativity's product. Selected core industries of the creative economy are research and development, publishing, software, design, advertising, architecture, arts, and a variety of media (music, film, video games) (Howkins 2001, p. 116). Accompanying an 800-percent explosion in R\&D spending from 1953 to 2000 
(Florida 2002b, p. 45) has been a corresponding increase in the employment of scientists and engineers specifically (Florida 2002b, pp. 45, 47) and creative occupations more generally (Florida 2002b, pp. 72-77).

Creative occupations take two forms; those that fall into what Florida (2002b) calls "the super-creative core" and those composing a stratum of "creative professionals." All of these are lumped together into a "creative class." The super-creative core includes the following major occupational categories as defined by the U.S. government: computer and mathematical; architecture and engineering; life, physical, and social science; education, training, and library; arts, design, entertainment, sports, and media. The occupations of creative professionals are: management (including high-end sales and sales management), business and financial operations, legal, and healthcare practitioners and technical occupations. The super-creative core is directly engaged in the creation of new products and ideas; creative professionals apply knowledge to solve problems (Florida 2002b, pp. 69, 74, 328). Rounding out the rest of the nonagricultural occupational structure are traditional working class occupations of construction and extraction; installation, maintenance, and repair; production; and transportation and material moving; and service class occupations, which include health care support; food preparation and food service; building and grounds cleaning and maintenance; personal care and service; low-end sales; office and administrative support; community and social service; and protective service (Florida 2002b, pp. 328-329). All told, this is the new class structure of the creative economy. 
3. Tolerance is measured by four separate indices which are combined into an overall index. The four indices are derived from Census 2000. The four are:

- Melting Pot index

- Gay and Lesbian index

- Bohemian index

- Racial Integration index

The melting pot index, gay and lesbian index and bohemian index are essentially location quotient calculations ${ }^{2}$ which compare MSAs with national averages. The Racial Integration index measure uses the conventional segregation index. The overall tolerance score is an average of these four components.

The two technology measures, the talent measure, and the tolerance measure are equally weighted and combined to produce the creativity index for a metropolitan area. In Cities and the Creative Class (Florida 2005a), Florida gives additional statistical background on these various measures. Florida bases the link between these measures and economic growth on population growth and job growth. Florida focuses on creative occupations because he realizes that low-wage service sector job growth does not necessarily translate to regional economic growth. Sassen (1999) points out that the service economy exacerbates income polarity, where the distance between the well compensated high-end sector and the poorly compensated low-end sector is growing. Given this polarity, it seems plausible that, on balance, population growth and job growth would not necessarily translate to regional economic growth. This dissertation will

\footnotetext{
${ }^{2}$ A location quotient is calculated by dividing the percentage of some component in the study area by the percentage of that component in the comparison area. In this case the study area is the MSA and the comparison area is the nation.
} 
challenge the idea that the creativity index measure is in fact predictive of economic growth and whether MSA economic development strategies do, or should, focus on improving this measure.

\subsection{Creativity/Innovation}

Many consider creativity as some mystical power available only to great artists and thinkers, but it is really a process that all people can and do participate in albeit to varying degrees (Amabile 1983, Ray \& Myers 1986, Kaufman \& Baer(eds) 2005, Florida 2002a and 2002b). Theresa Amabile (1983, p. 8) provides a definition of creativity in The Social Psychology of Creativity:

A response will be judged as creative to the extent that (a) it is both a novel and appropriate, useful, correct, or valuable response to the task at hand and (b) the task is heuristic rather than algorithmic.

Ray and Myers (1986, p. 7) state further that:

It seems that creativity starts with some problem or need and moves in various ways through a series of stages, consisting of information gathering, digestion of the material, incubation or forgetting the problem, sudden inspiration (when the conditions are idiosyncratically right), and, finally, implementation.

According to Ray and Myers (1986), everyone has an inner capacity for creativity and their book is itself a heuristic for enhancing ones creative capacity.

Florida (2002b, p. 33) agrees stating "Many researchers see creative thinking as a four step process: preparation, incubation, illumination and verification or revision." He credits this to Graham Wallace's 1926 book The Art of Thought. He also states "[Creativity] is a capacity inherent to varying degrees in virtually all people" (p. 32).

In his final two chapters Florida (2002b) makes the following points. 
- Many cities states and regions continue to use financial incentives some of them obscenely extravagant - in their efforts to lure companies.

- ...companies increasingly go and are started where talented and creative people are.

- ...cities need a people climate even more than they need a business climate. This means supporting creativity across the board - in all of its various facets and dimensions - and building a community that is attractive to creative people, not just to high tech companies.

- This entails remaining open to diversity and actively working to cultivate it, and investing in the lifestyle amenities that people really want and use often, as opposed to using financial incentives to attract companies, build professional sports stadiums or develop retail complexes... Whereas companies - or sports teams for that matterthat get financial incentives can pull up and leave at virtually a moment's notice, investment in amenities like urban parks, for example, last for generations.

- Other amenities - like bike lanes or off-road trails for running, cycling, rollerblading or just walking your dog — benefit a wide swath of the population.

- ...we need to shift both public and private funds away from investments in physical capital toward investment in creative capital.

Thus, according to Florida (2002b), economic development expenditure intended to lure companies, even high-tech companies, to an area is misdirected. Economic development expenditures should build a city's creative capital comprising 3Ts- - technology, talent and tolerance. Therefore investment should be redirected to educate the populace, increase expenditure in research and development and purchase or enhance those things which cultivate a tolerant environment. Florida (2002b) argues that certain amenities appeal to creative individuals. Cities that provide these amenities will attract creative individuals and eventually tap the creative potential of the indigenous population resulting in economic benefits. It seems that many of the actions taken by cities in response to Florida's analysis focus on the amenities aspect (Malanga 2004, Clark 2004). A number of other authors have addressed creativity as an engine for growth. In 
Cities and the Wealth of Nations Jane Jacobs (1984) identifies import substitution as the necessary ingredient for sustained economic growth in a city. She states that "economic development has to be open-ended rather than goal-oriented, and has to make itself up expediently and empirically as it goes along" (p. 221). She also states that faltering city economies can be helped if they experience germane correction where "germane correction depends on fostering creativity in whatever forms it happens to appear in a given city at a given time, It is impossible to know in advance what may turn up, except that—especially if it is to prove important—it is apt to be unexpected" (p. 230). Peter Hall (1998) in Cities in Civilization discusses the innovative milieu and states "Building the innovative milieu is not something that can be done either easily or to order. Indeed, we may doubt whether in the final analysis it can be done at all that way" (p. 498). Hall (2000) speculates on where the next creative breakthrough will occur. He states “...the innovative places the last time around look like being the creative places the next time around. But not necessarily; there are no absolute rules in this ultimate game; time and chance happen to cities too" (p. 648). Sir Peter Hall and Jane Jacobs seem to be saying that creativity is critically important but not subject to orchestration. By contrast, in Urban Innovation: Creative Strategies for Turbulent Times (Clark 1994) successful strategies for dealing with fiscal strain are addressed. None of them involve improved amenities or creative class attraction.

The literature states that creativity should be nurtured but that it can not be orchestrated, or its effects predicted, reinforcing the notion that "creative class" economic development strategies may have little, if any, payoff. It also tends to equate creativity from an economic perspective with innovation. Howkins (2001) discusses the fact that 
innovation and commercially successful innovation are two obviously related but different phenomena. Commercial success requires knowledge of patent and copyright law as well as the ability to bring innovation to commercial and cost effective scale. Being creative does not necessarily result in economic success.

Acs (2002) in Innovation and the Growth of Cities quantitatively supports several interesting findings regarding innovation. He points out that research and development expenditures and patent measures may not be effective measures of innovation because $R \& D$ expenditure measures capture efforts toward successful innovation but include expenditure for unsuccessful efforts as well, many commercially successful innovations are not patented and many patents do not result in commercial success (Acs 2002, p. 18). To overcome these deficiencies he uses a dataset of specific successful innovations published by the Small Business Administration to make several important findings. In general, knowledge as an aspect of innovation comes in two forms--public knowledge available from patent applications and published research, and tacit knowledge that comes from direct research and a geographically limited set of networked entrepreneurs who can take advantage of this tacit knowledge (Acs 2002, pp. 10-11). Small entrepreneurial firms contribute to innovation by "exploiting knowledge created by expenditure on research and development in universities and on R\&D in large corporations." (Acs 2002, p. 42). Innovation in large firms is less dependent on university research and large firms must allocate $R \& D$ spending on both process and product innovation (ACS 2002, p. 42 and Chapter 5 generally). University research has geographical spillover effects in the economy of an MSA that may extend as far as 75 miles from the MSA depending on the industry or product - the effects are largest in 
electronics and instrumentation while the effects in drugs, chemicals or machinery have little to no spillover effect (Acs 2002, pp. 61, 73, 75). Finally the industry mix in an MSA as captured by shift-share analysis has implications for the level of innovation and the consequent spillover effect (Acs 2002, Ch 5). These findings are important because they imply that creative class concentration is less a cause of economic growth from innovation and more of an effect resulting from the presence of large firms, universities, and entrepreneurs with sufficient human capital to take advantage of the $R \& D$ undertaken in firms and universities. There is no consideration given to the notion that cities can attract creative individuals with amenities, or tolerant auras, and that firms and entrepreneurial innovation will follow.

\subsection{Amenities}

As previously stated, The Rise of the Creative Class (Florida 2002b) presents an argument that creativity is the major force driving the U. S. economy and that occupations in the "creative class" constitute today's economic engine. Florida posits that by redirecting local economic development efforts toward education, research and development, and appropriate amenities U. S. regions can enlarge their creative class resulting in economic growth. While he encourages attention to all three dimensions, much of the economic development activity based on his theory has focused on the amenities dimension (Malanga 2004).

Amenities strategies may, if successful, increase the concentration of the creative class in a city, but as indicated above, innovation and economic success do not necessarily follow. A more fundamental question is whether amenities really attract the creative class? Scott $(2006$, p. 15) argues that "creativity is not something that can be 
simply imported into the city on the backs of peripatetic computer hackers, skateboarders, gays, and assorted bohemians but must be organically developed through the complex interweaving of relations of production, work, and social life in specific urban contexts." He further argues that without available jobs, creative individuals are unlikely to take up permanent residence "no matter what other encouragements policy makers may offer" (Scott 2006, p. 11). Clark's (2004) study of urban amenities concludes that urban "amenities do attract people" (p. 132) but that different types of amenities appeal to different subpopulations and that the percentage of gays in the urban population is nearly unrelated to urban growth. Clark's is not a direct criticism of Florida, but it raises the question of whether the creative class constitutes a homogeneous subpopulation to which certain types of amenities will universally appeal and whether the gay index as a gauge for tolerance should be linked with urban growth.

\subsection{Culture}

Urban literature is replete with debate over whether and to what extent a city's development strategies are influenced by structural limitations (Peterson 1981); who calls the shots in the face of these limitations - the power-elite via the growth machine (Logan \& Molotch 1987), an urban coalition or regime (Swanstrom 1988, Stone \& Sanders 1987), community writ small through community development initiatives, or community writ large via the political process (Williamson, Imbroscio \& Alperovitz 2003, Simon 2001); and who really benefits from development. Florida defines the creative class based on a broad array of occupations including teachers, doctors, lawyers, architects, artists, actors, corporate managers, and software engineers. Situating Florida's creative class argument in the structure versus agency debate is difficult. The class does not seem 
homogeneous enough to act as an independent force in the development agenda setting process nor large enough to influence structural limitations. Would they, as a class, drive a city's economy? Could they do so, as a class, if they so desired?

Peck (2005) writing for the International Journal of Urban and Regional Research, critiques Florida's theory concluding that “...creativity strategies subtly canalize and constrain urban-political agency, even as their material payoffs remain extraordinarily elusive. The cult of urban creativity is therefore revealed in its true colors, as a form of soft law/lore for a hypercompetitive age" (p. 768). In other words, creative class attraction is not intended as a fundamental change to the economic development agenda. It is simply another tool for those already controlling that agenda to distinguish a city in the competitive arena in the hope that it will prove a competitive advantage.

But let us assume for the moment that the creative class is both willing and able to change the development agenda, is economic health and growth assured? Savitch and Kantor (2002) explore the interaction of structure and agency in the determination of a city's bargaining position in the global economy. The market and a particular nation's approach to intergovernmental support form the structural constraints. The agency dimension is a function of local culture. Retrenchment policies in the U.S. translate to poorer intergovernmental support for U.S. cities than those in Canada or Europe. Market conditions and local cultures vary across U.S. cities. Cities with poor market conditions and weak local cultures will undertake nearly anything that smacks of development. Cities with good market conditions and strong local cultures can be more selective in what constitutes effective development. This theory relates to Florida's theory in two 
ways. First, it raises questions about whether, given structural constraints, increasing the size of the creative class will improve every city's economy. Second, it raises the issue of culture.

An important tenet in Florida's (2002b) argument is the necessity for a place to be tolerant--accepting of cultural diversity. Florida operationalizes diversity through the melting pot index (immigrants in the population), the gay and lesbian index, the bohemian index, and a measure of racial integration. Florida's point is not that the creative class is comprised of members of these groups but that the presence of such groups signals an open society which appeals to the creative class (or conversely repels them if absent). I believe that there is a more complex dynamic at work--cities are a product of their physical location and history which establishes a city culture. A city culture may perhaps be changed and become more accepting of diversity, but not easily and not fast.

Elazar (1998, p. 5) states this in much more eloquent terms:

We are all inheritors of a culture that, to some degree, we can continue to shape but which in some respects is as much beyond the reach of our influence as the land forms upon which we live or the inexorable march of time from the beginning to the end of our lives.

Landry (2000, p. 259) discusses seven characteristics important to the "next wave" of creativity and innovation. Two of the seven involve diversity-living interculturally and valuing varied visions. The other five - creating value and values simultaneously, from hardware solutions to software solutions, recombining the old and the new imaginatively and, the learning city-- involve the contextual elements of culture. In his words "...to fully understand why one city rather than its neighbor is innovating 
requires much more description, research and knowledge of its specific history and context..." (p. 258).

Savitch and Kantor (2002) note the significance of local culture on the economic development bargaining context of a city. Florida seems to propose that culture can be changed through economic development efforts. Savitch and Kantor make no such claim. Culture is the independent variable, not vice-versa.

This literature in no way refutes a potential link between "openness" and economic growth as proposed by Florida. The question is really the reverse. If a region's culture is "closed," can economic development strategies open it? Culture is not immutable, but I question the extent to which economic development practitioners do what they can within a given cultural context or specifically target initiatives to change the culture.

Tolerance is an important aspect of Florida's theory. While local culture as operationalized by Savitch and Kantor is not equivalent to tolerance as operationalized by Florida, tolerance is, in my opinion, an element of culture. Changing a city from intolerant to tolerant (or less tolerant to more tolerant) is a daunting task not likely to be solved by the addition of a few more creative individuals who, according to Florida, would not be attracted to such a city in the first place. While culture and economy clearly interact (Inglehart 1990), it may take a generation or more for the interaction to manifest itself, and which serves as cause vs. effect is difficult to discern (Inglehart 1997, pp. 141142). Additionally, Thomas and Darnton (2006, p. 1) examined "evidence for the importance of tolerance in promoting metropolitan economic development." They found that diversity does matter but conclude that Florida's creative cities model "focuses on 
several dimensions of diversity that may not in fact be strongly associated with economic development." (Thomas \& Darnton 2006, p. 36).

The point here is that economic development literature recognizes the importance of culture but it is unclear whether the economy changes culture or culture changes the economy. It is also unclear whether the notion of a "creative class" as a cultural phenomenon constitutes a change agent, or whether a tolerant cultural milieu sparks economic development.

\subsection{Economic Development Context}

Florida encourages regions to harness the creativity of their indigenous population but fails to provide an actionable process for accomplishing this. How might a city develop an actionable strategy? Strategic planning generally involves the notion of an environmental scan (Mintzberg \& Quinn 1996). From an economic development perspective, Koven and Lyons (2003) have characterized the environmental scan as an assessment of economic development context. Discussed in greater detail in subsequent sections, this context involves a region's economic base, workforce characteristics, workforce skills, land and physical capital, energy resources, financial capital, tax structure, community culture, geography, and research environment. Assessment of these elements is a critical first step in determining what can be changed and for developing the strategies necessary to accomplish an economic development goal. Some might argue that the creativity index is in a sense a composite measure of the interaction of all these elements in a specific region but, as such, it can only tell us that work needs to be done, not what work needs to be done.

Economic development strategies have been referred to as a three legged stool 
(Markley 2004, Sampson 2003). The three legs are business attraction, business retention and business creation. If any of the legs are missing, the stool obviously collapses, and metaphorically the economy likewise collapses or becomes unstable. Initiating and maintaining balanced strategies requires an understanding of the economic development context in which those strategies play out (Koven \& Lyons 2003).

Blakely and Bradshaw (2002, pp. 43-48) discuss three waves of economic development. The first wave is business attraction; the second is business retention, expansion, and incubation. These two waves include the "three legs" from above. They go on to define a third wave which "rather than dealing with firms one by one, focus on using regional resources to support the growth of specified industrial clusters of related firms" (Blakely \& Bradshaw 2002, p. 46). Fitzgerald and Leigh (2002, p. 10-21) discuss five phases of economic development. Five phases interrelate the waves of economic development with trends in planning theory. Essentially, the extra phases add the notions of equity, justice and sustainability to economic development practice. Koven and Lyons (2003, pp. 174-177) discuss the elements of economic development context or economic environment as follows:

- Economic base - regional employment compared to national employment to determine export industries as well as dependence on a single firm or industry. To the extent such a dependency exists. An economic base study would also determine a region's capacity and will to diversify.

- Workforce characteristics - the size and location of the workforce, the unemployment rate and average wages/salaries. 
- Skill - the percent of the workforce competent in high-technology fields, the percent competent in other fields and the percent unskilled.

- Land/physical capital - vacant land, underused land, and access to utilities and transportation.

- Energy - reliability, access and price.

- Financial capital - local bank policies on business lending, gap financing (financing required to move from one stage of business development to the next), venture and angel capital.

- Tax structure - business related taxes, general tax rates.

- Community culture - norms and values. Koven and Lyons (2003) list support of business values, willingness to innovate and risk personal capital, willingness to accept externalities and, willingness to alter the status quo as important cultural characteristics. The tolerance component of the creativity index would fall in this area as well.

- Geography - climate, topography, distance from economic centers, distance from complimentary clusters of business/industry and access to global markets

- Research environment - major university nearby, college(s) nearby, internet access.

This literature is important for this study because the creative class approach covers some of the elements of context but not all of them. Technology is an element of economic base. Talent is a workforce characteristic. Tolerance is a dimension of culture. 
In addition, the creativity index combines these measures into a single numeric which is intended to differentiate creative MSAs from those less so. Evaluating the subelements of the creativity index coupled with other measures of context that are not captured in the index may reveal specific elements that could be better addressed by specific economic development strategies. In addition, the cultural aspect of economic development context should include elements that involve equity, justice and sustainability.

Especially related to creativity, the work of Lichstentein and Lyons (1996) and Lichstentein, Lyons and Kutzhanova (2004) discuss an Economic Development System (EDS) in which entrepreneurs and business related programs are coordinated such that entrepreneurialism is encouraged, directed toward the economic needs of the community, and evaluated as to its success in moving a community forward with respect to its economic goals. The result is an entrepreneurial community. This literature will be relied on to facilitate the case study research of the four cities selected for in-depth analysis - Louisville, KY; Nashville, TN; Indianapolis, IN and Raleigh/Durham, NC.

\subsection{Other Criticisms of Florida}

There have been other criticisms of Florida's work. Some argue its primary function is to promote a neo-liberal agenda (Malanga 2004, Kotkin \& Seigel 2004). Others argue that it simply fails to effectively make its case ( $\operatorname{Li} 2005)$. The Journal of the American Planning Association (JAPA) organized a review roundtable on Cities and the Creative Class held at the Association of Collegiate Schools of Planning annual meeting in Portland, Oregon in 2004. While focused on Cities and the Creative Class, the roundtable also addressed The Rise of the Creative Class as well. The review editors' synopsis of the roundtable discussion states that two overarching themes emerged. The 
first is that while his work has traction with economic development practitioners, it often "trivializes the concepts, which in the worst case may encourage practitioners to misread the policy implications and thereby pursue potentially counterproductive economic development strategies based on Florida's ideas" (Lang 2005, p. 204). The second is that Florida has failed to adequately respond to academic criticism of his empirical work (Lang 2005, p. 205). Florida has responded to some of this criticism, calling some of it mere squelching. His reply to JAPA was that his research was exploratory rather than confirmatory in nature (Florida 2005a, p. 218) implying, to me at least, that his work was being judged by inappropriate standards. Admitting to the exploratory nature of his work, I add to the criticism of the quantitative support for his theory. 


\section{CHAPTER 3}

\section{RESEARCH METHODOLOGY}

\subsection{Research Questions - Overview}

To support his theory Florida develops a "creativity index" for Metropolitan Statistical Areas (MSAs) based on certain measures of talent, technology, and tolerance. This index is then used to rank MSAs. If his premise is valid, one might reasonably expect that per capita incomes would be higher in more "creative" MSAs. One might also expect creative class mean earnings to be higher. The initial analysis in this dissertation explored the bivariate relationship between the creativity index, the percentage of the creative class in an MSA, per capita income, and class mean earnings. I also used regional dummy variables ${ }^{3}$ to control for the effect of regional economies. These relationships may be influenced by cost-of-living as many of the MSAs with high creativity indices are also high cost-of-living locations. An adjustment for cost-of-living (see section 4.1.1 for details) was made in the analyses. For these analyses I used per capita income available from the 2000 Census and also the average earnings for the

\footnotetext{
${ }^{3}$ Region : Four groupings of states established by the Census Bureau in 1942 for the presentation of census data: Northeast Region: Maine, New Hampshire, Vermont, Massachusetts, Connecticut, Rhode Island, New Jersey, New York, Pennsylvania; South Region: Maryland, Delaware, West Virginia, Virginia, Kentucky, Tennessee, North Carolina, South Carolina, Georgia, Florida, Alabama, Mississippi, Arkansas, Louisiana, Oklahoma, Texas; Midwest Region: North Dakota, South Dakota, Nebraska, Kansas, Missouri, Iowa, Minnesota, Wisconsin, Illinois, Michigan, Indiana, Ohio; West Region: Washington, Idaho, Montana, Wyoming, Oregon, California, Nevada, Utah, Colorado, Arizona, New Mexico, Alaska, Hawaii
} 
creative, service and working class which I independently developed. ${ }^{4}$

The United States Conference of Mayors (USCM) does not rely on per capita income to evaluate MSAs. It relies instead on a measurement of Gross Metropolitan Product (GMP) produced by Global Insights specifically for use by the USCM as a tool to evaluate metropolitan area economic performance. I studied the relationship of GMP with per capita income and I studied the correlations of the creativity index and percentage of the creative class with GMP and GMP percent change. I also used bivariate linear regression to compute the predictive effect of the creativity index on economic strength and growth. Because Florida conceived the creativity index as a broad measure of technology, talent, and tolerance, I expected these correlations to be positive; but any differences between raw per capita income data and cost-of-living adjusted per capita income, as well as any differences between per capita income and GMP, may be important for further analyses. In studying GMP change over time, it is quite possible that macroeconomic effects can impact different regions and different industries in different ways. The regional controls I use are very broad and may not effectively capture such effects. In addition, the federal Bureau of Economic Analysis reports the following annual percent change in GDP in year 2000 dollars ${ }^{5}$ :

$\begin{array}{ll}\frac{\text { Period }}{2000-2001} & \text { \% Change } \\ 2001-2002 & 1.6 \\ 2002-2003 & 2.5 \\ 2003-2004 & 3.9 \\ 2004-2005 & 3.2\end{array}$

Global Insights, Inc. develops Gross State and Gross Metropolitan Product from national

\footnotetext{
${ }_{5}^{4}$ See Data Appendix for details.

${ }^{5}$ Source: http://www.bea.gov/national/xls/gdpchg.xls
} 
reports. I used the real percent change in GMP from 2000 to 2004 and from 2000 to 2005. GDP steadily increased from 2000 to 2004 . GDP growth from 2004 to 2005 actually slowed somewhat and as a result any comparison of GMP results from 2000 to 2004 versus 2000 to 2005 might overemphasize this slowing effect. Given that as a caveat, I proceeded with my analysis based on available data.

I hypothesized that creative capital does not trump human capital in terms of influence on economic growth. First, using all the MSAs for which a creativity index is developed, I decomposed the creativity index into its subelements and ran multivariate linear regressions with percent change in GMP as the dependent variable and the subelements of the creativity index as independent variables. I then substituted a direct measure of human capital - the percentage of the population over 25 years of age with a bachelor's degree or higher - for the percent creative class measure. I expected the human capital measure to be a better predictor of economic growth. Second, consistent with Savitch and Kantor's (2002) consideration of the market as a structural constraint, it is likely that region would affect these results. I introduced the regional control variables as mentioned above to determine if multivariate relationships changed after controlling for geographic region.

I also hypothesized that creativity index components are subsumed by economic development contextual variables. That is, creativity index components are only a part of the economic development context and other variables will emerge as more important. As mentioned above, a number of elements comprise the economic development context: economic base, workforce characteristics, workforce skill, land/physical capital, energy, financial capital, tax structure, community culture, geography, and research environment. 
Some of these elements are difficult to operationalize. Using data from various sources I operationalized economic base, workforce characteristics, workforce skill, tax structure, community culture, climate, and research environment. The specific manner in which these were operationalized is presented in section 3.1.3. The analysis was conducted in two parts. First, for the 49 MSAs with populations over one million, I used the context variables in addition to the subelements of the creativity index to conduct an exploratory factor analysis. According to Tabachnick and Fidell (2001) factor analysis is a statistical technique "applied to a single set of variables when the researcher is interested in discovering which variables in the set form coherent subsets that are relatively independent of one another" (p. 582). The question is whether three factors consistent with technology, talent, and tolerance emerge and the degree to which the creativity index subelements load on those factors. Secondly, the economic development context variables were used as a block of control variables in multivariate linear regressions. Using percent change in GMP as the dependent variable I initially ran a regression with only the context variables as independent variables. Then the creativity index variables were introduced in the models to determine the impact of these variables in terms of changes in adjusted $\mathrm{R}^{2}$ and any changes in the statistical significance of variable coefficients. My expectation was that the introduction of the creativity index variables will add little if any explanatory power beyond the control variables.

Public sector economic development incentive effort generally takes place on a smaller scale - namely cities. Quantitatively, this was evaluated by analyzing results at the PMSA/MSA level as described above. However, numbers may not tell the whole story. Economic development decisions are made by individuals in a political context. 
Rubin and Rubin (2005) state that "Qualitative interviewing projects are especially good at describing social and political processes, that is, how and why things change" (p. 3). As a result I felt it important to conduct qualitative research at the city level. I selected cities in four MSAs--Louisville, Nashville, Indianapolis and Raleigh/Durham--whose creativity indices vary considerably but that are frequently benchmarked against one another. I conducted qualitative research in the major cities in these MSAs, five ${ }^{6}$ cities in all, to evaluate whether they have implemented economic development strategies based on the creativity index; if so, to determine what they have done and the extent to which they have been successful; and if not, to determine what drives their economic development efforts. Based on the theoretical link between innovation and entrepreneurialism, entrepreneurialism is one area where indigenous creativity might surface. Consequently, I also explored what these cities do to foster entrepreneurialism. This research allowed me to draw some conclusions about whether the differences in the respective creativity indices are meaningful and why. Consistent with my other hypotheses, I did not expect to find the differences in the indices meaningful. That is to say, I expected each city to be pursuing economic development strategies consistent with its particular structural constraints and local culture and not responding in any particular way to the index differences.

In general this research is focused on whether the creativity index actually predicts economic strength and growth, on the elements of economic development that might better predict economic strength and growth, and on whether the creativity index actually influences economic development decision makers in specific cities. Thus, both

\footnotetext{
${ }^{6}$ Separate qualitative research was conducted in Raleigh and in Durham. See section 3.1.4.
} 
quantitative and qualitative methods were employed in this research.

\subsubsection{Research Question 1}

As stated above, the creativity index does capture some but not all elements of the economic development context. It includes a partial measure of workforce characteristics (creative class occupations) and partial measures of community culture (the tolerance measures). A specific element of that context is the average wage/salary of the workforce. The creativity index does not specifically capture this measure. Based on Florida's theory, however, if an MSA could improve its creativity index, its economy would improve and/or its tolerance would increase and per capita income, as a general measure of quality of life, would likewise increase. The creative class makes up a substantial portion of the workforce in MSAs with high creativity indices (roughly 30 to 40 percent). Therefore, if tolerance is an important dimension of the locational decisions of the creative class as Florida argues, creative class individuals may locate in "tolerant" locales with little concern for the impact the locality may have on their personal earnings. In short, per capita income should correlate with the creativity index but creative class earnings may not correlate as well. Also, if the distribution of economic benefit is equitable, then not only the creative class, but the working and service class earnings should also rise. To address the possibly different earnngs effects of creativity that might not be captured in a per capita income measure, I developed the average earnings of the creative, working, and service class using BLS data. ${ }^{7}$ An additional concern is that, on the surface, it appears that regions with a higher creativity index have higher costs-ofliving. I expected the per capita income and average earnings correlations to diminish 
after adjusting for cost-of-living.

The first research question, then, explored the bivariate correlations of the MSA per capita income and the average earnings of the creative class, working class and service class in an MSA with the creativity index for that MSA and the percentage of the creative class with and without adjusting for cost-of-living. I included dummy control variables for region (see footnote 2) to gauge the impact of region using OLS linear regressions to determine the relative effect of the relationship based on the coefficients in the various linear equations. The definition of creative professionals includes categories of occupations that appear in the public sector and, thus, might be concentrated in Washington, DC or in state capitals. I included a control for the presence of a state (or federal) capital in an MSA/CMSA to isolate any independent contribution that government workers might make to the relationships.

\subsubsection{Hypothesis 1}

Based on Florida's theory the relationships between the creativity index, the percentage of the creative class, and income, or earnings, as described above should all be positive and cost-of-living should have a diminished impact for the creative class as their choice of region may be based more on "openness" than earnings potential (Florida 2002). I hypothesized, however, that no such positive relationship exists for the percentage of the creative class and the positive effect for the creativity index results from its other components.

\footnotetext{
${ }^{7}$ See Data Appendix
} 


\subsubsection{Hypothesis 2}

The United States Conference of Mayors uses Gross Metropolitan Product as a measure of MSA economic performance. Developed initially by McGraw Hill Companies' Standard and Poor's DRI division and continued by Global Insights, Inc. after they acquired DRI in 2001, this measure is a top-down distribution of State Gross Domestic Product to metropolitan areas. The Federal Bureau of Economic Analysis is developing a bottoms-up measure of Gross Metropolitan Product but that measure is not yet available. ${ }^{8}$ This measure is a broader measure of economic strength and growth than per capita income; as a result, I hypothesized that when the analyses from hypothesis 1 were repeated using GMP for 2000 and percent change in GMP from 2000 to 2004, the relationships between the creativity index, or the percentage of the creative class would deteriorate or vanish.

\subsubsection{Research Question 2}

The second question then is whether and which creativity index components do, in fact, predict a stronger economy, or faster economic growth as measured by GMP related variables.

\subsubsection{Hypothesis 3}

Based on Florida's theory, the creativity index is positively correlated with economic growth operationalized as population growth or job growth. However, there is little evidence presented by Florida on this relationship. In addition, the index mixes together several contextual dimensions which make the development of improvement

\footnotetext{
${ }^{8}$ See https://bea.gov/bea/about/StrategicPlan2006 2010.pdf
} 
strategies problematic. My hypothesis here is that when economic growth is operationalized using GMP and the creativity index is separated into its subcomponents - percent creative class, high-tech location quotient, patent growth, gay index, bohemian index, immigration index, and racial integration index - certain elements will emerge as most important. This hypothesis was tested using multivariate linear regression. In keeping with Glaeser's (2004) notion that creative capital may simply be another measure of human capital, I included a measure of educational attainment $^{9}$ in these regressions. By including educational attainment I was able to test the question of whether human capital might be a stronger predictor of economic growth than creative class proportion. I also included the broad controls for geographic region and the presence of a state capital as mentioned above to test the question of whether regional characteristics would affect the outcomes.

\subsubsection{Research Question 3}

The third question is whether economic development context across MSAs predicts economic growth and what factors might be most predictive. Analysis of this question was based on a quantitative analysis of the 49 MSAs with populations over one million using contextual data from various sources. Gross Metropolitan Product data are used to operationalize economic strength and growth and data from various sources is used to operationalize economic development context. The following briefly describes these operationalizations:

\footnotetext{
${ }^{9}$ See Data Appendix.
} 
- Economic base: location quotients and shift-share analysis were used to operationalize this factor. Location quotients determine the concentration of employment in an industry relative to the U. S. concentration and therefore indicate basic (i.e., export) industries. Shift-share analysis separates industry growth into national, industry and regional growth components. I undertook this analysis for the each of the 49 MSAs using employment by industry data available from the 1990 and 2000 Census. I also calculated the multiplier effect for each region and included this as a separate variable. The multiplier refers to the number of non-basic industry jobs for each basic industry job. Basic jobs in export industries bring revenue into a region from outside the region. Non-export jobs are created within a region to support the export jobs. These may comprise suppliers, local distributors, specific service jobs, such as financial or legal services, or general services (restaurants, automotive shops, beauty salons, etc.).

- Workforce characteristics: size of the labor force, average wages/salaries and unemployment rates by MSA are available from the Bureau of Labor Statistics.

- Workforce skills: percent of the population over 25 with a bachelor's degree or higher is available from the 2000 Census. The percent of the population with a high school diploma, some college, or associate's degree is likewise available. 
- Tax structure: the County Data Book from the U.S. Census provides government revenues per capita for counties which can then be aggregated to MSA level.

- Community culture: poverty, crime, home ownership, homelessness, voting participation, and young single migration data are used to represent this dimension. Additionally the association index of occupational gender equity is also included.

- Geography: climate and terrain variables available from other published research and the US Census regional designations were used for this dimension.

- Research environment: the total number of institutions of higher learning and the number of high-level research institutions available from The Carnegie Foundation for the Advancement of Teaching were used for this aspect of context. In addition the amount of research funding for colleges and universities available from National Science Foundation was also used.

As indicated above, the purpose of the factor analysis is to determine whether three factors consistent with technology, talent and tolerance emerge and the degree to which the creativity index subelements load on those factors.

\subsubsection{Hypothesis 4}

Hypothesis 4 was that the factor analysis would not produce clear distinctions between the subelements of the creativity index and that other elements of economic development context would prove more significant than the creativity index subelements. Secondly, the economic development context variables were used as a block of control 
variables in multivariate linear regressions. Using percent change in GMP as the dependent variable I ran a regression with only the context variables as independent variables. Then the creativity index variables were introduced in the model to determine the impact of these variables in terms of changes in adjusted $R^{2}$ and any changes in the statistical significance of variable coefficients.

\subsubsection{Hypothesis 5}

Hypothesis 5 was that the introduction of the creativity index variables to the regression would add little if any explanatory power beyond the control variables.

\subsubsection{Hypothesis 6}

If hypotheses 4 and 5 are correct, creativity index subcomponents add little to the predictive power of other context variables. Nevertheless, Florida's implication is that MSAs with high creativity indices are more tolerant locales. From an equity perspective it is reasonable to question whether the proportion of the creative class in an MSA translates to better quality of life. Hypotheses 4 and 5 were limited to the 49 MSAs with populations over one million. To address this quality of life question I ran a series of regressions using the percentage of the creative class in an MSA and regional dummy variables as independent variables and poverty, homelessness and crime as dependent variables. Hypothesis 6 was that there would be no significant improvement in the dependent variables as a result of creative class concentration controlled for region.

\subsubsection{Research Question 4 and Hypothesis 7}

The final research question is whether specific economic development actions in certain cities, in light of the economic development context in those cities, point to 
specific factors that result in economic growth, or lack thereof. The secondary data used in the previous research questions relate to the entire MSA while different jurisdictions within these MSAs may vary as to governance and policy direction. Consequently, the unit of analysis for this final question was the primary city within the MSA.

Exploring this question required qualitative research (Rubin \& Rubin 1995, McCracken 1988) and was restricted to the five major cities in four MSAs: Raleigh, Durham, Nashville, Indianapolis, and Louisville. Nashville and Indianapolis have been used as peer cities in comparing Louisville's economic competitiveness (Coomes \& Kornstein 2004) and Indianapolis, Nashville and Raleigh/Durham have been used as comparison regions on various economic dimensions by the Brookings Institution (Brookings Institution Center on Urban and Metropolitan Policy 2002, Competitive Cities Report 2005). The four MSAs were selected for analysis because as shown in Table 1, their ranks on the creativity index and its components are substantially different. Raleigh/Durham is the only MSA in the top 10 large MSAs which is geographically near the Nashville, Louisville, Indianapolis cluster and that might be considered traditionally southern $^{10}$. The question of importance is what contextual differences contribute to the difference in rankings for these MSAs that are geographically close and economically comparable.

\footnotetext{
10. The Washington-Baltimore MSA is also in the top 10 and being in Maryland, is sometimes classified in the South region of the U.S. but this MSA is rarely compared to Louisville on economic dimensions.
} 


\begin{tabular}{|c|c|c|c|c|c|}
\hline & \multirow[b]{2}{*}{$\begin{array}{c}\text { Creativity } \\
\text { Index Rank } \\
\text { among MSAs } \\
\text { over } 1 \mathrm{M} \\
\text { population }\end{array}$} & \multicolumn{4}{|c|}{ Rank among all 276 MSAs } \\
\hline & & Talent Rank & $\begin{array}{c}\text { Technology } \\
\text { Rank }\end{array}$ & $\begin{array}{c}\text { Tolerance } \\
\text { Rank }\end{array}$ & $\begin{array}{c}\text { Creativity } \\
\text { Index } \\
\text { Rank } \\
\text { among all } \\
\text { MSAs }\end{array}$ \\
\hline Raleigh/Durham & 6 & 2 & 5 & 52 & 6 \\
\hline Nashville & 24 & 72 & 79 & 56 & 42 \\
\hline Indianapolis & $\overline{38}$ & 119 & 133 & $\overline{90}$ & 98 \\
\hline Louisville & 49 & 160 & 189 & 143 & 171 \\
\hline
\end{tabular}

The International City/County Management Association conducts an annual survey of economic development. However, of the cities under study, only Indianapolis replied to the survey, thus making comparison impossible. The survey questions serve as a useful boilerplate, but more in depth research is obtainable through qualitative interviewing. Officials in economic development agencies or chambers-of commerce for five ${ }^{11}$ cities (or equivalent positions) were contacted and asked a series of questions similar to those in the ICMA survey. The questions were asked in an open-ended format in the context of an interview, not simply asked verbatim from the survey. For example, the following is a template for questions posed in the interview:.

1. What is the role of local government in economic development?

2. What business attraction strategies does your local government pursue?

3. What business retention strategies does your local government pursue?

${ }^{11}$ Raleigh and Durham have separate offices responsible for economic development planning and separate 
4. What small business development strategies does your local government pursue?

5. How is local economic development funded?

6. What business incentives are utilized to attract, retain, or facilitate small business development?

7. Does the city have a method of measuring the success or failure of economic development projects?

8. Please describe a specific economic development project that you consider successful and why.

9. Are there economic development projects that you feel are/were not successful? Why?

10. Are there specific barriers that may have prevented this or other economic development efforts from succeeding?

11. Are you familiar with the work of Dr. Richard Florida?

12. Has this city undertaken any economic development projects based on direct advice from Dr. Florida? If so, what projects and have those projects been successful? If not, have any projects been undertaken as a result of Dr. Florida's theories? What projects and have those projects been successful?

13. Are there specific local groups or coalitions that oppose economic development?

14. Focusing now on small business development, are individual small business programs coordinated in any way?

15. How would you define the stages in an entrepreneur's learning process?

16. Does the city have a method for evaluating an entrepreneur's stage of development?

chambers-of-commerce. So while four MSAs were selected for study, five cities were studied. 
In addition to interviewing economic development officials, I attempted to identify and interview community organizations that oppose, or have in the past opposed, economic development initiatives to obtain a balanced perspective on the economic development context of the area. These efforts met with very limited success.

Lang (2005, p. 204) states that while Florida's work has traction with economic development practitioners, it often "trivializes the concepts, which in the worst case may encourage practitioners to misread the policy implications and thereby pursue potentially counterproductive economic development strategies based on Florida's ideas." This is the crux of hypothesis 7. I hypothesize that economic development officials will be doing things that are creative class oriented but that without an underlying change in economic development context, these efforts are unlikely to produce changes in economic growth. 


\section{CHAPTER 4}

\section{QUANTITATIVE ANALYSIS}

\subsection{Research Question 1}

\subsubsection{Hypothesis 1: Creativity Index vs. Income and Earnings}

In Cities and the Creative Class Florida states, "My theory is concerned primarily with the quality of economic growth, and quality of growth is not reflected in job growth at all, but in the wages and incomes that people make" (Florida 2005b, p. 24). On the other hand, there is considerable discussion in both of his books regarding the fact that creative class individuals will sacrifice income ${ }^{12}$ for a creative environment. There is also discussion of the management literature regarding the fact that salary is a necessary but insufficient condition for motivation. These contrasting ideas raise questions as to the relationship between creativity and earnings. The first idea would say that people in creative MSAs should have higher earnings. The second and third lines of thought would say that for creative class individuals, a tolerant environment or creative work itself is more important than earnings. From an economic perspective, it seems reasonable that people in creative occupations (as named by Florida) possess valuable skill sets and are compensated accordingly but do relative MSA rankings based on the creativity index

\footnotetext{
${ }^{12}$ In general income is not equivalent to earnings because income can come from other than job earnings. I have used per capita income data in this analysis but I also use average earnings. I have attempted to distinguish between these two measures throughout this analysis.
} 
mean that these people are more valued in some MSAs? If so, is this value affected by cost-of-living? Does the creativity of a region, as measured by the creativity index, in any way predict the annual mean earnings of the creative class? If the creativity index captures the "quality of economic growth" then MSA per capita income should correlate with the creativity index. Does it? If creativity as measured by the creativity index predicts higher creative class earnings, does that benefit extend to the service and working classes in the MSA? To test these questions I ran correlations between the creativity index for the year 2000 and per capita income as well as the mean annual earnings of creative, working and service classes for the year 2000 with and without adjusting for cost-of-living and I ran bivariate linear regressions using this same dataset adding control variables for regions and the presence of state capitals. The cost-of-living adjusted income and earnings data were developed by multiplying per capita income figures and the annual mean income for the classes by a cost-of-living index from Sperling's Best Places ${ }^{13}$. The creativity indices are from The Rise of the Creative Class (Florida 2002, Appendix B). As I used the creativity index for these analyses, I studied the 258 MSAs and the 18 CMSAs for which a creativity index was developed. The bivariate linear regressions were run with per capita income, or the annual mean earnings for the creative class as the dependent variable and the creativity index and regional controls as the independent variables. Correlations and bivariate linear regressions were run in SPSS.

The bivariate correlations and scatter plots for the creativity index versus per

\footnotetext{
${ }^{13}$ These data were taken from the Sperling's Best Places web site early in 2004. While these numbers do change, I do not expect that the relative differences in cost-of-living between MSAs have changed dramatically between 2000 and 2004, when the numbers were captured.
} 
Figure 1: Scatter Plot of Per Capita Income vs. Creativity Index

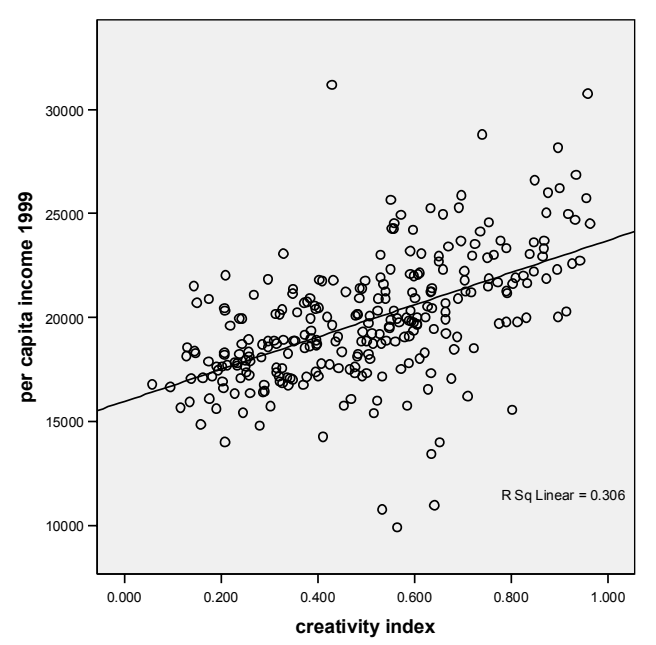

Figure 2: Scatter Plot of Creative Class Mean Earnings vs. Creativity Index

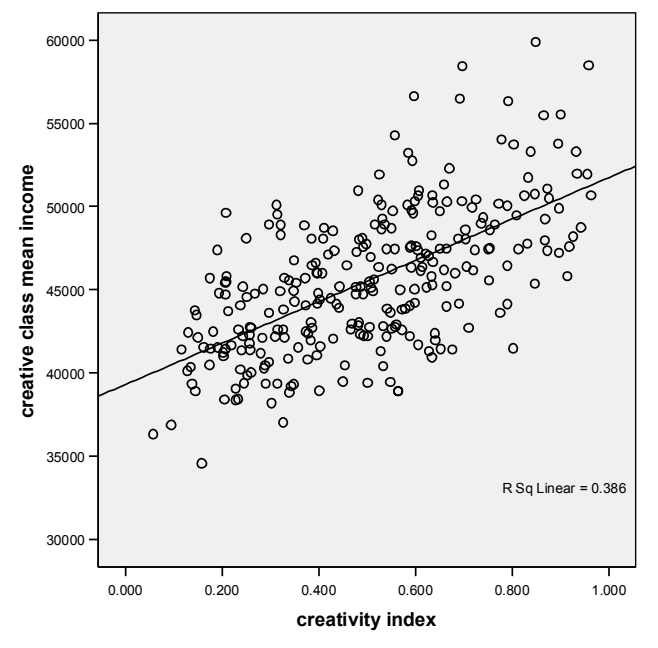

Figure 3: Scatter Plot of Service Class Mean Earnings vs. Creativity Index

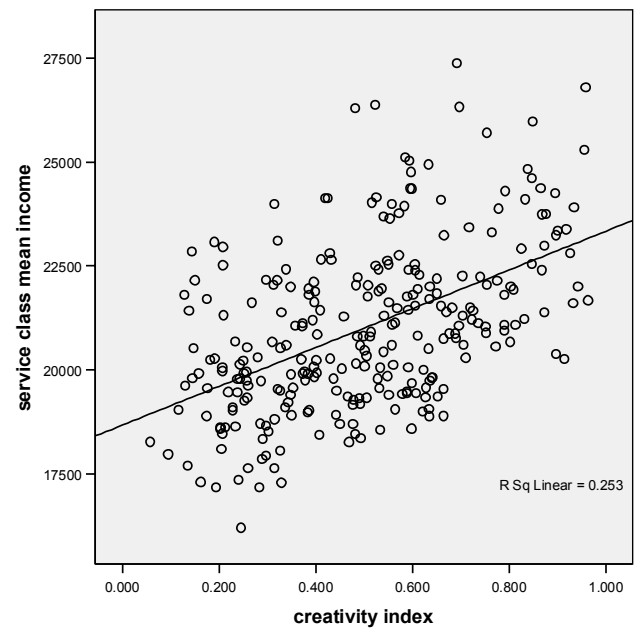

Figure 4: Scatter Plot of Per Capita Income Adjusted for cost of Living vs. Creativity Index

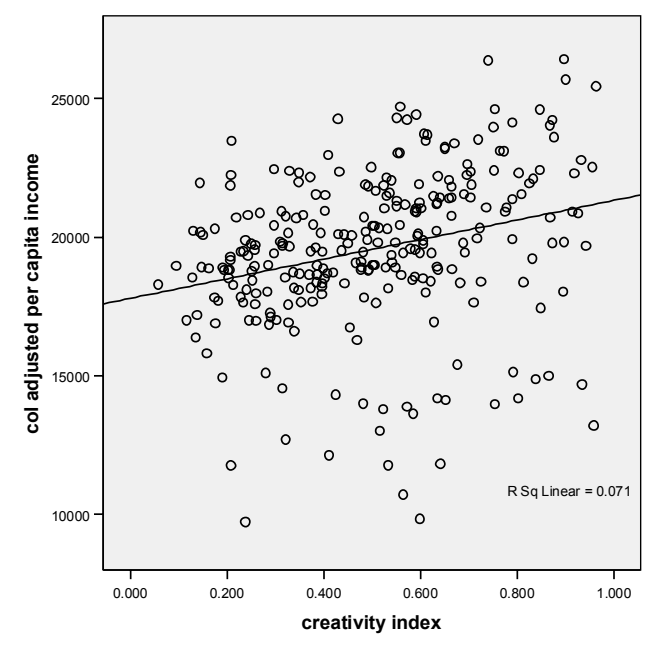

Figure 5: Scatter Plot of Creative Class Mean Earnings Adjusted for Cost of Living vs. Creativity Index

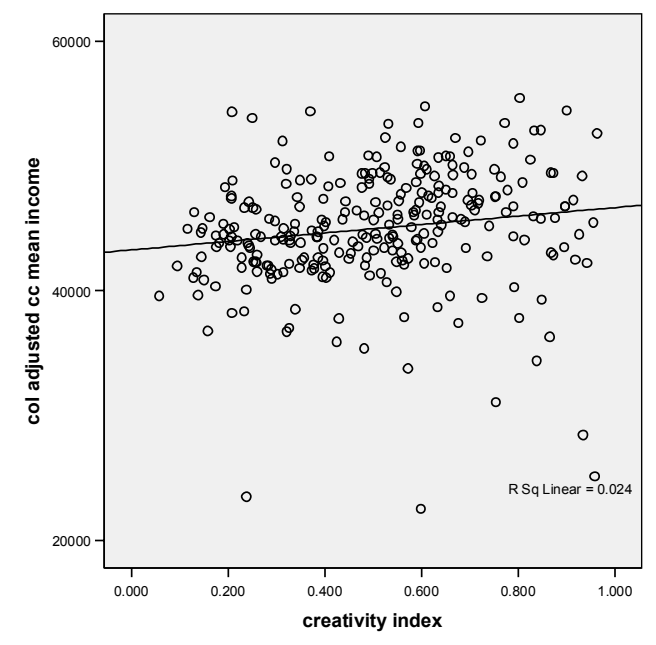

Figure 6: Scatter Plot of Service Class Mean Earnings Adjusted for Cost of Living vs. Creativity Index

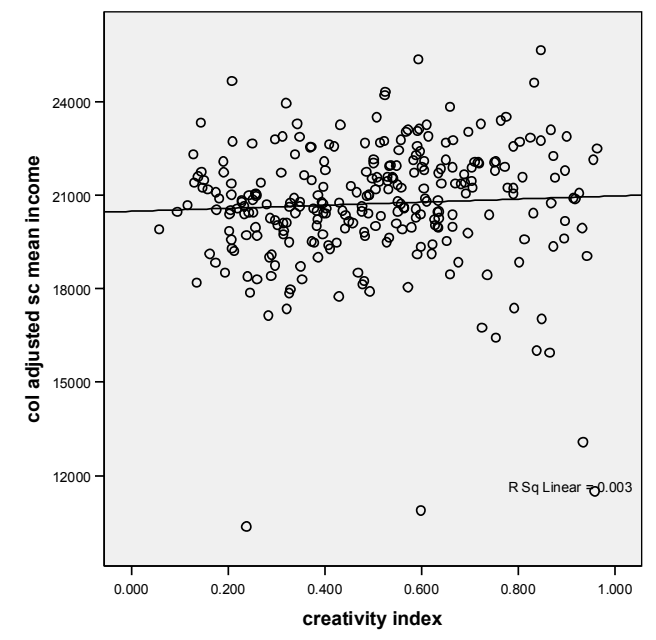



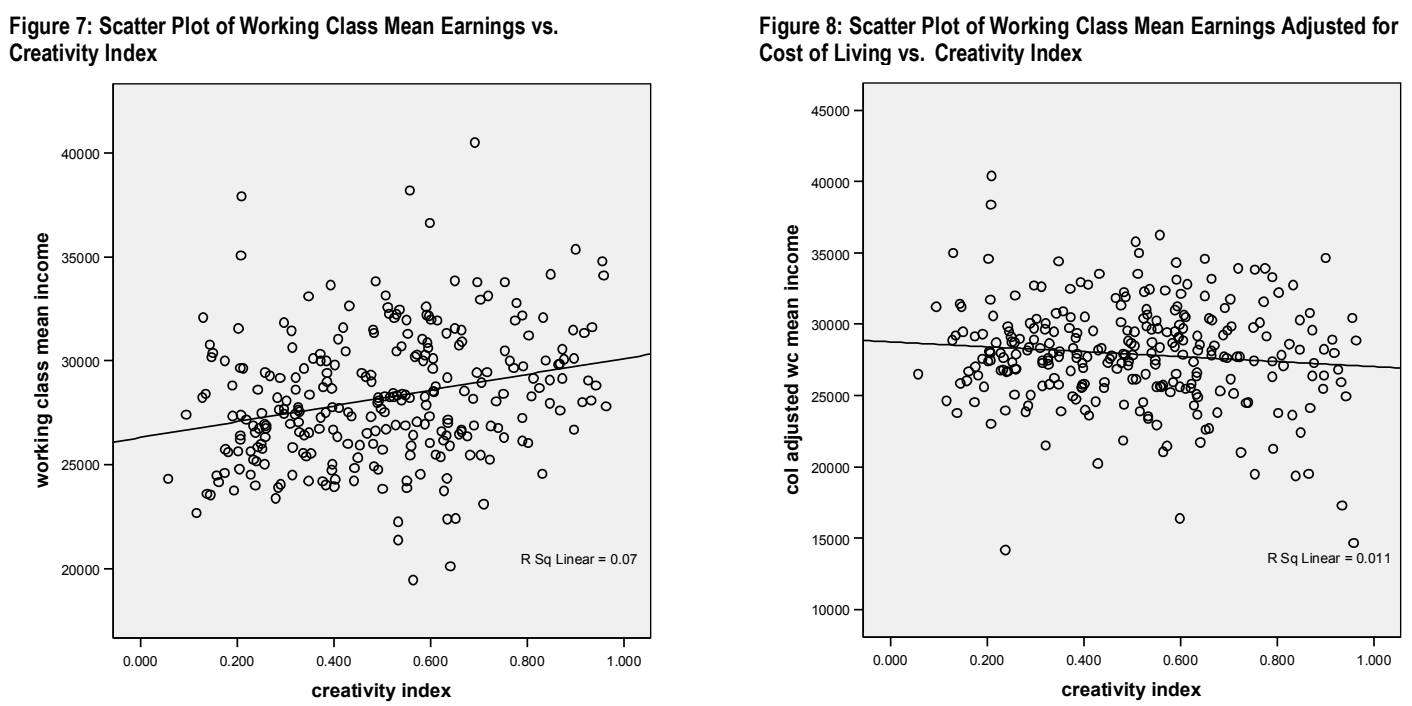

When similar correlations between the percentage of the creative class in an MSA and the same income and earnings variables are computed, the difference in results is more pronounced. Table 3 shows these correlations. The scatter plots are not presented.

\begin{tabular}{|c|c|c|c|}
\hline \multicolumn{4}{|c|}{$\begin{array}{l}\text { Table 3:Income and Earnings Variable Correlations with the Percentage of the } \\
\text { Creative Class for } 276 \mathrm{MSAs}\end{array}$} \\
\hline $\begin{array}{c}\text { creative class mean } \\
\text { earnings }\end{array}$ & $\begin{array}{c}\text { service class mean } \\
\text { earnings }\end{array}$ & $\begin{array}{c}\text { working class mean } \\
\text { earnings }\end{array}$ & $\begin{array}{c}\text { per capita income } \\
1999\end{array}$ \\
\hline $.440(* *)$ & $.281(* *)$ & $.212(* *)$ & $.357(* *)$ \\
\hline $\begin{array}{c}\text { Cost of living } \\
\text { adjusted creative } \\
\text { class mean earnings }\end{array}$ & $\begin{array}{c}\text { Cost of living } \\
\text { adjusted service class } \\
\text { mean earnings }\end{array}$ & $\begin{array}{c}\text { Cost of living } \\
\text { adjusted working } \\
\text { class mean earnings }\end{array}$ & $\begin{array}{c}\text { Cost of living } \\
\text { adjusted per capita } \\
\text { income }\end{array}$ \\
\hline $.162(* *)$ & 0.023 & -0.007 & $.192(* *)$ \\
\hline \multicolumn{4}{|c|}{ ** Correlation is significant at the 0.01 level (2-tailed). } \\
\hline \multicolumn{4}{|c|}{ * Correlation is significant at the 0.05 level (2-tailed). } \\
\hline
\end{tabular}

As can be seen in Table 3, the correlations of the percent creative class with the various income and earnings variables behave similarly to the creativity index correlations in Table 2. That is, adjusting for cost of living lowers all the correlations and eliminates the significance for the service and working classes. It is also of some interest that the correlations with the creativity index are, with one exception, larger than the 
correlations with the percent creative class. The percentage of the creative class is the talent component of the creativity index. Thus it appears that the other components are exerting some independent influence on income. The exception is important, however, because it indicates that the percentage of the creative class is positively $(0.162)$ and significantly $(\mathrm{p}=0.01)$ related to the creative class mean income after adjusting for cost of living and is, in fact, slightly larger than that same correlation for the creativity index $(0.162-0.155=.007)$. This difference is not large but it does indicate that the proportion of the creative class in an MSA taken alone is better correlated with creative class mean income than when it is aggregated with the other components of the creativity index. This also tends to refute the notion that creative class individuals prefer tolerant locales over higher earnings.

These relationships are likely influenced by region. In addition, many public sector employees are included in the creative class and the presence of a state capital in an MSA and the attendant government employment might influence these results. Dummy variables were created for the presence of a state capital and for assigning each MSA to a specific region as defined by the Census. Four stepwise linear regressions were run. The first used the cost of living adjusted per capita income as the dependent variable and the creativity index and geographical dummy variables as independent variables. The second replaced the creativity index with the percentage of the creative class as an independent variable. The third and fourth models used the cost of living adjusted creative class mean earnings as the dependent variable with the same independent variables as in models 1 and 2. Table 4 presents a high level summary of the results. The stepwise linear regression process adds/removes independent variables in an 
iterative process. In these four models the variables remaining in the final iterations are significant (at $p=.016$ or lower) while non-significant variables are removed. Only the signs of the associated coefficients are reported in Table 4 as the signs are sufficient to draw the conclusions warranted by the hypothesis.

These models generally indicate that both the creativity index and the percentage of the creative class are influenced by geographic considerations. In addition, once again the creativity index $\left(\mathrm{R}^{2}=.340\right.$ and .142 for models 1 and 3 respectively) is somewhat more powerful than the percentage of the creative class $\left(\mathrm{R}^{2}=.280\right.$ and .126 for models 2 and 4 respectively) in predicting variations in income.

\begin{tabular}{|l|c|c|c|c|c|c|c|c|}
\hline \multicolumn{7}{|c|}{ Table 4:Regression Results for Per Capita Income and Creative Class Mean Earnings with } \\
Regional Controls at the MSA/CMSA Level
\end{tabular}

$\mathrm{N}=276$ for all models, + reflects a positive coefficient, - reflects a negative coefficient

It is also interesting to note the change in these models when PMSAs are used as the unit of analysis. Much of the data for Boston were only available at the CMSA level. Excluding the other 17 CMSAs leaves 259 MSAs with a creativity index. However, the reconstruction of the Florida dataset allowed for the incorporation of the mean earnings data for the 59 PMSAs that make up the 17 CMSAs resulting in 318 MSAs. Regressions 
similar to those above were run on the PMSA dataset. Table 5 shows a summary of those results. All the significant variables were significant at $p=0.04$ or below and only the signs of the coefficients are reported. Notice that when using PMSAs as the unit of analysis, the percentage of the creative class is not statistically significant.

My initial hypothesis that the concentration of the creative class would have little influence on income variables is rejected at the MSA/CMSA level, but supported at the MSA/PMSA level. However, it is clear that, regardless of study level, based on the $\mathrm{R}^{2}$ values in the above models, other components of the creativity index do exert some influence. Also, given that the percentage of the creative class may simply be a matter of human capital, it is worthwhile to investigate the impact of creativity index

\begin{tabular}{|c|c|c|c|c|c|c|c|c|}
\hline & $\mathrm{R}^{2}$ & $\begin{array}{l}\text { Creativity } \\
\text { Index }\end{array}$ & $\begin{array}{c}\% \\
\text { Creative } \\
\text { Class }\end{array}$ & $\begin{array}{c}\text { State } \\
\text { Capital } \\
\text { in MSA }\end{array}$ & $\begin{array}{l}\text { Northeast } \\
\text { Region }\end{array}$ & $\begin{array}{l}\text { Midwest } \\
\text { Region }\end{array}$ & $\begin{array}{l}\text { South } \\
\text { Region }\end{array}$ & $\begin{array}{c}\text { West } \\
\text { Region }\end{array}$ \\
\hline $\begin{array}{l}\text { Model } 1 \\
\text { CoL Adjusted } \\
\text { Per Capita } \\
\text { Income N = } \\
259\end{array}$ & .317 & + & & + & Not sig. & + & Not sig. & - \\
\hline $\begin{array}{l}\text { Model } 2 \\
\text { CoL Adjusted } \\
\text { Per Capita } \\
\text { Income N = } \\
318\end{array}$ & .200 & & Not sig. & + & Not sig. & + & Not sig. & - \\
\hline $\begin{array}{l}\text { Model } 3 \\
\text { CoL Adjusted } \\
\text { Creative Class } \\
\text { Mean Income } \\
\mathrm{N}=259\end{array}$ & .146 & + & & Not sig. & Not sig. & Not sig. & Not sig. & - \\
\hline $\begin{array}{l}\text { Model } 4 \\
\text { CoL Adjusted } \\
\text { Creative Class } \\
\text { Mean Income } \\
\mathrm{N}=318\end{array}$ & .092 & & Not sig. & Not sig. & - & Not sig. & Not sig. & - \\
\hline
\end{tabular}


Product.

\subsubsection{Hypothesis 2: Creative class percentage vs. GMP measures}

Gross Metropolitan Product as explained above is a broader measure of the economic conditions in an MSA than per capita income. As opposed to evaluating income data with the creativity index, this hypothesis tests the relationship of GMP with the creativity index and the percentage of the creative class. GMP for the year 2000 and the percent change in GMP from 2000 to 2004 and from 2000 to $2005^{14}$ are used in the analysis. However, I also looked at the correlation of GMP with the income measures to determine whether this analysis might be reasonably different than the income based analysis. Table 6 reflects several interesting phenomena. First, while GMP is significantly correlated with per capita income and creative class mean income for CMSA data, it is not significantly correlated with these data after adjusting for cost of living. For PMSA data, GMP is positively and significantly correlated with per capita income and creative class mean income data, but after adjusting for cost of living, it is significantly and negatively correlated. As a result, I proceeded with the analysis of GMP measures as dependent variables with the creativity index or the proportion of the creative class as the independent variable.

\footnotetext{
${ }^{14}$ Global Insights, Inc. published the 2000 to 2005 GMP data in January 2007 after the original analyses had been conducted.
} 


\begin{tabular}{|l|l|r|r|r|r|}
\hline Table 6:Correlations of GMP with Income Data for 276 MSA/CMSAs and 318 MSA/PMSAs \\
\hline \multirow{5}{*}{} & For CMSAs & $\begin{array}{c}\text { per capita } \\
\text { income 1999 }\end{array}$ & $\begin{array}{c}\text { Cost of } \\
\text { living } \\
\text { adjusted } \\
\text { per capita } \\
\text { income }\end{array}$ & $\begin{array}{c}\text { creative } \\
\text { class mean } \\
\text { income }\end{array}$ & $\begin{array}{c}\text { Cost of living } \\
\text { adjusted cc } \\
\text { mean income }\end{array}$ \\
\hline \multirow{5}{*}{$\begin{array}{l}\text { Gross Metropolitan } \\
\text { Product year 2000 }\end{array}$} & Pearson Correlation & $.407^{* *}$ & 0.068 & $.485^{* *}$ & -0.037 \\
\cline { 2 - 6 } & Sig. (2-tailed) & 0.000 & 0.261 & 0.000 & 0.544 \\
\cline { 2 - 6 } & For PMSAs & 276 & 276 & 276 & 276 \\
\cline { 2 - 6 } & Pearson Correlation & $.432^{* *}$ & $-.162^{* *}$ & $.567^{* *}$ & $-.266^{* *}$ \\
\cline { 2 - 6 } & Sig. (2-tailed) & 0.000 & 0.004 & 0.000 & 0.000 \\
\cline { 2 - 7 } & N & 318 & 318 & 318 & 318 \\
\hline
\end{tabular}

Table 7 presents the correlations of the creativity index with the GMP percent change measures. It's important to note at the outset that GMP data for the year 2000 were produced using PMSA/MSA/CMSA definitions as used in the 2000 Census. However, in reporting GMP data for 2004, Global Insights, Inc. used the MSA definitions as defined by the Bureau of the Census in December 2004. I made adjustments to the GMP data to make them consistent with the 2000 definitions and as a result the full compliment of MSAs is not available for the GMP percent change data. Note that Ns in the percent change columns for the MSA/CMSA analysis are 295 for 00 04 and 294 for 00-05. The details of these adjustments are in the Data Appendix. 


\begin{tabular}{|c|c|c|c|c|}
\hline \multicolumn{5}{|c|}{$\begin{array}{l}\text { Table 7:Correlations of the Creativity Index and Percentage of the Creative Class with } \\
\text { Year 2000GMP and Percent Change in GMP from 00-04 and 00-05 }\end{array}$} \\
\hline \multicolumn{2}{|c|}{ For CMSAs } & \multirow{2}{*}{$\begin{array}{r}\begin{array}{c}\text { Gross Metropolitan } \\
\text { Product year } 2000\end{array} \\
.375(* *)\end{array}$} & \multirow{2}{*}{$\begin{array}{c}\text { Real Gross } \\
\text { Metropolitan } \\
\text { Product percent } \\
\text { change } 2000 \text { to } \\
\mathbf{2 0 0 4} \\
0.103\end{array}$} & \multirow{2}{*}{$\begin{array}{c}\text { Real Gross } \\
\text { Metropolitan } \\
\text { Product percent } \\
\text { change } 2000 \text { to } \\
\mathbf{2 0 0 5} \\
0.094\end{array}$} \\
\hline \multirow{3}{*}{$\begin{array}{l}\text { creativity } \\
\text { index }\end{array}$} & Pearson Correlation & & & \\
\hline & Sig. (2-tailed) & 0.000 & 0.090 & 0.121 \\
\hline & $\bar{N}$ & 276 & 272 & 272 \\
\hline \multirow{3}{*}{$\begin{array}{l}\text { \%creative } \\
\text { class }\end{array}$} & Pearson Correlation & $.288(* *)$ & -0.081 & -0.044 \\
\hline & Sig. (2-tailed) & 0.000 & 0.183 & 0.468 \\
\hline & $\mathrm{N}$ & 276 & 272 & 272 \\
\hline \multicolumn{5}{|c|}{ For PMSAs } \\
\hline \multirow{3}{*}{$\begin{array}{l}\text { creativity } \\
\text { index }\end{array}$} & Pearson Correlation & $.438(* *)$ & $.129(*)$ & 0.101 \\
\hline & Sig. (2-tailed) & 0.000 & 0.429 & 0.583 \\
\hline & $\mathrm{N}$ & $\mathrm{N}=259$ & $\mathrm{~N}=255$ & $\mathrm{~N}=255$ \\
\hline \multirow{3}{*}{$\begin{array}{l}\% \text { creative } \\
\text { class }\end{array}$} & Pearson Correlation & $.354(* *)$ & -0.100 & -0.067 \\
\hline & Sig. (2-tailed) & 0.000 & 0.183 & 0.468 \\
\hline & $\mathrm{N}$ & $\mathrm{N}=318$ & $\mathrm{~N}=295$ & $\mathrm{~N}=294$ \\
\hline
\end{tabular}

Table 7 shows that the creativity index and the percent creative class are significantly and positively correlated with GMP for the year 2000 but not with its subsequent growth from 2000 to 2004 or from 2000 to 2005. Based on these results additional analysis was undertaken to determine whether and which subcomponents of the creativity index might be better predictors of GMP or GMP percent change.

\subsubsection{Summary of Research Question 1 Findings}

Results under hypothesis 1 indicate that the concentration of the creative class does have some influence on income variables. However, it is also clear that the other components of the creativity index do exert some influence. Results under hypothesis 2 indicate that the creativity index and the percent creative class are significantly and positively correlated with GMP for the year 2000 but not with its subsequent growth from 2000 to 2004 or from 2000 to 2005 . Also, given that the percentage of the creative class 
may simply be a matter of human capital, it is worthwhile to investigate the impact of creativity index subcomponents after controlling for human capital. Based on these results additional analysis was undertaken to determine whether and which subcomponents of the creativity index might be better predictors of GMP or GMP percent change.

\subsection{Research Question 2}

\subsubsection{Hypothesis 3: Creativity index components vs. GMP measures}

Hypothesis 3 states that the elements of the creativity index, constructed by Florida to compare the "creativity" of metropolitan regions, may quantitatively relate to the economic health and growth of those regions but the percentage of the creative class will not.

I constructed four regression models ${ }^{15}$ to test this hypothesis relative to economic health. GMP per capita in 2000 was used as the dependent variable. The correlations matrix for all variables in these analyses is provided in Tables 34 and 35 in the Data Appendix. Model 1 contains the elements of the creativity index. Model 2 adds an educational attainment variable to model 1 . Model 3 removes the educational attainment variable but includes variables for region and the presence of a state (or federal) capital. Finally, model 4 adds the educational attainment variable to model 3 . The results are shown in Tables 8 and 9.

\footnotetext{
${ }^{15}$ I used the ENTER method in SPSS to run these regressions.
} 
Table 8: Regression Results for GMP per Capita (2000) with Independent Variables in Four Models

\begin{tabular}{|c|c|c|c|c|c|c|c|c|}
\hline & \multicolumn{2}{|c|}{ Model 1} & \multicolumn{2}{|c|}{ Model 2} & \multicolumn{2}{|c|}{ Model 3} & \multicolumn{2}{|c|}{ Model 4} \\
\hline (Constant) & $32,940.2$ & $* * *$ & $31,967.6$ & $* * *$ & $29,759.0$ & $* * *$ & $29,738.5$ & $* * *$ \\
\hline $\begin{array}{l}\text { Percent Creative } \\
\text { Class }\end{array}$ & $19,747.7$ & $*$ & $2,957.4$ & & $12,870.1$ & & $2,357.8$ & \\
\hline $\begin{array}{l}\text { Educational } \\
\text { Attainment }\end{array}$ & & & $6,789.7$ & $* * *$ & & & $4,641.3$ & $* *$ \\
\hline $\begin{array}{l}\text { Growth in patents } \\
1990-1999\end{array}$ & 92.6 & & -67.8 & & 114.7 & & -2.0 & \\
\hline $\begin{array}{l}\text { Log of Milken } \\
\text { Index }\end{array}$ & $1,479.5$ & $* * *$ & $1,147.3$ & $* *$ & $1,195.7$ & $* * *$ & 991.8 & $* *$ \\
\hline $\begin{array}{l}\text { Log of Melting Pot } \\
\text { Index }\end{array}$ & 125.0 & & 568.1 & & $1,056.1$ & & $1,086.0$ & \\
\hline Log of Gay Index & $1,908.5$ & & $-1,757.5$ & & $5,585.7$ & & $1,918.7$ & \\
\hline $\begin{array}{l}\text { Log of Bohemian } \\
\text { Index }\end{array}$ & $3,019.5$ & $* *$ & $1,539.1$ & & $2,660.2$ & $*$ & $1,819.9$ & \\
\hline Tolerance score & -3069.4 & & $-6,697.4$ & & $3,839.1$ & & -317.1 & \\
\hline $\begin{array}{l}\text { State capital in } \\
\text { MSA }\end{array}$ & & & & & $1,448.0$ & & $1,279.5$ & \\
\hline Northeast region & & & & & $5,808.7$ & $* * *$ & $5,421.2$ & $* * *$ \\
\hline West region & & & & & -4.1 & & 442.7 & \\
\hline Midwest region & & & & & $3,361.0$ & $* * *$ & $2,582.1$ & $* * *$ \\
\hline $\mathrm{F}$ & 9.2 & & 10.4 & & 10.0 & & 9.9 & \\
\hline Sig. & $* * *$ & & $* * *$ & & $* * *$ & & $* * *$ & \\
\hline Adjusted R Square & 0.176 & & 0.218 & & 0.268 & & 0.284 & \\
\hline $\mathrm{N}$ & 271 & & 271 & & 271 & & 271 & \\
\hline
\end{tabular}

Dependent Variable: GMP per Capita in 2000

Significance: $* * * \mathrm{p}<.01, * * \mathrm{p}<.05, * \mathrm{p}<.10$

Sources: GMP is available online from the U. S. Conference of Mayors at http://www.usmayors.org/metroeconomies/0703/metroecon appendix 0703.pdf. GMP/capita is the author's calculation based on population data from the Census 2000, Summary File 1, Table P1- Total Population. The number of patents is available from the U. S Office of Patents and Trademarks at http://www.uspto.gov/web/offices/ac/ido/oeip/taf/county.pdf. Melting Pot Index derived from Census 2000, SF3, Table P22-Year of Entry for the Foreign Born Population. Gay Index derived from Census 2000, SF4, Table PCT22 -Households by Presence of Nonrelatives. Tolerance derived from Census data available from http://www.census.gov/hhes/www/housing/housing patterns/gettable msa.html. Tech pole available from the Milken Institute at:

http://www.milkeninstitute.org/pdf/hightech metros.pdf. The percentage of the creative class was derived from data from the Bureau of Labor Statistics 2000 Occupational Employment Survey. Education Attainment derived from Census 2000, SF3, Table P37 Sex by Educational Attainment for the Population 25+ Years. The Milken Index, Melting Pot Index, Gay and Lesbian Index and Bohemian Index were logarithmically transformed to more closely approximate a normal distribution (Tabachnick \& Fidell 2001, p. 83).

The differences between Tables 8 and 9 result from the exclusion of four univariate outliers based on the distribution of GMP per capita for 2000 and four multivariate outliers which exceeded the critical value of the Mahalanobis distance. The four univariate outliers were Bloomington-Normal, IL; Elkhart-Goshen, IN; Hartford, CT; and Pittsfield, MA. The four multivariate outliers were Rochester, MN; Las Vegas, NV; Kileen-Temple, TX; and Boise, ID. Data for these MSAs were rechecked for 
accuracy and I found no logical reason for excluding them other than the fact that they are statistical outliers. Table 8 presents the results with these MSAs included and Table 9 presents the results with them excluded. Excluding these MSAs does improve the models in terms of $\mathrm{F}$ statistics and adjusted $\mathrm{R}^{2}$ values. There are also some changes in the significance of variables, particularly the bohemian index in models 2,3 , and 4 and the gay and lesbian index in model 2. Collinearity diagnostics for all four models are in acceptable ranges.

The key finding from these models is that the percentage of the creative class, while marginally significant in model 1 , is not significant when educational attainment is controlled. In addition, it is not significant when regional controls are introduced in model 3. Finally, in model 4, educational attainment and region remain significant while percent creative class remains insignificant. The Milken high-tech index is significant in all four models as is the bohemian index. The gay index is only significant in model 3 after outliers are excluded (see Table 9). The control for the presence of a state (or federal) capital had no significant effect.

Given these results, the hypothesis regarding economic health as measured by GMP per capita is confirmed. Clearly, some elements of the creativity index are related to MSA economic health. The high-tech measure dominates the models and educational attainment and region tend to remove the influence of the creative class percentage for an MSA.

I also ran four similar models using GMP percent change from 2000 to 2004 as the dependent variable. The correlation matrix for these variables is provided in Tables 36 and 37 in the Data Appendix. There were no univariate outliers in these models. The 
same four MSAs were above the Mahalanobis distance critical value. However,

removing these four MSAs weakened the $\mathrm{F}$ statistics and the $\mathrm{R}^{2}$ values. Model results

with the outliers deleted are not presented. Tolerance, Variance Inflation Factors and

Condition Indices were all within acceptable limits for each model ruling out any

potentially negative effects from multicollinearity. The results for these models are

shown in Table 10.

Table 9: Regression Results for GMP per Capita (2000) with Independent Variables in Four Models (8 Outliers Removed)

\begin{tabular}{|c|c|c|c|c|c|c|c|c|}
\hline & \multicolumn{2}{|c|}{ Model 1} & \multicolumn{2}{|c|}{ Model 2} & \multicolumn{2}{|c|}{ Model 3} & \multicolumn{2}{|c|}{ Model 4} \\
\hline (Constant) & $32,937.2$ & $* * *$ & $32,478.5$ & $* * *$ & $30,907.0$ & $* * *$ & $30,950.2$ & $* * *$ \\
\hline $\begin{array}{l}\text { Percent Creative } \\
\text { Class }\end{array}$ & $18,758.5$ & $*$ & $6,392.5$ & & $13,043.0$ & & $5,610.8$ & \\
\hline $\begin{array}{l}\text { Educational } \\
\text { Attainment }\end{array}$ & & & $4,816.2$ & $* * *$ & & & $3,229.4$ & * \\
\hline $\begin{array}{l}\text { Growth in patents } \\
1990-1999\end{array}$ & 243.3 & & 43.1 & & 242.6 & & 102.5 & \\
\hline Log of Milken Index & $1,396.2$ & $* * *$ & $1,180.7$ & $* * *$ & $1,192.2$ & $* * *$ & $1,052.9$ & $* *$ \\
\hline $\begin{array}{l}\text { Log of Melting Pot } \\
\text { Index }\end{array}$ & -527.7 & & -169.5 & & 108.3 & & 156.8 & \\
\hline Log of Gay Index & $4,171.3$ & & $1,371.8$ & & $6,479.4$ & $*$ & $3,959.9$ & \\
\hline $\begin{array}{l}\text { Log of Bohemian } \\
\text { Index }\end{array}$ & $3,289.6$ & $* *$ & $2,276.4$ & $*$ & $2,940.5$ & $* *$ & $2,397.7$ & $*$ \\
\hline Tolerance score & $-3,686.7$ & & $-6,229.2$ & & 764.8 & & $-2,023.3$ & \\
\hline State capital in MSA & & & & & $1,353.6$ & & $1,194.4$ & \\
\hline Northeast region & & & & & $4,492.0$ & $* * *$ & $4,244.2$ & $* * *$ \\
\hline West region & & & & & 450.0 & & 726.5 & \\
\hline Midwest region & & & & & $2,514.8$ & $* * *$ & $2,014.2$ & $* *$ \\
\hline $\mathrm{F}$ & 12.2 & & 12.2 & & 10.9 & & 10.4 & \\
\hline Sig. & $* * *$ & & $* * *$ & & $* * *$ & & $* * *$ & \\
\hline Adjusted R Square & 0.231 & & 0.254 & & 0.294 & & 0.301 & \\
\hline $\mathrm{N}$ & 263 & & 263 & & 263 & & 263 & \\
\hline
\end{tabular}

Significance: $* * * \mathrm{p}<.01,{ }^{* *} \mathrm{p}<.05,{ }^{*} \mathrm{p}<.10$

Sources: GMP is available online from the U. S. Conference of Mayors at http://www.usmayors.org/metroeconomies/0703/metroecon_appendix 0703.pdf. GMP/capita is the author's calculation based on population data from the Census 2000, Summary File 1, Table P1- Total Population. The number of patents is available from the U. S Office of Patents and Trademarks at http://www.uspto.gov/web/offices/ac/ido/oeip/taf/county.pdf. Melting Pot Index derived from Census 2000, SF3, Table P22-Year of Entry for the Foreign Born Population. Gay Index derived from Census 2000, SF4, Table PCT22 -Households by Presence of Nonrelatives. Tolerance derived from Census data available from http://www.census.gov/hhes/www/housing/housing patterns/gettable msa.html. Tech pole available from the Milken Institute at:

http://www.milkeninstitute.org/pdf/hightech metros.pdf. The percentage of the creative class was derived from data from the Bureau of Labor Statistics 2000 Occupational Employment Survey. Education Attainment derived from Census 2000, SF3, Table P37 Sex by Educational Attainment for the Population 25+ Years. The Milken Index, Melting Pot Index, Gay and Lesbian Index and Bohemian Index were logarithmically transformed to more closely approximate a normal distribution (Tabachnick \& Fidell 2001, p. 83).

These models do show a statistically significant relationship between the percentage of the creative class in an MSA and the GMP percent change for that MSA from 2000 to 2004, but the influence is negative. Tolerance and the melting pot index 
show consistent statistically significant positive influence on economic growth. The hypothesis that elements of the creativity index will relate to economic growth but the percentage of the creative class will not is essentially confirmed. I expected little if any statistically significant relationship for the percentage of the creative class in these models and certainly did not expect a significant negative relationship. However, this model does seem consistent with the literature that culture, as captured by a measure of immigrants in an MSA (the melting pot index) and racial tolerance, does impact the economic growth of an MSA. Perhaps more importantly, the negative coefficient of the percentage of the creative class indicates that the larger the percentage of the creative class in an MSA the smaller the growth. Regional controls were statistically significant but did not affect the significance of other variables. The control for state or federal capital was not significant. 
Table 10: Regression Results for GMP Percent Change from 2000 to 2004 with Independent Variables is Four Models

\begin{tabular}{|c|c|c|c|c|c|c|c|c|}
\hline & \multicolumn{2}{|c|}{ Model 1} & \multicolumn{2}{|c|}{ Model 2} & \multicolumn{2}{|c|}{ Model 3} & \multicolumn{2}{|c|}{ Model 4} \\
\hline (Constant) & 0.087 & $* *$ & 0.089 & $* *$ & 0.122 & $* * *$ & 0.121 & $* * *$ \\
\hline Percent Creative Class & -0.223 & $* *$ & -0.186 & $*$ & -0.238 & $* *$ & -0.271 & $* * *$ \\
\hline Educational Attainment & & & -0.015 & & & & 0.014 & \\
\hline $\begin{array}{l}\text { Growth in patents } 1990 \\
-1999\end{array}$ & -0.002 & & -0.001 & & -0.002 & & -0.002 & \\
\hline Log of Milken Index & -0.005 & & -0.004 & & -0.004 & & -0.004 & \\
\hline $\begin{array}{l}\text { Log of Melting Pot } \\
\text { Index }\end{array}$ & 0.085 & $* * *$ & 0.084 & $* * *$ & 0.083 & $* * *$ & 0.084 & $\star * *$ \\
\hline Log of Gay Index & 0.002 & & 0.010 & & -0.064 & $*$ & -0.075 & * \\
\hline Log of Bohemian Index & 0.015 & & 0.018 & & 0.021 & & 0.018 & \\
\hline Tolerance score & 0.239 & $* * *$ & 0.247 & $* * *$ & 0.203 & $* * *$ & 0.190 & $* * *$ \\
\hline State capital in MSA & & & & & 0.015 & & 0.015 & \\
\hline Northeast region & & & & & -0.027 & $* *$ & -0.028 & $* * *$ \\
\hline West region & & & & & -0.005 & & -0.004 & \\
\hline Midwest region & & & & & -0.043 & $* * *$ & -0.045 & $* * *$ \\
\hline $\mathrm{F}$ & 17.0 & & 15.0 & & 14.5 & & 13.3 & \\
\hline Sig. & $* * *$ & & $* * *$ & & $* * *$ & & $* * *$ & \\
\hline Adjusted R Square & 0.3 & & 0.3 & & 0.4 & & 0.4 & \\
\hline $\mathrm{N}$ & 269.0 & & 269.0 & & 269.0 & & 269.0 & \\
\hline
\end{tabular}

Significance: $* * * p<.01,{ }^{* *} \mathrm{p}<.05,{ }^{*} \mathrm{p}<.10$
Sources: GMP is available online from the U. S. Conference of Mayors at http://www.usmavors.org/74thWinterMeeting/metroeconreport January2006.pdf. The number of patents is available from the U. S Office of Patents and Trademarks at http://www.uspto.gov/web/offices/ac/ido/oeip/taf/county.pdf. Melting Pot Index derived from Census 2000, SF3, Table P22-Year of Entry for the Foreign Born Population. Gay Index derived from Census 2000, SF4, Table PCT22 -Households by Presence of Nonrelatives. Tolerance derived from Census data available from http://www.census.gov/hhes/www/housing/housing patterns/gettable msa.html. Tech pole available from the Milken Institute at: $\mathrm{http} / /$ www.milkeninstitute.org/pdf/hightech metros.pdf. The percentage of the creative class was derived from data from the Bureau of Labor Statistics 2000 Occupational Employment Survey. Education Attainment derived from Census 2000, SF3, Table P37 Sex by Educational Attainment for the Population 25+ Years. The Milken Index, Melting Pot Index, Gay and Lesbian Index and Bohemian Index were logarithmically transformed to more closely approximate a normal distribution (Tabachnick \& Fidell 2001, p. 83).

The Model 1- 4 regressions in Table 10 were repeated based on new GMP data for 2005 which enabled a calculation of percent change in GMP from 2000 to 2005 for both MSA/CMSA and MSA/PMSA groupings. These results are presented in Table 11. Updating the data series to include GMP data for 2005 made no substantial change to the results. 
Table 11: Regression Results for GMP Percent Change from 2000 to 2005 with Independent Variables is Four Models

\begin{tabular}{|c|c|c|c|c|c|c|c|c|}
\hline & \multicolumn{2}{|c|}{ Model 1} & \multicolumn{2}{|l|}{ Model 2} & \multicolumn{2}{|c|}{ Model 3} & \multicolumn{2}{|c|}{ Model 4} \\
\hline (Constant) & 0.099 & $* *$ & 0.105 & $* *$ & 0.175 & $* * *$ & 0.175 & $* * * *$ \\
\hline Percent Creative Class & -0.249 & $*$ & -0.152 & & -0.238 & * & -0.299 & ** \\
\hline Educational Attainment & & & -0.039 & & & & 0.027 & \\
\hline $\begin{array}{l}\text { growth in patents } 1990 \text { - } \\
1999\end{array}$ & -0.001 & & 0.000 & & -0.002 & & -0.003 & \\
\hline Log of Milken Index & -0.004 & & -0.002 & & -0.000 & & -0.001 & \\
\hline Log of Melting Pot Index & 0.111 & $* * *$ & 0.109 & $* * *$ & 0.102 & $* * *$ & 0.103 & $* * *$ \\
\hline Log of Gay Index & 0.077 & & 0.098 & * & -0.055 & & -0.077 & \\
\hline Log of Bohemian Index & 0.017 & & 0.009 & & 0.005 & & 0.010 & \\
\hline Tolerance score & 0.313 & $* * *$ & 0.333 & $* * *$ & 0.209 & $* * *$ & 0.185 & $* * *$ \\
\hline state capital in MSA & & & & & 0.018 & & 0.017 & \\
\hline northeast region & & & & & -0.072 & $* * *$ & -0.074 & $* * *$ \\
\hline west region & & & & & -0.004 & & -0.001 & \\
\hline Midwest region & & & & & -0.090 & $* * *$ & -0.095 & $* * *$ \\
\hline $\mathrm{F}$ & 15.1 & & 13.6 & & 18.2 & & 16.8 & \\
\hline Sig. & $* * *$ & & $* * *$ & & $* * *$ & & $* * *$ & \\
\hline Adjusted R Square & 0.27 & & 0.274 & & 0.414 & & 0.414 & \\
\hline $\mathrm{N}$ & 269.0 & & 269.0 & & 269.0 & & 269.0 & \\
\hline
\end{tabular}

Significance: $* * * \mathrm{p}<.01,{ }^{* *} \mathrm{p}<.05,{ }^{*} \mathrm{p}<.10$

Sources: GMP is available online from the U. S. Conference of Mayors at http://www.usmayors.org/74thWinterMeeting/metroeconreport January2007.pdf. The number of patents is available from the U. S Office of Patents and Trademarks at http://www.uspto.gov/web/offices/ac/ido/oeip/taf/county.pdf. Melting Pot Index derived from Census 2000, SF3, Table P22-Year of Entry for the Foreign Born Population. Gay Index derived from Census 2000, SF4, Table PCT22 -Households by Presence of Nonrelatives. Tolerance derived from Census data available from http://www.census.gov/hhes/www/housing/housing patterns/gettable msa.html. Tech pole available from the Milken Institute at: $\mathrm{http}: / /$ www.milkeninstitute.org/pdf/hightech metros.pdf. The percentage of the creative class was derived from data from the Bureau of Labor Statistics $2000 \mathrm{Occupational}$ Employment Survey. Education Attainment derived from Census 2000, SF3, Table P37 Sex by Educational Attainment for the Population 25+ Years. The Milken Index, Melting Pot Index, Gay and Lesbian Index and Bohemian Index were logarithmically transformed to more closely approximate a normal distribution (Tabachnick \& Fidell 2001, p. 83).

I ran all these models at the MSA/PMSA level by excluding the CMSA data and including the underlying PMSA data. Running these models at the MSA/PMSA level had no impact on the results. The differentiation I expected at smaller geographical size did not occur. The addition of these 25 MSAs was insufficient to change the statistical relationships in the models. I still believe, however, that further research at a smallerthan-MSA level would provide additional insight into economic development policy outcomes. This is left for future research.

\subsubsection{Summary of Research Question 2 Findings}

The occupational structure of creative metro areas contains a higher proportion of the creative class, however, this does not seem to translate to significantly better regional 
economic performance as measured by GMP. High-technology and educational attainment of the population over age 25 are more important predictors in this analysis of GMP per capita when controlling for region of the country or the presence of a state capital. Racial tolerance and the relative concentration of the foreign born population are the only positive and strongly significant predictors of GMP growth. Larger creative class percentages detract from GMP growth. Taken together these models imply that merely adding creative class individuals in an MSA will not lead to a stronger economy in terms of GMP.

\subsection{Research Question 3}

The preliminary quantitative analysis provides the backdrop for the additional questions raised in this dissertation. Does economic development context across MSAs predict economic growth? Controlling for context, do creativity index tolerance subcomponents add any predictive power to the analysis? Analysis of this question was based on secondary data relative to the parameters of the economic development context. Once again the unit of analysis is the MSA, but is restricted to the 49 MSAs with populations over one million. The various economic context factors were operationalized as mentioned above and described in more detail below. The majority of these data are available from the Census Bureau or the Bureau of Labor Statistics and each of the 49 MSAs were, to the extent possible, evaluated using these variables. Exploratory factor analysis was conducted to determine if there are underlying factors of importance and whether they will align along the three dimensions of technology, talent and tolerance . Statistical regression techniques were applied to determine the predictive effect of these dependent variables on economic health and growth as measured by 2000 GMP per 
capita and GMP percent change 2000 - 2004 and 2000 -2005 respectively. My

underlying hypothesis is that factor analysis will not produce results consistent with the three T's and that certain measures from the economic development context will prove more significant than the specific tolerance variables included in the creativity index. It is also under this section that I explore the relationship of the percentage of the creative class with certain variables that measure social ills of one form or another to analyze whether and the extent to which a concentration of the creative class predicts improved social conditions.

\subsubsection{Economic Base}

The first element of economic context is economic base. Economic base can be derived through the use of location quotients. Shift-share analysis can also be used to determine the extent to which industry growth in an MSA is due to national, industry or local factors. An economic multiplier can also be computed which quantifies the number of non-basic jobs for each basic job. Using employment data by industry from the U. S. Census for 1990 (Table P077) and 2000 (Table P049) and a downloadable crosswalk ${ }^{16}$ available from the Census Bureau I performed a shift-share analysis and calculated a location quotient for all 20 of the industrial classifications provided in Census data and economic multipliers for each of the 49 MSAs.

A similar process was undertaken for employment by occupation to develop local factors and location quotients for occupations in the creative class, service class and working class (U.S. Census Tables P078 and P050 for 1990 and 2000 respectively). Creative occupations take two forms: those that fall into what Florida (2002) calls "the

\footnotetext{
${ }^{16}$ See http://www.census.gov/hhes/www/ioindex/faqs.html\#Q11
} 
super-creative core" and those composing a stratum of "creative professionals." All of these are lumped together into a "creative class." The super-creative core (SCC) includes the following major occupational categories as defined by the U.S. government: computer and mathematical (CMO); architecture and engineering (A\&E); life, physical, and social science (LPSS); education, training, and library (ETL); arts, design, entertainment, sports, and media (ADE). The occupations of creative professionals (CP) are: management (MGMT), business and financial operations (B\&F), legal, healthcare practitioners and technical (HPT), and high-end sales and sales management. The supercreative core is directly engaged in the creation of new products and ideas; creative professionals apply knowledge to solve problems (Florida 2002b, pp. 69, 74, 328). Rounding out the rest of the nonagricultural occupational structure are traditional working class (WC) occupations of construction and extraction (C\&E); installation, maintenance, and repair (IMR); production (PROD); and transportation and material moving (T\&MM); and service class (SC) occupations, which include health care support (HCS); food preparation and food service (FP\&S); building and grounds cleaning and maintenance (BGCM); personal care and service (PCS); low-end sales (SRO); office and administrative support (OAS); community and social service (CSS); and protective service (PS) (Florida 2002b, pp. 328-329). All told, this is the new class structure of the creative economy. I then conducted a factor analysis of the local factor variables and a separate analysis of the location quotient variables. Tables 12 and 13 relate to the local factor variables and Tables 14 and 15 relate to the location quotient variables. 
Table 12: SPSS Total Variance Explained Table for Local Industry Factors

\begin{tabular}{|c|c|c|c|c|c|c|c|c|c|}
\hline \multirow[b]{2}{*}{ Component } & \multicolumn{3}{|c|}{ Initial Eigenvalues } & \multicolumn{3}{|c|}{$\begin{array}{l}\text { Extraction Sums of Squared } \\
\text { Loadings }\end{array}$} & \multicolumn{3}{|c|}{$\begin{array}{c}\text { Rotation Sums of Squared } \\
\text { Loadings }\end{array}$} \\
\hline & Total & $\begin{array}{c}\% \text { of } \\
\text { Variance }\end{array}$ & Cum.\% & Total & $\begin{array}{c}\% \text { of } \\
\text { Variance }\end{array}$ & Cum.\% & Total & $\begin{array}{c}\% \text { of } \\
\text { Variance }\end{array}$ & $\begin{array}{c}\text { Cum. } \\
\%\end{array}$ \\
\hline 1 & 12.75 & 55.446 & 55.446 & 12.75 & 55.446 & 55.446 & 10.82 & 47.027 & 47.027 \\
\hline 2 & 2.208 & 9.602 & 65.048 & 2.208 & 9.602 & 65.048 & 3.383 & 14.709 & 61.736 \\
\hline 3 & 2.011 & 8.745 & 73.793 & 2.011 & 8.745 & 73.793 & 2.212 & 9.618 & 71.354 \\
\hline 4 & 1.138 & 4.949 & 78.742 & 1.138 & 4.949 & 78.742 & 1.699 & 7.388 & 78.742 \\
\hline 5 & 0.977 & 4.25 & 82.992 & & & & & & \\
\hline 6 & 0.691 & 3.006 & 85.998 & & & & & & \\
\hline 7 & 0.563 & 2.447 & 88.445 & & & & & & \\
\hline 8 & 0.543 & 2.361 & 90.806 & & & & & & \\
\hline 9 & 0.441 & 1.917 & 92.723 & & & & & & \\
\hline 10 & 0.364 & 1.581 & 94.304 & & & & & & \\
\hline 11 & 0.333 & 1.449 & 95.753 & & & & & & \\
\hline 12 & 0.224 & 0.975 & 96.728 & & & & & & \\
\hline 13 & 0.166 & 0.723 & 97.451 & & & & & & \\
\hline 14 & 0.148 & 0.641 & 98.093 & & & & & & \\
\hline 15 & 0.097 & 0.423 & 98.515 & & & & & & \\
\hline 16 & 0.089 & 0.389 & 98.904 & & & & & & \\
\hline 17 & 0.08 & 0.347 & 99.251 & & & & & & \\
\hline 18 & 0.055 & 0.238 & 99.489 & & & & & & \\
\hline 19 & 0.042 & 0.181 & 99.67 & & & & & & \\
\hline 20 & 0.04 & 0.173 & 99.843 & & & & & & \\
\hline 21 & 0.021 & 0.093 & 99.936 & & & & & & \\
\hline 22 & 0.01 & 0.045 & 99.98 & & & & & & \\
\hline 23 & 0.005 & 0.02 & 100 & & & & & & \\
\hline
\end{tabular}

Extraction Method: Principal Component Analysis.

Table 12 provides information that, based on using eigenvalues greater than 1 (Tabachnick \& Fidell 2001, p. 620), only four factors are important and the fourth explains only 4.9 percent of the variation. Table 13 provides the components that load on the top three factors which explain $71.3 \%$ of total variance. Nearly all the industries significantly load on factor 1 , but the creative class variable is the weakest of the class variables on this component. This component might be interpreted as a general employment component. Information and professional, scientific and technical services significantly load on factor two and might generally be considered high-tech. Again the creative class variable loads with little significance. Factor three seems a catchall for industries that do not load on the first two factors, and none of the class variables are 
significant.

Table 13: SPSS Rotated Components Matrix for Local Factor Data

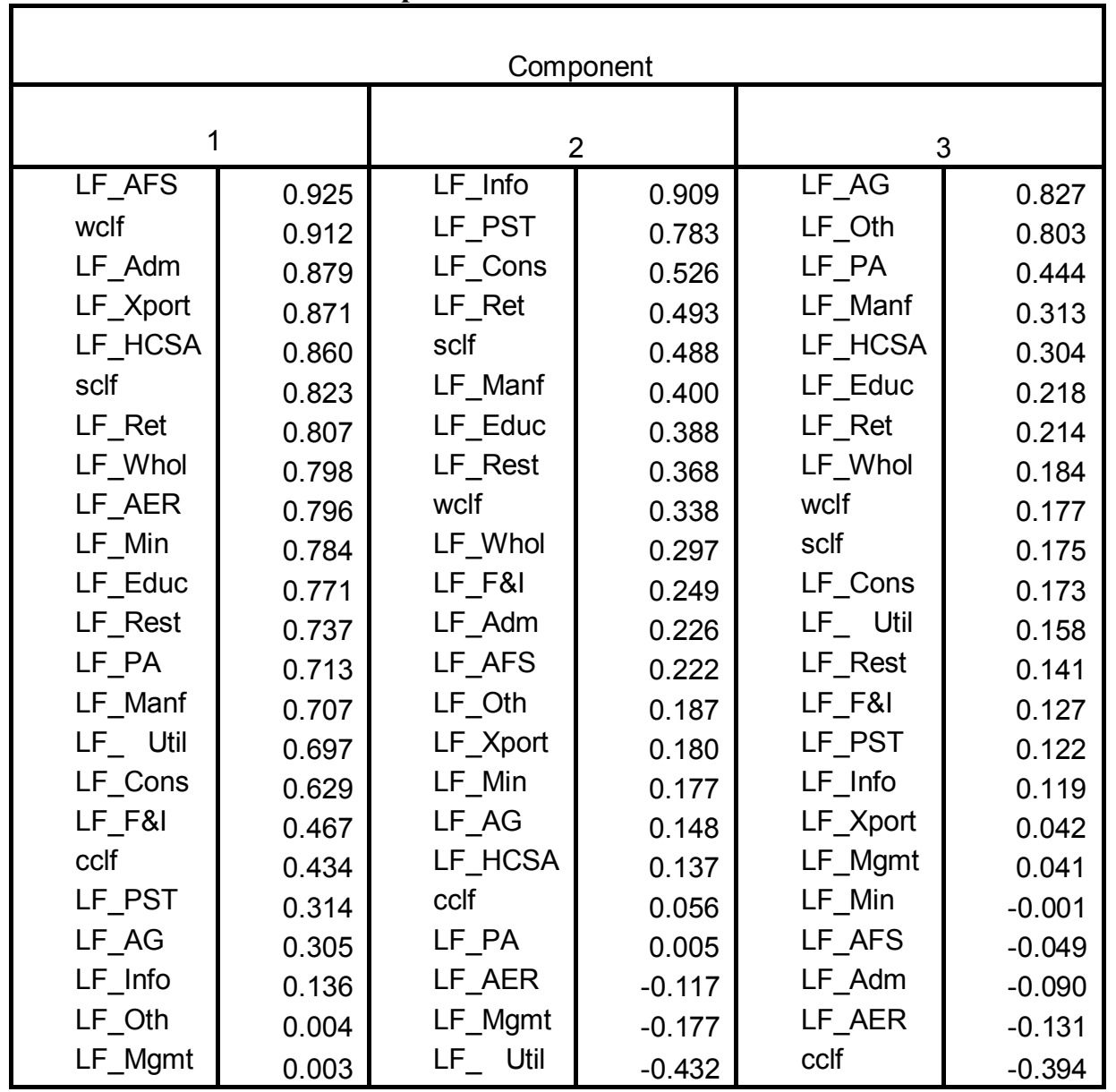

Extraction Method: Principal Component Analysis. Rotation Method: Varimax with Kaiser Normalization. Rotation converged in 6 iterations.

The industry abbreviations that apply to Tables 13 and 15 are as follows:

Adm $=$ Administrative $\&$ support $\&$ waste management services.

$\mathrm{AER}=$ Arts, entertainment, and recreation AFS $=$ Accommodation and food services $\mathrm{AG}=$ Agriculture, forestry, fishing and hunting

cclf $=$ Creative Class

Cons $=$ Construction

Educ $=$ Educational services

$\mathrm{F} \& \mathrm{I}=$ Finance and insurance

HCSA = Health care and social assistance

Info $=$ Information

Manf $=$ Manufacturing

Mgmt $=$ Management of companies and enterprises

Min = Mining
Oth $=$ Other services (except public administration)

$\mathrm{PA}=$ Public administration

PST $=$ Professional, scientific, and technical services

Rest $=$ Real estate and rental and leasing

Ret $=$ Retail trade

sclf $=$ Service Class

Util $=$ Utilities

wclf $=$ Working Class

Whol $=$ Wholesale trade

Xport $=$ Transportation and warehousing: 
Table 14: SPSS Total Variance Explained Table for Location Quotient Factors

\begin{tabular}{|c|c|c|c|c|c|c|c|c|c|}
\hline \multirow[b]{2}{*}{ Component } & \multicolumn{3}{|c|}{ Initial Eigenvalues } & \multicolumn{3}{|c|}{$\begin{array}{l}\text { Extraction Sums of } \\
\text { Squared Loadings }\end{array}$} & \multicolumn{3}{|c|}{$\begin{array}{c}\text { Rotation Sums of Squared } \\
\text { Loadings }\end{array}$} \\
\hline & Total & $\begin{array}{c}\% \text { of } \\
\text { Variance }\end{array}$ & $\begin{array}{c}\text { Cum } \\
. \%\end{array}$ & Total & $\begin{array}{c}\% \text { of } \\
\text { Variance }\end{array}$ & $\underset{\%}{\text { Cum. }}$ & Total & $\begin{array}{c}\% \text { of } \\
\text { Variance }\end{array}$ & $\underset{\%}{\text { Cum. }}$ \\
\hline 1 & 5.847 & 25.422 & 25.422 & 5.85 & 25.422 & 25.422 & 3.92 & 17.028 & 17.028 \\
\hline 2 & 3.702 & 16.097 & 41.519 & 3.7 & 16.097 & 41.519 & 3.73 & 16.206 & 33.234 \\
\hline 3 & 2.464 & 10.714 & 52.233 & 2.46 & 10.714 & 52.233 & 3.28 & 14.247 & 47.481 \\
\hline 4 & 2.123 & 9.228 & 61.462 & 2.12 & 9.228 & 61.462 & 2.58 & 11.205 & 58.687 \\
\hline 5 & 1.745 & 7.589 & 69.05 & 1.75 & 7.589 & 69.05 & 1.95 & 8.489 & 67.176 \\
\hline 6 & 1.676 & 7.286 & 76.336 & 1.68 & 7.286 & 76.336 & 1.75 & 7.617 & 74.792 \\
\hline 7 & 1.205 & 5.239 & 81.575 & 1.21 & 5.239 & 81.575 & 1.56 & 6.783 & 81.575 \\
\hline 8 & 0.884 & 3.842 & 85.417 & & & & & & \\
\hline 9 & 0.694 & 3.016 & 88.434 & & & & & & \\
\hline 10 & 0.636 & 2.765 & 91.199 & & & & & & \\
\hline 11 & 0.466 & 2.025 & 93.224 & & & & & & \\
\hline 12 & 0.352 & 1.53 & 94.754 & & & & & & \\
\hline 13 & 0.348 & 1.514 & 96.267 & & & & & & \\
\hline 14 & 0.211 & 0.918 & 97.185 & & & & & & \\
\hline 15 & 0.203 & 0.885 & 98.07 & & & & & & \\
\hline 16 & 0.16 & 0.694 & 98.764 & & & & & & \\
\hline 17 & 0.104 & 0.454 & 99.217 & & & & & & \\
\hline 18 & 0.061 & 0.265 & 99.483 & & & & & & \\
\hline 19 & 0.052 & 0.228 & 99.711 & & & & & & \\
\hline 20 & 0.028 & 0.122 & 99.832 & & & & & & \\
\hline 21 & 0.024 & 0.102 & 99.935 & & & & & & \\
\hline 22 & 0.015 & 0.065 & 100 & & & & & & \\
\hline 23 & $-5.90 \mathrm{E}-17$ & $-2.56 \mathrm{E}-16$ & 100 & & & & & & \\
\hline
\end{tabular}

Table 14 shows seven important factors with respect to location quotient.

However, the largest loading factor for the seventh factor was .508 and was omitted from Table 15. 
Table 15: SPSS Rotated Components Matrix for Local Factor Data

\begin{tabular}{|c|c|c|c|c|c|c|c|c|c|c|c|}
\hline \multicolumn{12}{|c|}{ Component } \\
\hline \multicolumn{2}{|c|}{1} & \multicolumn{2}{|c|}{2} & \multicolumn{2}{|c|}{3} & \multicolumn{2}{|c|}{4} & \multicolumn{2}{|c|}{5} & \multicolumn{2}{|c|}{6} \\
\hline LQ_Info & 0.67 & wclq & 0.92 & cclq & 0.83 & LQ_Xport & 0.83 & LQ_AG & 0.76 & LQ_Util & 0.83 \\
\hline LQ PA & 0.65 & LQ_AFS & 0.91 & LQ_Cons & 0.74 & LQ_Whol & 0.77 & LQ_Ret & 0.69 & LQ_Min & 0.80 \\
\hline LQ_PST & 0.64 & LQ_AER & 0.85 & Lq_Rest & 0.49 & LQ_Mgmt & 0.48 & Lq_Adm & 0.39 & LQ_Cons & 0.39 \\
\hline Lq_Rest & 0.59 & Lq_Adm & 0.40 & LQ_AER & 0.38 & LQ_Oth & 0.37 & LQ_Whol & 0.39 & LQ_Oth & 0.24 \\
\hline LQ_Oth & 0.54 & Lq_Rest & 0.36 & Lq_Adm & 0.37 & Lq_Adm & 0.31 & Lq_Rest & 0.36 & LQ_Mgmt & 0.14 \\
\hline Lq_Adm & 0.53 & LQ_Ret & 0.33 & LQ Info & 0.34 & sclq & 0.27 & wclq & 0.22 & sclq & 0.09 \\
\hline LQ_Cons & 0.22 & LQ_Cons & 0.31 & LQ_AFS & 0.32 & LQ_Ret & 0.26 & LQ_Oth & 0.18 & LQ PA & 0.08 \\
\hline Wclq & 0.18 & LQ_Xport & 0.14 & LQ_PST & 0.28 & Lq_Rest & 0.17 & LQ_Cons & 0.15 & LQ_AFS & 0.08 \\
\hline LQ_F\&I & 0.15 & LQ_Util & 0.08 & LQ_AG & 0.11 & wclq & 0.16 & sclq & 0.13 & wclq & 0.08 \\
\hline LQ Educ & 0.07 & cclq & 0.06 & LQ_Min & 0.08 & LQ_F\&I & 0.14 & LQ_Util & 0.04 & LQ_Whol & 0.06 \\
\hline LQ_Min & 0.06 & LQ_PA & 0.01 & LQ_Whol & -0.01 & LQ_Min & 0.11 & LQ_PA & 0.03 & LQ_Educ & 0.06 \\
\hline LQ_Xport & 0.03 & LQ_Min & 0.00 & LQ Util & -0.02 & LQ_Cons & 0.07 & LQ_HCSA & -0.01 & LQ_F\&I & 0.05 \\
\hline Cclq & 0.00 & LQ_Oth & -0.07 & sclq & -0.02 & LQ_Info & 0.06 & LQ_F\&I & -0.02 & Lq_Rest & 0.04 \\
\hline LQ_AFS & -0.01 & sclq & -0.07 & LQ_Ret & -0.04 & LQ_Util & -0.02 & LQ_AFS & -0.02 & Lq_Adm & 0.04 \\
\hline LQ_AER & -0.01 & LQ_F\&I & -0.10 & LQ_Xport & -0.05 & LQ_HCSA & -0.08 & LQ_Manf & -0.05 & LQ_Xport & 0.02 \\
\hline LQ_AG & -0.03 & LQ_HCSA & -0.10 & LQ_Mgmt & -0.08 & LQ_Manf & -0.09 & cclq & -0.06 & LQ_Ret & 0.01 \\
\hline LQ_Ret & -0.06 & LQ_AG & -0.19 & wclq & -0.08 & LQ_AFS & -0.11 & LQ_Info & -0.11 & LQ_HCSA & -0.01 \\
\hline LQ_ Util & -0.11 & LQ_Mgmt & -0.19 & LQ_PA & -0.11 & LQ_AER & -0.12 & LQ_Min & -0.12 & LQ_AER & -0.07 \\
\hline LQ_HCSA & -0.16 & LQ_Whol & -0.21 & LQ_Manf & -0.14 & LQ_PST & -0.17 & LQ_Xport & -0.15 & LQ_AG & -0.08 \\
\hline LQ_Whol & -0.23 & LQ_Info & -0.31 & LQ_F\&I & -0.16 & LQ_AG & -0.26 & LQ_AER & -0.16 & cclq & -0.11 \\
\hline LQ_Mgmt & -0.35 & LQ_Educ & -0.37 & LQ_Oth & -0.16 & cclq & -0.26 & LQ_Educ & -0.19 & LQ_PST & -0.13 \\
\hline LQ_Manf & -0.80 & LQ_PST & -0.44 & LQ_Educ & -0.55 & LQ_PA & -0.34 & LQ_Mgmt & -0.32 & LQ_Manf & -0.19 \\
\hline Sclq & -0.86 & LQ_Manf & -0.48 & LQ_HCSA & -0.89 & LQ_Educ & -0.53 & LQ_PST & -0.36 & LQ_Info & -0.29 \\
\hline
\end{tabular}

Extraction Method: Principal Component Analysis. Rotation Method: Varimax with Kaiser Normalization. Rotation converged in 13 iterations.

Table 15 is much more difficult to interpret in terms of meaningful factors.

Factor one is arguably high-tech, however, the creative class does not load on this factor.

Factor three is a creative class component but only population growth industries, such as

Construction and Real Estate, load heavily on this factor. Information, public

administration and professional, scientific, and technical services seem to be relatively

important across the 49 MSAs, although the highest loading is 0.67 . 


\subsubsection{Other Contextual Variables}

Several other variables were constructed to complete the evaluation of economic development context and the impact of the percentage of the creative class on social ills.

\subsubsection{Workforce Characteristics}

Workforce Characteristics include the size of the labor force as measured by total employment and average wages/salaries and unemployment data. Employment and wage data are incorporated in the occupational data used to reconstruct the creative class structure. The unemployment rates for 2000 through 2005 by MSA were downloaded from the Bureau of Labor Statistics at http://www.bls.gov/lau/home.htm\#data. The following six variables were used in analyses:

Total employment in 2000.

Creative Class mean earnings in 2000.

Service Class mean earnings in 2000.

Working Class mean earnings in 2000.

Unemployment rate in 2000.

Percent change in unemployment 2000 to 2004

Percent change in unemployment 2000 to 2005

\subsubsection{Educational Attainment}

The skill of the workforce is assessed through two educational attainment variables derived from the 2000 Census Summary File 3, Table P37 Sex by Educational Attainment for the Population 25+ Years. These data were used to calculate the percentage of the population over 25 in the United States with a bachelor's degree or higher. A similar percentage was developed for each MSA and CMSA. The MSA/CMSA percentage divided by the national percentage provides a location quotient for post-secondary educational attainment. A similar calculation, derived from the same 
source, was performed for the percent of the population with a high school diploma or equivalent, some college, or an associate's degree. These two variables are referred to as:

Educational Attainment - Post-secondary Educational Attainment - HS \& Associate's

\subsubsection{Tax Structure}

The source for the MSA tax structure variable is a Census publication entitled Finances of County Governments: 2002 available at http://www.census.gov/prod/2005pubs/gc02x43.pdf. While this document does not provide a breakdown of taxes collected from businesses versus individuals, it does provide tax revenue by county for 2001-2002. I was unable to locate a report for the year 2000. The county data were aggregated to the MSA/CMSA level based on Census 2000 definitions and then divided by MMSA/CMSA population in 2000 to derive a relative measure for tax structure. I felt this measure of per capita taxes should generally be representative of taxation policy for comparative purposes. The variable is called 01-02 Per Capita Taxes Paid.

\subsubsection{Geography}

Geography related variables include three climate related variables ${ }^{17}$ measuring cooling days (the number of days where the temperature is in excess of 65 and the number of degrees over 65) referred to as Hot Climate, heating days (the number of days where the temperature is below 65 and the degrees below 65) referred to as Cold Climate, and a terrain variable used to gauge the ruggedness of an MSA referred to as Terrain (see the Data Appendix Section 7.2.1 for further descriptions of these variables).

\footnotetext{
${ }^{17}$ See the Data Appendix Section 7.4.1.1 for a more thorough definition and reference source.
} 


\subsubsection{University Research Environment}

The research environment is captured in four variables. The first is a count of Research I or Research II universities in an MSA. The second is a count of other institutions of higher learning in an MSA below Research II. The most recent school rankings are available from The Carnegie Foundation for the Advancement of Teaching (see http://www.carnegiefoundation.org/classifications/index.asp?key=783) based on 2003 and 2004 data. I was unable to find such a listing for the year 2000 but I felt that significant variations in these quantities at the MSA level were unlikely. I assigned each institution to its appropriate county and then to an MSA. The third and fourth variables are the amount of "R\&D expenditures at universities and colleges" available from the National Science Foundation (downloadable from the NSF website (http://www.nsf.gov/statistics/nsf07318/tables/tab27.xls)). Data are provided from 1998 to 2005. I selected 2004 expenditures to be consistent with the 03-04 listing of institutions. I felt that this data, aggregated at the MSA level, would be fairly representative of the research context for comparison to GMP data in 2000 or the change in GMP from 2000 to 2004, or 2000 to 2005.

\subsubsection{Community Culture}

Sources for all the variables in this category are provided in the Data Appendix Section 7.2.2. The variables measure poverty rates, crime rates, percent of the population that is homeless, home ownership rates, voting participation, and young single migration. Additionally the association index of occupational gender equity is also included (Charles $\&$ Grusky 2004, p. 42). From a theoretical perspective, this may seem like a loosely coupled dataset. However, poverty, homelessness and crime are social maladies typically 
associated with urban areas (Banfield 1974). Home ownership rates relate to the stability and wealth of an MSA. Voting participation gives us a sense for the extent to which citizens are engaged in the political process. Young single migration is a measure of an urban area's attractiveness to recent college graduates. Taken together, these seven variables should provide some sense of the cultural context of an MSA.

Gender inequity, via the association index, is included as a cultural variable but also constitutes a separate line of investigation. Charles and Grusky (2004, pp. 14-15) point out that occupational gender inequality is a cultural phenomenon. In previous research (Negrey \& Rausch 2004), the earnings of females versus males in creative and non-creative MSAs was explored and a significant disparity was found between male earnings and female earnings in creative class occupations regardless of whether the areas were more or less creative. That research is confirmed here by presenting an improved statistical analysis of the gender wage gap. Thus membership in the creative class does not improve the gender wage gap as one might expect from a presumably progressive creative class. Charles and Grusky discuss the horizontal and vertical dimensions of gender inequity where horizontal inequity refers to the gender essentialist notion that females are more competent than men in service, nurturance and social interaction (Charles \& Grusky 2004, pp. 14-15) and hold jobs accordingly, while the vertical dimension refers to the notion that men hold the power positions in any occupation and are compensated accordingly. The wage gap is consistent with the vertical dimension. It is possible that, given the imbedded horizontal and vertical constraints in the U.S. labor force, the creative class is hampered in making progress on either front. Since the wage gap persists, structural gender inequality is likely at work in both creative and non- 
creative MSAs. Charles and Grusky introduce a measure on gender inequality called the association index. The higher the association index for an area, the higher the gender inequality. This measure is akin to the index of dissimilarity, but is not dependent on the percentage of females in the workforce and captures the effect of both horizontal and vertical dimensions of inequity. I include the association index as a measure of gender equity from both a cultural and structural perspective.

\subsubsection{Gender Wage Inequity}

This analysis is related to the cultural variables because it demonstrates that gender wage inequity is not ameliorated by creativity as measured by the creativity index. This analysis demonstrates that gender consideration is a necessary element of the MSA cultural analysis and supports my inclusion of the association index, which captures both the vertical and horizontal dimension of gender inequity, as an individual MSA measure.

To test whether creativity as measured by the creativity index made a difference in the wage gap between men and women, four separate regressions were run. The 49 MSAs were sorted in descending order by creativity index, then using dummy variables for MSAs with high $(C=0)$ and low $(C=1)$ creativity indices and gender $(M=0, F=1)$ four regression models were run using creative class earnings as the dependent variable and either the MSA or gender dummy variables as independent variables. Since the MSAs are sorted by their creativity indices, the size and significance of the coefficient of the dummy variable identifies the creative class income gap between MSA with high and low indices and the gap between genders.

Model 1: tests for significant difference between earnings in creative class occupations in the top 10 and bottom 10 grouping of MSAs. 
Model 2: tests for significant difference between the earnings of males and females in creative class occupations in the top 10 and bottom 10 MSAs Models 3 and 4: conduct similar tests to Model 1 and 2 but with the top 16 and bottom 16 MSAs (approximately one third of the MSAs) to determine if an increased number of MSAs in the analysis would change the result.

The results are presented in Tables 16 through 19. Note that this analysis requires grouping high and low MSAs by earnings. As a result not all 49 MSAs are included in the groupings.

Table 16: Differences in Creative Class Mean Earnings for Top 10 and Bottom 10 Large MSAs (Model 1)

\begin{tabular}{|r|c|r|r|r|r|r|}
\hline Model & & \multicolumn{2}{|c|}{$\begin{array}{c}\text { Unstandardized } \\
\text { Coefficients }\end{array}$} & $\begin{array}{c}\text { Standardized } \\
\text { Coefficients }\end{array}$ & $\mathrm{t}$ & Sig. \\
\hline & & $\mathrm{B}$ & \multicolumn{1}{c|}{ Std. Error } & Beta & & \\
\hline 1 & (Constant) & 27850.450 & 1397.166 & & 19.934 & .000 \\
& topbot10 & -2660.850 & 1975.892 & -.213 & -1.347 & .186 \\
\hline
\end{tabular}

a Dependent Variable: creative class income in MSA

Table 17: Differences in Male/Female Creative Class Mean Earnings in Top 10 and Bottom 10 Large MSAs (Model 2)

\begin{tabular}{|c|c|c|c|c|c|c|}
\hline Model & & \multicolumn{2}{|c|}{$\begin{array}{l}\text { Unstandardized } \\
\text { Coefficients }\end{array}$} & $\begin{array}{c}\text { Standardized } \\
\text { Coefficients }\end{array}$ & $\mathrm{t}$ & Sig. \\
\hline & & B & Std. Error & Beta & & \\
\hline 1 & $\begin{array}{l}\text { (Constant) } \\
\text { gender }\end{array}$ & $\begin{array}{r}32062.750 \\
-11085.450\end{array}$ & $\begin{array}{l}654.444 \\
925.523\end{array}$ & -.889 & $\begin{array}{r}48.992 \\
-11.977\end{array}$ & $\begin{array}{l}.000 \\
.000\end{array}$ \\
\hline
\end{tabular}

a Dependent Variable: creative class income in MSA

Table 18: Differences in Creative Class Mean Earnings for Top 16 and Bottom 16 Large MSAs (Model 3)

\begin{tabular}{|l|c|r|r|r|r|r|}
\hline Model & & \multicolumn{2}{|c|}{$\begin{array}{c}\text { Unstandardized } \\
\text { Coefficients }\end{array}$} & $\begin{array}{c}\text { Standardized } \\
\text { Coefficients }\end{array}$ & $\mathrm{t}$ & Sig. \\
\hline & & $\mathrm{B}$ & \multicolumn{1}{c|}{ Std. Error } & Beta & & \\
\hline 1 & & & & 25.636 & .000 \\
& (Constant) & 27194.750 & 1060.813 & -.215 & -1.730 & .089 \\
\hline
\end{tabular}


Table 19: Differences in Male/Female Creative Class Mean Earnings in Top 16 and Bottom 16 Large MSAs (Model 4)

\begin{tabular}{|c|c|c|c|c|c|c|}
\hline \multirow[t]{2}{*}{ Model } & & \multicolumn{2}{|c|}{$\begin{array}{c}\text { Unstandardized } \\
\text { Coefficients }\end{array}$} & \multirow{2}{*}{$\begin{array}{c}\begin{array}{c}\text { Standardized } \\
\text { Coefficients }\end{array} \\
\text { Beta } \\
\end{array}$} & \multirow[t]{2}{*}{$\mathrm{t}$} & \multirow[t]{2}{*}{ Sig. } \\
\hline & & B & Std. Error & & & \\
\hline 1 & (Constant) & 31169.594 & 531.859 & & 58.605 & .000 \\
\hline & gender & -10545.156 & 752.163 & -.872 & -14.020 & .000 \\
\hline
\end{tabular}

As can be seen from these tables, the difference between the top and bottom MSA groupings is approximately $\$ 2,600$ in both models 1 and 3 and is not significant in the top 10 vs. bottom 10 grouping and only marginally significant in the top 16 vs. bottom 16 grouping $(\mathrm{p}=.089)$. The difference between male and female earnings, however, is approximately $\$ 11,000$ and significant in both models 2 and 4 . What this demonstrates is that females in creative class occupations are unlikely to earn the same as men in creative class occupations, regardless of the creativity index ranking of an MSA and that gender inequity, in terms of the gender wage gap is unaffected by creativity so measured. As this analysis is based on grouped data, it is impossible to assign a meaningful measure of the wage gap to an individual MSA. In order to include a gender related variable for each of the 49 MSAs, the association index was computed for each MSA. Charles and Grusky (2004, Ch. 3), argue that while this index is an improvement over the dissimilarity index, additional analysis using log-linear modeling is necessary to thoroughly evaluate gender inequity across geographies and across both the horizontal and vertical dimensions. That more complex analysis is left for future research.

\subsubsection{Contextual Variable Analysis}

The correlation matrix of the 22 variables in the contextual analysis is quite large and is included in the Data Appendix Tables 36-38. Several of the variables have large 
correlations (above 0.4 or below -0.4$)$ and are significant $(\mathrm{p}<=.05)$. For this reason these variables were entered into a stepwise backward linear regression ${ }^{18}$ using 2000 GMP per capita and percent change in GMP from 2000 to 2004 and 2000 to 2005 as dependent variables. The unemployment rate in 2000 was used in the analysis of 2000 GMP per capita, the percent change in unemployment from 2000 to 2004 was used in the analysis of GMP percent change from 2000 to 2004, and the percent change in unemployment from 2000 to 2005 was used in the analysis of GMP percent change from 2000 to 2005. The results are presented in Tables 20, 21 and 22 for the three regressions. The model numbers in the Tables refer to the number of iterations required to achieve the most efficient model.

Table 20: Regression Results of GMP per capita with Contextual Variables

\begin{tabular}{|l|r|r|r|r|r|}
\hline & \multicolumn{2}{|c|}{$\begin{array}{l}\text { Standardized } \\
\text { Coefficients }\end{array}$} & $\mathrm{t}$ & Sig. \\
\hline & \multicolumn{1}{|c|}{$\mathrm{B}$} & \multicolumn{1}{c|}{ Std. Error } & \multicolumn{1}{c|}{ Beta } & & \\
\hline (Constant) 17 & $41,278.014$ & $10,672.210$ & & 3.868 & 0.001 \\
\hline Hot climate & -2.902 & 1.052 & -0.713 & -2.759 & 0.010 \\
\hline Cold climate & -1.114 & 0.552 & -0.588 & -2.017 & 0.053 \\
\hline Percent of home ownership & 431.391 & 138.163 & 0.481 & 3.122 & 0.004 \\
\hline $\begin{array}{l}\text { Educational Attainment HS \& } \\
\text { Associate's }\end{array}$ & $-16,219.693$ & $6,582.391$ & -0.307 & -2.464 & 0.020 \\
\hline $\begin{array}{l}\text { Association Index based on Census } \\
\text { 2000 occupations by gender }\end{array}$ & $-5,622.098$ & $1,639.746$ & -0.404 & -3.429 & 0.002 \\
\hline Working Class Mean 2000 & 0.567 & 0.223 & 0.398 & 2.542 & 0.016 \\
\hline
\end{tabular}

a Dependent Variable: GMP per capita for 2000

Table 20 provides the dominant contextual variables all of which are significant at the $\mathrm{p}=$ .05 level or below (with the exception of the cold climate where $p=.053$ ). Thirty seven MSAs were included in this analysis due to missing tax, homelessness, or crime data. The average GMP per capita for these 37 MSAs was $\$ 37,058.00$. The adjusted $\mathrm{R}^{2}$ for

\footnotetext{
${ }^{18}$ Stepwise backward linear regression begins the analysis with all variables included and through an iterative process removes variables that do not significantly contribute to the model's explanatory power or that are highly correlated.
} 
the model with all 22 variables was 0.457 and improved to 0.628 for the final model.

The association index $(\mathrm{p}=.002)$ has a substantial negative coefficient meaning that a one unit increase in the association index (higher gender inequity) lowers GMP per capita by $\$ 5,622$ holding other variables constant. The percent of home ownership and hot climate variables are the next most significant variables respectively but their coefficients are small. Educational attainment at the high school, some college, or associate's degree level has a substantial negative effect on per capita GMP and is significant at $p=.02$. I interpret this as a general indication that a poorly educated workforce can have a significant negative effect on GMP.

Table 21: Regression of Percent Change in GMP from 2000 to 2004 with Contextual Variables

\begin{tabular}{|l|c|c|c|c|c|}
\hline Model 17 & \multicolumn{2}{|c|}{$\begin{array}{l}\text { Unstandardized } \\
\text { Coefficients }\end{array}$} & $\begin{array}{c}\text { Standardized } \\
\text { Coefficients }\end{array}$ & $\mathrm{t}$ & Sig. \\
\hline & $\mathrm{B}$ & $\begin{array}{c}\text { Std. } \\
\text { Error }\end{array}$ & Beta & & \\
\hline (Constant) & 0.022 & 0.022 & & 1.017 & 0.318 \\
\hline '01-'02 Per Capita Taxes Paid per capita & 0.000 & 0.000 & 0.313 & 2.061 & 0.048 \\
\hline Hot climate & 0.000 & 0.000 & 0.627 & 3.610 & 0.001 \\
\hline Percent homeless population Census 2000 & 0.235 & 0.112 & 0.369 & 2.101 & 0.044 \\
\hline $\begin{array}{l}\text { Number of Colleges or Universities below RII } \\
\text { 2003/4 }\end{array}$ & 0.002 & 0.001 & 0.963 & 2.294 & 0.029 \\
\hline Research Dollars for C or U below RII 2004 & 0.000 & 0.000 & -0.426 & -2.515 & 0.018 \\
\hline Total Employment 2000 & 0.000 & 0.000 & -0.969 & -2.396 & 0.023 \\
\hline
\end{tabular}

a Dependent Variable: GMP real percent change 2000 to 2004. Variables also in Table 22 are in bold.

Table 22: Regression of Percent Change in GMP from 2000 to 2005 with Contextual Variables

\begin{tabular}{|l|c|c|c|c|c|}
\hline Model 18 & \multicolumn{2}{|c|}{$\begin{array}{c}\text { Unstandardized } \\
\text { Coefficients }\end{array}$} & $\begin{array}{c}\text { Standardized } \\
\text { Coefficients }\end{array}$ & $\mathrm{t}$ & Sig. \\
\hline & $\mathrm{B}$ & $\begin{array}{c}\text { Std. } \\
\text { Error }\end{array}$ & Beta & & \\
\hline (Constant) & 0.019 & 0.033 & & 0.566 & 0.576 \\
\hline Hot climate & 0.000 & 0.000 & 0.626 & 3.619 & 0.001 \\
\hline Percent homeless population Census 2000 & 0.511 & 0.195 & 0.461 & 2.621 & 0.014 \\
\hline $\begin{array}{l}\text { Number of Colleges or Universities below RII } \\
\text { 2003/4 }\end{array}$ & 0.003 & 0.002 & 0.905 & 2.152 & 0.040 \\
\hline Research Dollars for C or U below RII 2004 & 0.000 & 0.000 & -0.409 & -2.473 & 0.019 \\
\hline Total Employment 2000 & 0.000 & 0.000 & -0.725 & -1.793 & 0.083 \\
\hline
\end{tabular}

a Dependent Variable: GMP real percent change 2000 to 2005. Variables also in Table 21 are in bold

Twelve MSAs were excluded from this analysis due to missing tax, homelessness, or crime data. In addition the West Palm Beach MSA was excluded due to changes in 
MSA definitions which eliminated separate GMP data for 2004 and 2005 for this MSA. The average change in GMP for the 36 studied MSAs from 2000 to 2004 was $9.7 \%$ and from 2000 to 2005 was $13.25 \%$. For GMP percent change from 2000 to 2004 the adjusted $\mathrm{R}^{2}$ changed from 0.105 to for the model with all 22 variables to 0.291 for the final model. For GMP percent change from 2000 to 2005 the adjusted $\mathrm{R}^{2}$ changed from 0.132 to for the model with all 22 variables to 0.287 for the final model. The final set of variables, while all significant at $\mathrm{p}=0.083$ or below, have very small unstandardized coefficients with the exception of the percent homeless population and the number of colleges or universities below research II 2003/2004. An increase in the number of colleges and universities below RII 2003/4 predicts a slight increase in GMP growth. A rise in the homeless population predicts an approximate $.5 \%$ rise in GMP.

The standardized coefficients indicate that the number of colleges or universities below research II 2003/2004 is an important predictor of GMP growth, however, the amount of research and development funding received by these institutions predicts a reduction in GMP growth. So research and development in these institutions does not result in commercial success, is of insufficient scale to affect GMP, is exported to other communities, or there are other confounding variables which have not been included in these analyses. This bears additional research. The hot climate variable also predicts an increase in GMP growth consistent with the notion that the sunbelt experienced better economic performance during these periods. The standardized coefficient of total employment is negative reflecting, perhaps, the impact of productivity on GMP growth. An increasing percentage of homeless people predict higher GMP growth This is consistent with the notion that increasing GMP would potentially raise housing values 
and price more people out of the housing market. In addition, Fagan (2003) speculates

(although no scholarly research is cited in support) that homeless people may be attracted to wealthier regions because of the better care they might receive or because of perceived better job opportunities.

I added the percentage of the creative class in an MSA to the contextual variables to determine what impact that variable might have on the models. Table 23 provides the output from these models.

Table 23: Regressions of Context Variables Adding Percentage of the Creative Class

\begin{tabular}{|c|c|c|c|c|c|}
\hline & \multicolumn{2}{|c|}{ Unstandardized Coefficients } & \multirow{2}{*}{$\begin{array}{c}\begin{array}{c}\text { Standardized } \\
\text { Coefficients }\end{array} \\
\text { Beta }\end{array}$} & \multirow[b]{2}{*}{$\mathrm{t}$} & \multirow[b]{2}{*}{ Sig. } \\
\hline & B & Std. Error & & & \\
\hline \multicolumn{6}{|l|}{ DV $=2000$ GMP per capita } \\
\hline (Constant) & $53,380.089$ & $15,292.231$ & & 3.491 & 0.002 \\
\hline Terrain & 140.937 & 47.002 & 0.384 & 2.999 & 0.005 \\
\hline Percent of home ownership & 552.159 & 144.468 & 0.616 & 3.822 & 0.001 \\
\hline Educational Attainment HS \& Associate's & $-35,480.609$ & $9,727.362$ & -0.671 & -3.648 & 0.001 \\
\hline $\begin{array}{l}\text { Association Index based on Census } 2000 \\
\text { occupations by gender }\end{array}$ & $-5,980.575$ & $1,906.803$ & -0.430 & -3.136 & 0.004 \\
\hline Working Class Mean 2000 & 0.663 & 0.162 & 0.465 & 4.097 & 0.000 \\
\hline Percent Creative Class & $-38,753.687$ & $22,171.745$ & -0.313 & -1.748 & 0.091 \\
\hline $\mathrm{R}^{2}$ & \multicolumn{5}{|c|}{0.648} \\
\hline \multicolumn{6}{|l|}{ DV = GMP percent change 2000-2004 } \\
\hline (Constant) & 0.022 & 0.022 & & 1.017 & 0.318 \\
\hline '01-'02 Per Capita Taxes Paid & 0.000 & 0.000 & 0.313 & 2.061 & 0.048 \\
\hline Hot climate & 0.000 & 0.000 & 0.627 & 3.610 & 0.001 \\
\hline Percent homeless population Census 2000 & 0.235 & 0.112 & 0.369 & 2.101 & 0.044 \\
\hline $\begin{array}{l}\text { Number of Colleges or Universities below RII } \\
2003 / 4\end{array}$ & 0.002 & 0.001 & 0.963 & 2.294 & 0.029 \\
\hline Research Dollars for C or U below RII 2004 & 0.000 & 0.000 & -0.426 & -2.515 & 0.018 \\
\hline Total Employment 2000 & 0.000 & 0.000 & -0.969 & -2.396 & 0.023 \\
\hline $\mathrm{R}^{2}$ & \multicolumn{5}{|c|}{$\begin{array}{r}1 \\
0.291\end{array}$} \\
\hline \multicolumn{6}{|l|}{ DV = GMP percent change 2000-2005 } \\
\hline (Constant) & 1.515 & 0.412 & & 3.678 & 0.001 \\
\hline Hot climate & 0.000 & 0.000 & 0.612 & 2.974 & 0.006 \\
\hline Percent of home ownership & -0.007 & 0.003 & -0.409 & -2.093 & 0.046 \\
\hline Percent below poverty Census 2000 & -1.918 & 0.721 & -0.585 & -2.660 & 0.013 \\
\hline $\begin{array}{l}\text { Research Dollars to RI or II Universities } \\
2004\end{array}$ & 0.000 & 0.000 & 0.556 & 2.086 & 0.047 \\
\hline $\begin{array}{l}\text { Number of Colleges or Universities below RII } \\
2003 / 4\end{array}$ & 0.004 & 0.001 & 1.184 & 2.954 & 0.006 \\
\hline $\begin{array}{l}\text { Association Index based on Census } 2000 \\
\text { occupations by gender }\end{array}$ & -0.102 & 0.053 & -0.358 & -1.931 & 0.064 \\
\hline Total Employment 2000 & 0.000 & 0.000 & -1.453 & -3.311 & 0.003 \\
\hline Percent Creative Class & -1.279 & 0.537 & -0.521 & -2.379 & 0.025 \\
\hline $\mathrm{R}^{2}$ & \multicolumn{5}{|c|}{0.339} \\
\hline
\end{tabular}

Variables in italics reflect the variables that remain in final models when the percent creative class variable is added to the analyses that were not in final models before the percent creative class variable was added.

The important differences here are that variables with large beta coefficient in Tables 20 through 22 remain in the models, where the percentage of the creative class enters the 
final model it has a negative impact on the dependent variable, and the changes in adjusted $\mathrm{R}^{2}$ are small. For the GMP per capita model the adjusted $\mathrm{R}^{2}$ changes from 0.628 to 0.648 . For the GMP percent change from 2000 to 2005 model the adjusted $\mathrm{R}^{2}$ changes from 0.287 to 0.339 but three other variables also enter the final model.

\subsubsection{Context and Index Components}

The final test of context variables involves including the creativity index contextual (tolerance) subcomponents to determine if they make any significant change in the analyses from above. In each case I added the melting pot index, gay index, tolerance index and bohemian index to the significant variables reported in Tables 20 through 22 and ran regressions using the standard Enter method to see if the four creativity index related variables would prove significant. The results for GMP/capita and GMP percent change 2000 to 2004 are shown in tables 41 and 42 in the Data Appendix Section. The creativity index variables were not statistically significant in the case of GMP per capita. They were significant, however, for GMP percent change from 2000 to 2004 and from 2000 to 2005 . These results for 2000 to 2005 are shown in Table 24 below.

Table 24: Regression of Percent Change in GMP from 2000 to 2005 with Contextual Variables and Creativity Index Subcomponents

\begin{tabular}{|l|r|r|r|r|r|}
\hline $\begin{array}{l}\text { Dependent Variable: GMP percent change 2000 to } \\
2005\end{array}$ & \multicolumn{2}{|c|}{$\begin{array}{l}\text { Unstandardized } \\
\text { Coefficients }\end{array}$} & \multicolumn{1}{|c|}{$\begin{array}{c}\text { Stand. } \\
\text { Coeff. }\end{array}$} & \multicolumn{1}{c|}{$\mathrm{t}$} & Sig. \\
\hline & \multicolumn{1}{|c|}{ B } & \multicolumn{1}{c|}{$\begin{array}{c}\text { Std. } \\
\text { Error }\end{array}$} & \multicolumn{1}{c|}{ Beta } & & \\
\hline (Constant) & -0.052 & 0.077 & & -0.671 & 0.507 \\
\hline Hot climate & 0.000 & 0.000 & 0.221 & 1.559 & 0.127 \\
\hline Percent homeless population Census 2000 & 0.186 & 0.160 & 0.166 & 1.162 & 0.253 \\
\hline Number of Colleges or Universities below RII 2003/4 & 0.003 & 0.001 & 0.916 & 2.056 & 0.047 \\
\hline Research Dollars for C or U below RII 2004 & 0.000 & 0.000 & -0.186 & -1.426 & 0.162 \\
\hline Total Employment 2000 & 0.000 & 0.000 & -1.457 & -3.046 & 0.004 \\
\hline Melting Pot Index & 0.074 & 0.026 & 0.585 & 2.825 & 0.008 \\
\hline Gay Index & -0.026 & 0.057 & -0.080 & -0.449 & 0.656 \\
\hline Tolerance Index & 0.256 & 0.179 & 0.186 & 1.431 & 0.161 \\
\hline Bohemian Index & 0.062 & 0.025 & 0.331 & 2.485 & 0.018 \\
\hline
\end{tabular}


Comparing Table 24 with Table 22, the only variable that remains statistically significant is the number of colleges or universities below RII 2003/4. In addition, the melting pot and bohemian indices are significant at $\mathrm{p}=.008$ and $\mathrm{p}=.018$ respectively and have the expected sign. The adjusted $\mathrm{R}^{2}$ changed from 0.180 to 0.445 when the four tolerance measures were added to the model.

Table 42 reflects similar changes for the model of GMP percent change from 2000 to 2004 . The melting pot index was significant at $p=.007$ while the bohemian index was marginally significant at $p=.101$. The adjusted $R^{2}$ changed from 0.176 to 0.376 when the four tolerance measures were added to the model.

The general conclusion is that when the specific contextual elements of the creativity index are added to other context variables they do not influence 2000 GMP per capita but they do influence subsequent growth. That is, the larger the concentration of immigrants or bohemians relative to national averages in 2000 in an MSA the larger the increase in subsequent GMP growth.

\subsubsection{Creative Class and Social Ills}

Hypothesis 5 states that creative class concentration will not improve certain urban social ills, namely poverty, homelessness or crime. The previous analysis tested whether economic development context affected the economic growth in a subset of the 49 largest MSAs based on data availability. This question here is different although it involves cultural context variables. If the creative class can change the cultural milieu, then, theoretically, these measures of social ills should be smaller in MSAs with high percentages of the creative class. Testing this hypothesis required three linear regressions in which the percent of the creative class, as an independent variable, predicts a reduction 
in the social ill variable (the dependent variable) after region is controlled. The OLS regressions were run for all MSA/CMSAs for which data were available. The results are shown in Tables 25, 26 and 27 for poverty, homelessness and crime respectively.

Table 25: Regression Results of Percent Poverty (DV) against Creative Class Percentage

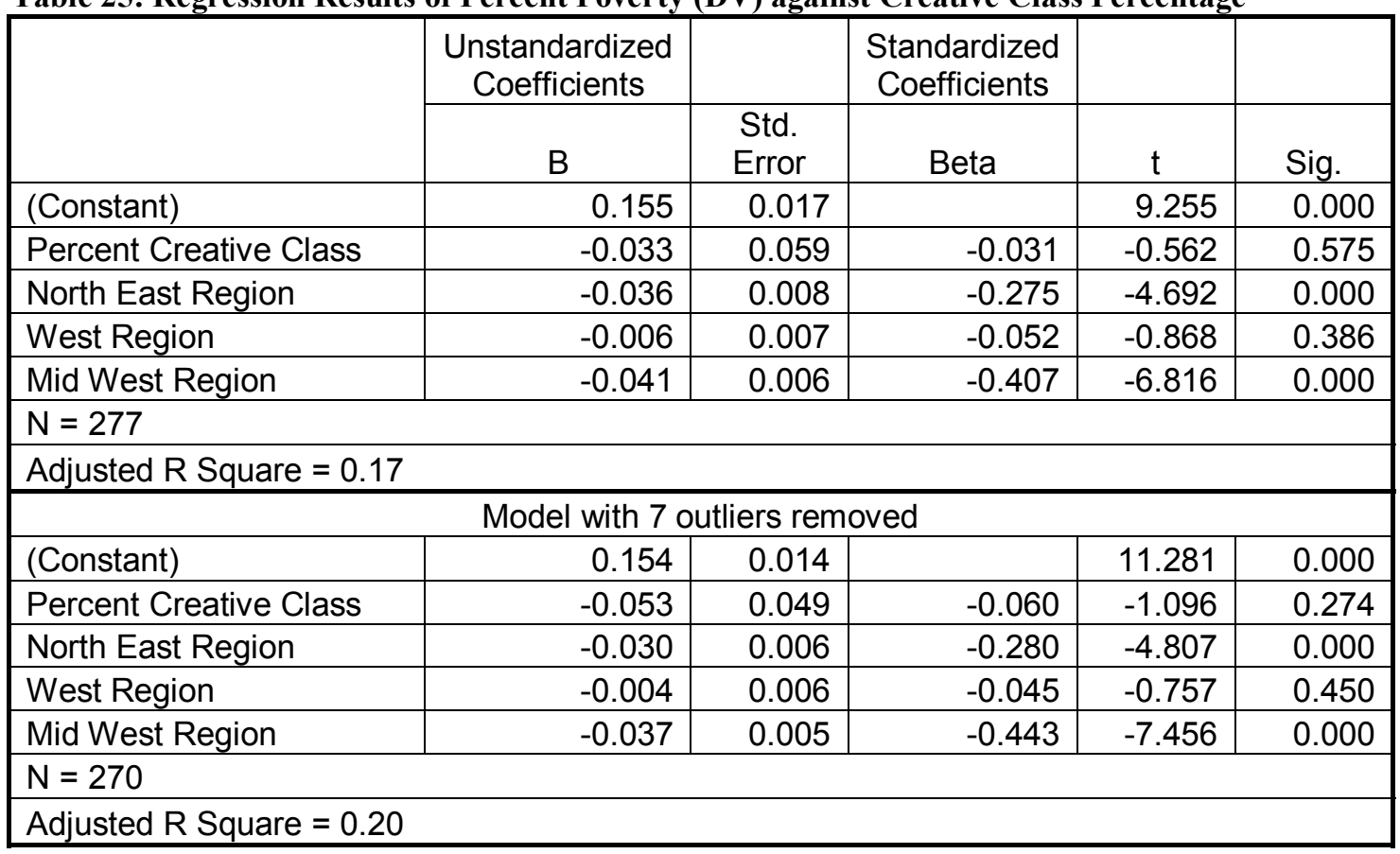

Poverty rates were available for 277 MSA/CMSAs and casewise diagnostics in SPSS identified seven statistical outliers. Table 25 shows the results of the regression with and without the outliers. The conclusion is unaffected by the outliers. Creative class percentage does not significantly predict poverty percentages when controlled for region $(\mathrm{p}=.274)$ although other influences affect poverty rates which are not included in this model (Adjusted $\mathrm{R}^{2}=0.20$ ). 
Table 26: Regression Results of Percent Homelessness (DV) against Creative Class Percentage

\begin{tabular}{|c|c|c|c|c|c|}
\hline & $\begin{array}{l}\text { Unstandardized } \\
\text { Coefficients }\end{array}$ & & $\begin{array}{l}\text { Standardized } \\
\text { Coefficients }\end{array}$ & & \\
\hline & B & $\begin{array}{l}\text { Std. } \\
\text { Error }\end{array}$ & Beta & $t$ & Sig. \\
\hline (Constant) & 0.035 & 0.031 & & 1.150 & 0.252 \\
\hline Percent Creative Class & 0.100 & 0.104 & 0.074 & 0.962 & 0.338 \\
\hline North East Region & 0.005 & 0.013 & 0.033 & 0.403 & 0.687 \\
\hline West Region & 0.038 & 0.012 & 0.282 & 3.341 & 0.001 \\
\hline Mid West Region & 0.006 & 0.011 & 0.049 & 0.571 & 0.569 \\
\hline \multicolumn{6}{|l|}{$N=165$} \\
\hline \multicolumn{6}{|l|}{ Adjusted R Square $=0.05$} \\
\hline \multicolumn{6}{|c|}{ Model with 9 outliers removed } \\
\hline (Constant) & 0.039 & 0.016 & & 2.485 & 0.014 \\
\hline Percent Creative Class & 0.072 & 0.053 & 0.103 & 1.364 & 0.174 \\
\hline North East Region & -0.008 & 0.007 & -0.097 & -1.198 & 0.233 \\
\hline West Region & 0.025 & 0.006 & 0.357 & 4.326 & 0.000 \\
\hline Mid West Region & 0.000 & 0.005 & 0.007 & 0.079 & 0.937 \\
\hline \multicolumn{6}{|l|}{$\mathrm{N}=156$} \\
\hline \multicolumn{6}{|l|}{ Adjusted R Square $=0.13$} \\
\hline
\end{tabular}

Table 26 shows that there were only 165 MSA/CMSAs with homelessness data. Once again, however, the percent creative class does not significantly predict homelessness ( $\mathrm{p}$ $=.338$ ) although there are other influences not captured in this model (Adjusted $\mathrm{R}^{2}=$ $0.13)$. 
Table 27: Regression Results of Crime Rate per 100,000 (DV) against Creative Class Percentage

\begin{tabular}{|c|c|c|c|c|c|}
\hline & $\begin{array}{l}\text { Unstandardized } \\
\text { Coefficients }\end{array}$ & & $\begin{array}{l}\text { Standardized } \\
\text { Coefficients }\end{array}$ & & \\
\hline & coumiom & $\begin{array}{l}\text { Std. } \\
\text { Error }\end{array}$ & Beta & $\mathrm{t}$ & Sig. \\
\hline (Constant) & 4053.434 & 479.197 & & 8.459 & 0.000 \\
\hline Percent Creative Class & 4012.149 & 1698.602 & 0.127 & 2.362 & 0.019 \\
\hline NorthEast Region & -2248.457 & 230.799 & -0.550 & -9.742 & 0.000 \\
\hline West Region & -378.282 & 191.420 & -0.113 & -1.976 & 0.049 \\
\hline MidWest Region & -1106.601 & 178.377 & -0.357 & -6.204 & 0.000 \\
\hline \multicolumn{6}{|l|}{$N=239$} \\
\hline \multicolumn{6}{|l|}{ Adjusted R Square $=0.32$} \\
\hline \multicolumn{6}{|c|}{ Model with 1 outlier removed } \\
\hline (Constant) & 4019.046 & 465.271 & & 8.638 & 0.000 \\
\hline Percent Creative Class & 4136.997 & 1649.254 & 0.135 & 2.508 & 0.013 \\
\hline NorthEast Region & -2249.871 & 224.052 & -0.565 & -10.042 & 0.000 \\
\hline West Region & -379.428 & 185.825 & -0.117 & -2.042 & 0.042 \\
\hline MidWest Region & -1031.956 & 174.206 & -0.339 & -5.924 & 0.000 \\
\hline \multicolumn{6}{|l|}{$N=238$} \\
\hline \multicolumn{6}{|l|}{ Adjusted R Square $=0.32$} \\
\hline
\end{tabular}

Table 27 shows that creative class percentage does positively and significantly influence crime rate $(\mathrm{p}=.019)$. The interpretation of this result is that if creative class percentage goes up, so does crime rate, however, other intervening variables are not tested herein.

In general these results confirm that creative class percentage has no effect on social ills or, in the case of crime rate, worsens the matter, although admittedly the adjusted $\mathrm{R}^{2} \mathrm{~s}$ of these models are low and there are other influences which are not captured in these models.

\subsubsection{Summary of Research Question 3 Findings}

My hypothesis that economic context variables would not align along the technology, talent and tolerance dimension seems acceptable given the factor analysis 
results. My hypothesis that economic context variables would be more significant than creativity index subcomponents is confirmed in part but rejected in part. The concentration of the creative class is not significant, or has a negative impact, when context is controlled. GMP growth, however, is influenced by the melting pot index and the bohemian index. In addition, given that these simple models omit other potential sources of influence, creative class percentage alone has no statistically significant influence, or a negative influence, on social ills. Further exploration of these relationships is warranted and is left for future analysis.

\subsection{Research Question 4}

Research question 4 involves qualitative analysis and is presented in the next chapter. 


\section{CHAPTER 5}

\section{QUALITATIVE ANALYSIS}

\subsection{Rationale for the Selection of the MSAs}

The quantitative research in this dissertation raises questions as to the impact that the creative class might have on economic development. Quantitative data, however, do not always tell the whole story regarding social phenomena (Rubin \& Rubin 2005). Louisville's creativity rank--49th out of 49 MSAs with population over one million-behind other MSAs with, in my opinion, poorer reputations, such as Detroit, Buffalo, and Memphis raised questions for me as to the validity of the measurement. My quantitative research seemed to confirm my suspicions. Nevertheless, a more in-depth exploration of the Louisville MSA compared to geographically close but higher ranked MSAs was necessary to determine if there were legitimate policy differences captured in the creativity index ranking. To that end I conducted a number of personal interviews with economic development officials in Louisville, Indianapolis, Nashville, Raleigh and Durham. In the 2000 Census Raleigh/Durham was a single MSA, and the data used in the development of the creativity index were for that MSA. The Raleigh/Durham MSA has since been split into two MSAs, and both Raleigh and Durham have separate economic development planning offices and separate chambers-of-commerce. As a result, I conducted interviews in both cities. 
The rationale for the selection of these MSAs was the geographic proximity of the MSAs, the frequent use of their major cities in benchmark studies, and their rank differences on the creativity index and its subelements. Table 1 summarized these differences and is shown again here:

\section{Replication of Table 1: Creativity Index Rankings for Studied MSAs}

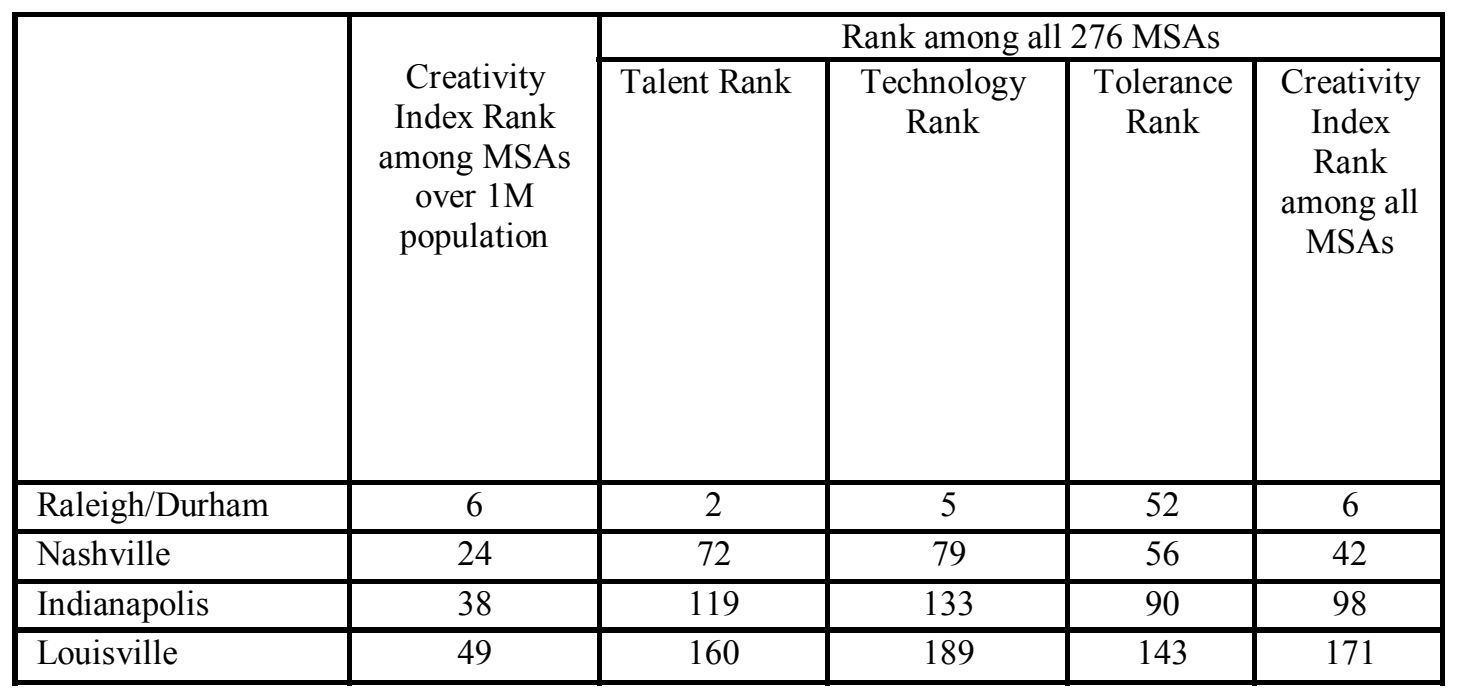

The map in Figure 7 shows the geographical proximity and relative size of the selected MSAs. The Louisville MSA is approximately 115 miles from Indianapolis, 175 miles from Nashville, and 573 miles from Raleigh/Durham. As mentioned above, Nashville and Indianapolis have been used as peer cities in comparing Louisville's economic competitiveness (Coomes \& Kornstein 2004), and Indianapolis, Nashville and Raleigh/Durham have been used as comparison regions on various economic dimensions by the Brookings Institution (Brookings Institution Center on Urban and Metropolitan Policy 2002; Competitive Cities Report 2005). 


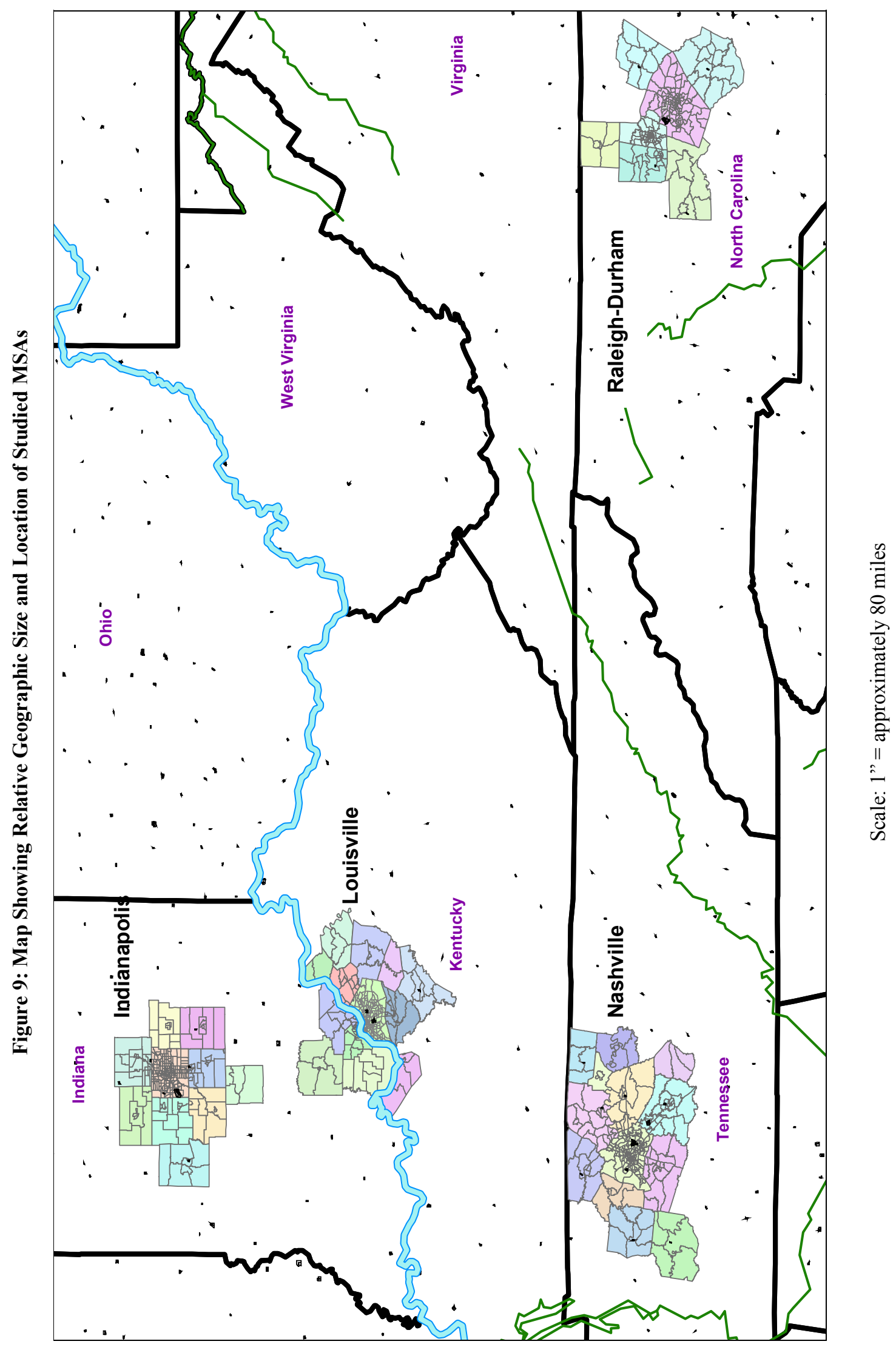


A larger view of each MSA is shown in Figures 8 through 11. These maps reflect the counties that are included in the MSAs under current Census definitions. These views include census tract boundaries that provide some sense of the density of population in the MSAs. As might be expected, the major cities in these MSAs represent the heaviest populated areas and many of the additional counties are sparsely populated.

To my knowledge, there has been no study conducted of the creative class that indicates the specific location of creative class individuals in these MSAs although it would make for interesting research in light of the notion that such individuals prefer urban amenities and might, therefore, concentrate in urban rather than suburban or exurban locations.

The cities of Indianapolis, Nashville and Louisville have merged city/county governments while Raleigh and Durham have separate city governments and are located in different counties. The Louisville MSA includes counties in both Kentucky and Indiana which might complicate regional approaches to economic development. The population of the related MSAs are moderately close (see Table 28). The city populations in the 2000 Census show more variation as follows:

Durham $(187,035)$

Louisville $(256,231)$

Raleigh $(276,093)$

Nashville $(545,524)$

Indianapolis $(781,870)$.

Whether these similarities and differences result in different economic development policies, or actions, is of interest in this study. 


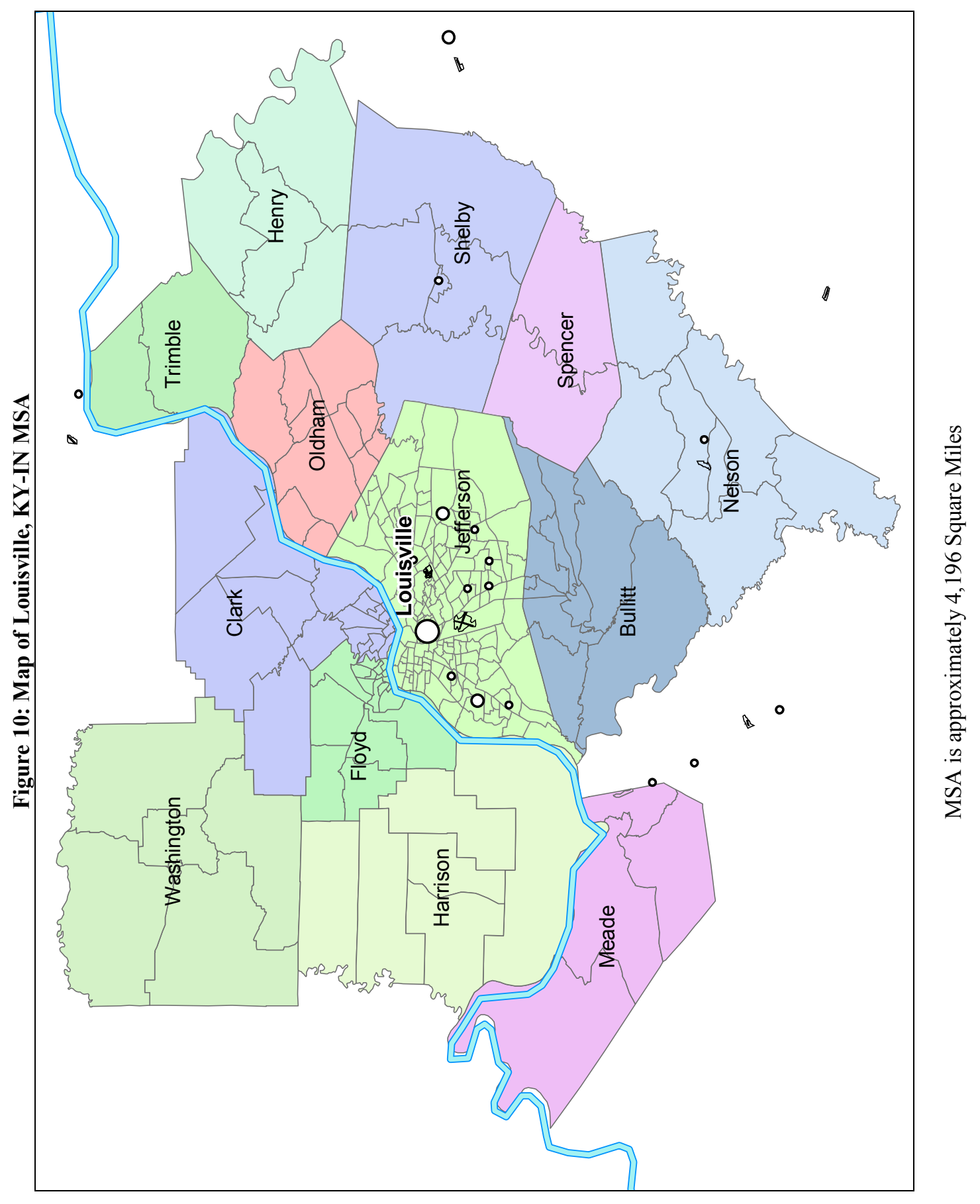




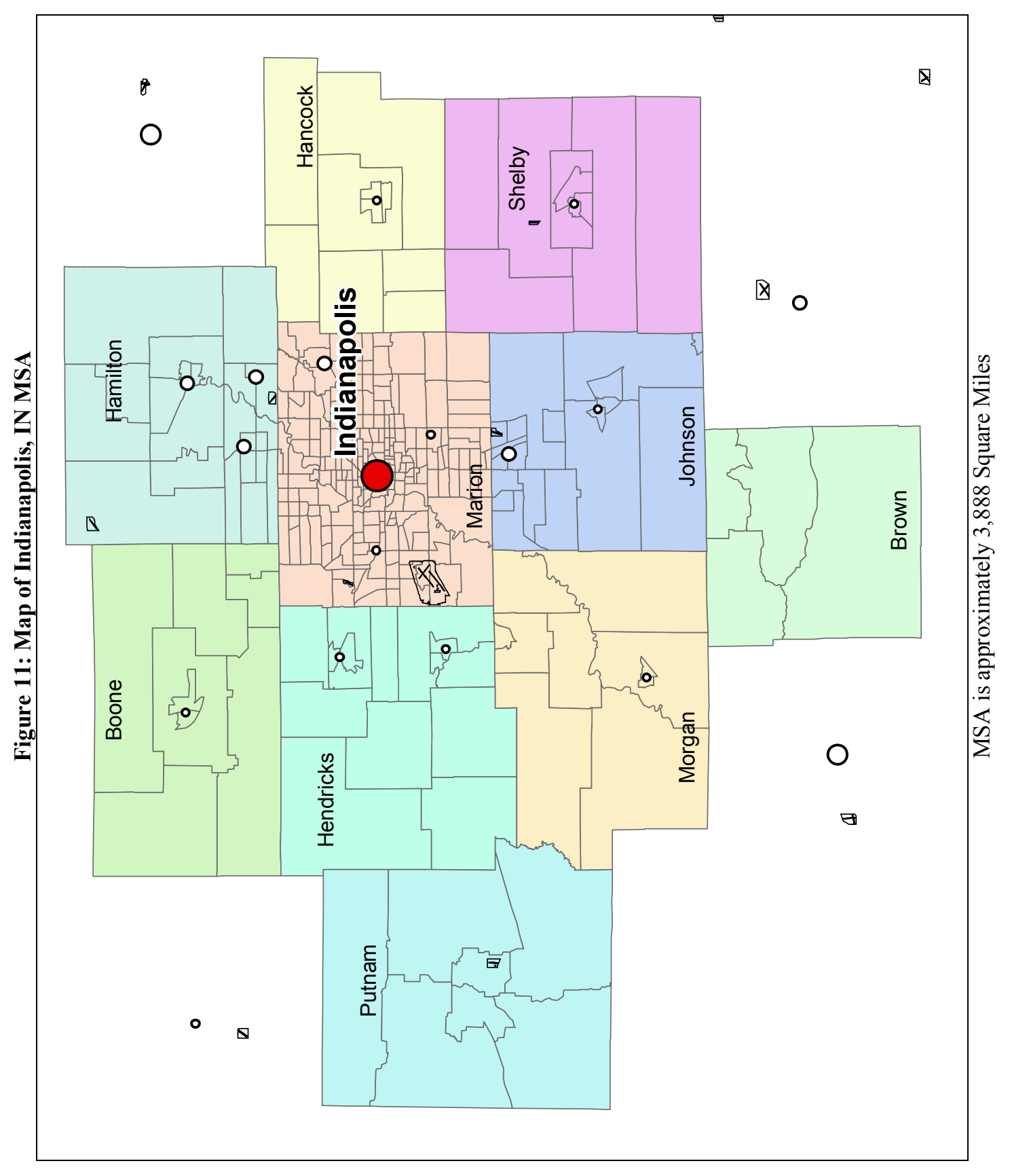




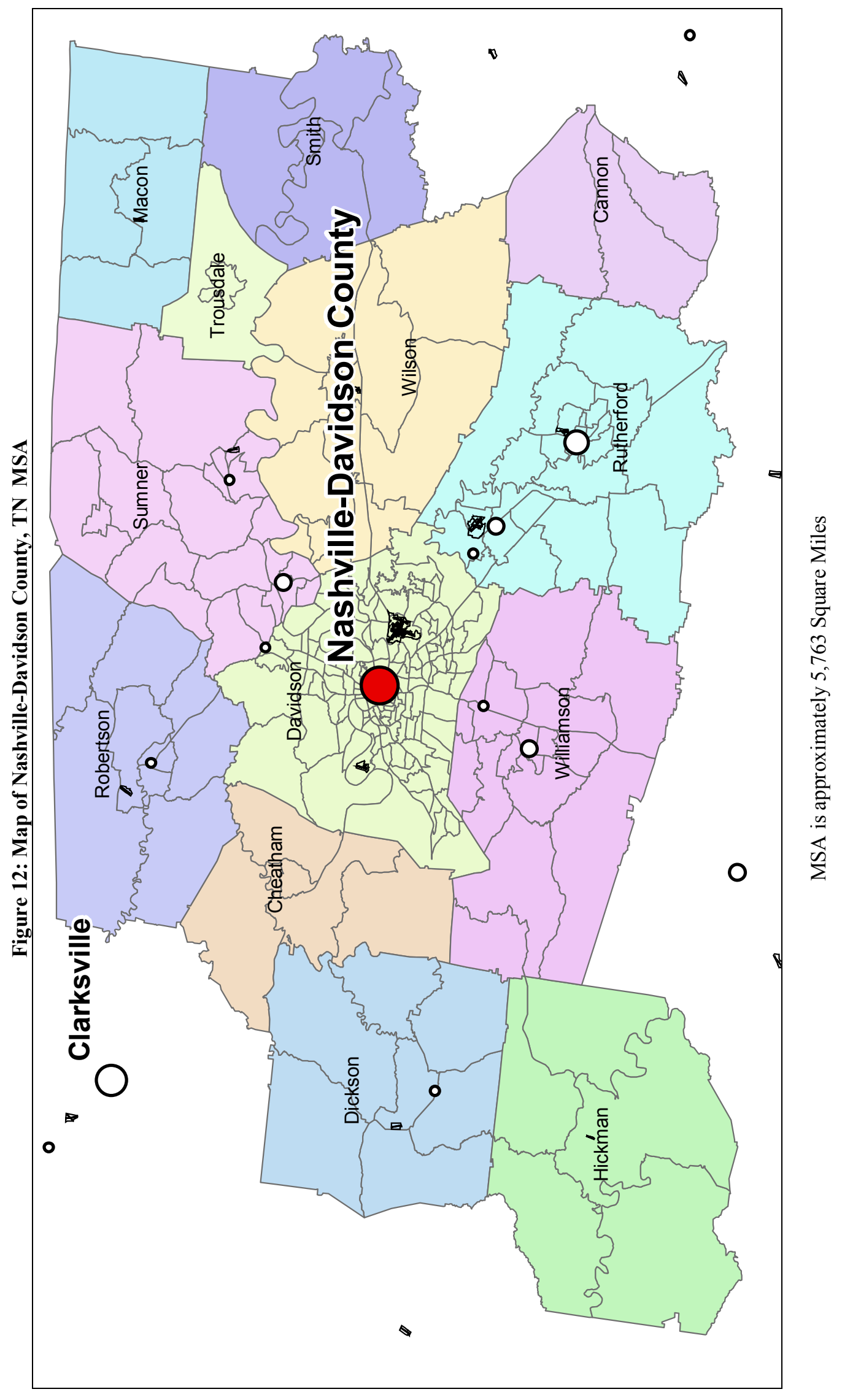




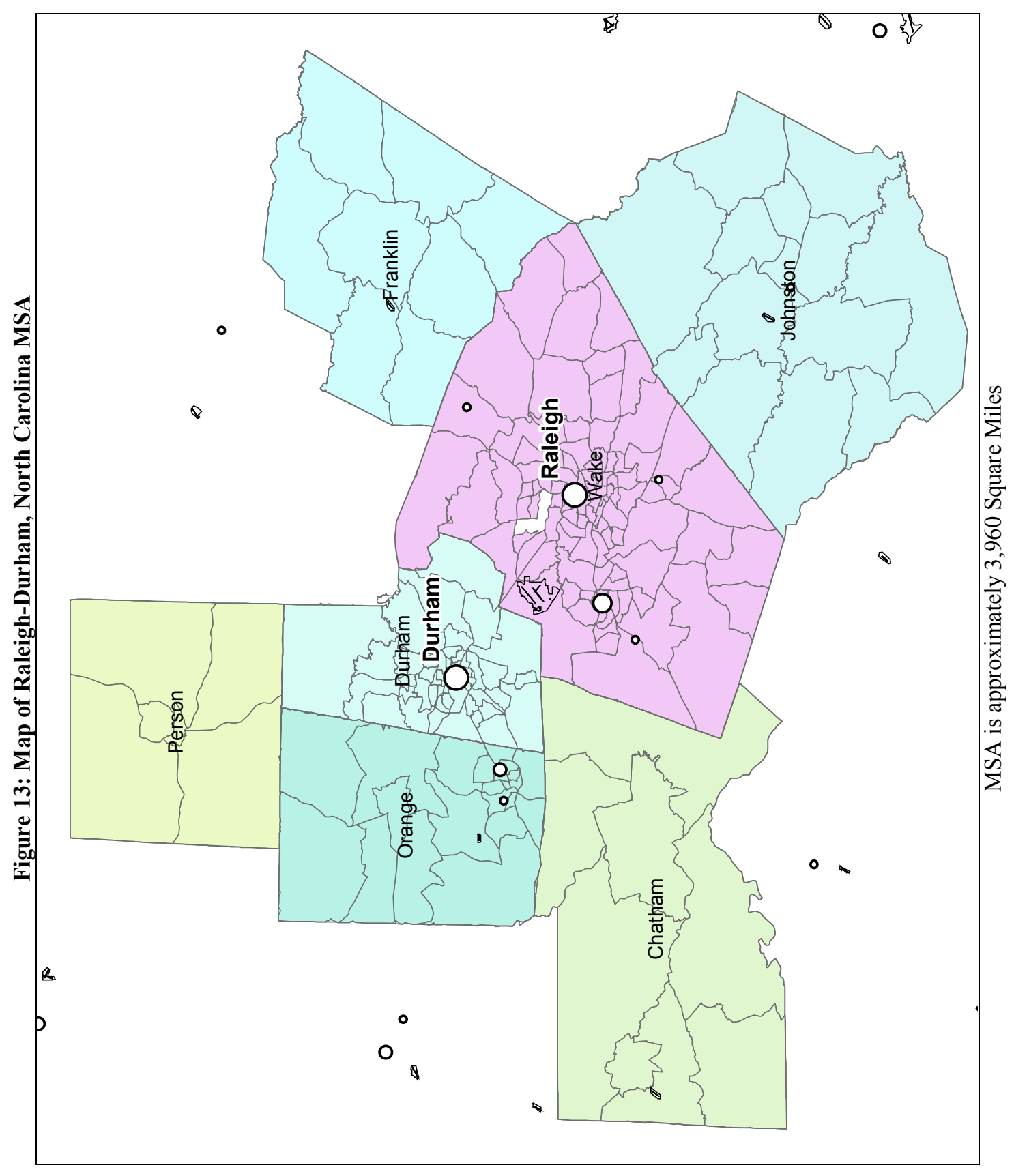




\subsection{Economic Comparison of the MSAs}

The populations of the selected MSAs from the 2000 Census and from the 2005 Current Population Survey are shown in Table 28.

Table 28: Population 2000 and 2005 for Four MSAs

\begin{tabular}{|l|r|r|r|r|}
\hline & Raleigh- Durham & Nashville & Indianapolis & Louisville \\
\hline 2000 Census & $1,187,941$ & $1,231,311$ & $1,607,486$ & $1,025,598$ \\
\hline 2005 CPS & $1,359,293$ & $1,384,347$ & $1,608,730$ & $1,183,916$ \\
\hline Percent Change & $14.4 \%$ & $12.4 \%$ & $0.1 \%$ & $15.4 \%$ \\
\hline
\end{tabular}

The selected MSAs have somewhat different economic development contexts. An updated shift-share analysis was conducted for these four MSAs using the Occupational Employment Survey data from the Bureau of Labor Statistics for the years 2000 and 2006. Location quotients for 2006 were calculated to determine which occupational categories are more heavily represented in these MSAs than in the nation. Table 29 shows the distribution of employment for 2006 organized along the creative class occupational classifications (the sales and related occupations category was not split between the service and creative class for this table). Table 30 shows the percent change in location quotients from 2000 to 2006 with basic industries in 2006 shaded. 
Table 29: Employment by Major Occupation for 2006 for Four MSAs

\begin{tabular}{|c|c|c|c|c|c|c|c|c|}
\hline \multirow{2}{*}{$\begin{array}{l}\text { Occupational Category } \\
\text { Creative Class }\end{array}$} & \multicolumn{2}{|c|}{ Raleigh/Durham } & \multicolumn{2}{|c|}{ Nashville } & \multicolumn{2}{|c|}{ Indianapolis } & \multicolumn{2}{|c|}{ Louisville } \\
\hline & & $35.1 \%$ & & $26.9 \%$ & & $26.0 \%$ & & $23.8 \%$ \\
\hline Super Creative Core & & $17.9 \%$ & & $10.5 \%$ & & $10.9 \%$ & & $9.4 \%$ \\
\hline $\begin{array}{l}\text { Computer and mathematical } \\
\text { occupations }\end{array}$ & 36,600 & $5.0 \%$ & 13,540 & $1.8 \%$ & 18,800 & $2.1 \%$ & 10,580 & $1.8 \%$ \\
\hline $\begin{array}{l}\text { Architecture and engineering } \\
\text { occupations }\end{array}$ & 16,830 & $2.3 \%$ & 10,990 & $1.5 \%$ & 15,130 & $1.7 \%$ & 7,080 & $1.2 \%$ \\
\hline $\begin{array}{l}\text { Life, physical, and social } \\
\text { science occupations }\end{array}$ & 20,620 & $2.8 \%$ & 4,450 & $0.6 \%$ & 9,170 & $1.0 \%$ & 3,150 & $0.5 \%$ \\
\hline $\begin{array}{l}\text { Education, training, and } \\
\text { library occupations }\end{array}$ & 48,630 & $6.6 \%$ & 37,180 & $5.0 \%$ & 41,110 & $4.7 \%$ & 29,090 & $4.9 \%$ \\
\hline $\begin{array}{l}\text { Arts, design, entertainment, } \\
\text { sports, and media } \\
\text { occupations }\end{array}$ & 9,320 & $1.3 \%$ & 11,600 & $1.6 \%$ & 10,850 & $1.2 \%$ & 6,290 & $1.1 \%$ \\
\hline Creative Professionals & & $17.2 \%$ & & $16.4 \%$ & & $15.1 \%$ & & $14.4 \%$ \\
\hline Management occupations & 42,950 & $5.8 \%$ & 46,620 & $6.3 \%$ & 38,870 & $4.4 \%$ & 26,680 & $4.5 \%$ \\
\hline $\begin{array}{l}\text { Business and financial } \\
\text { operations occupations }\end{array}$ & 36,250 & $4.9 \%$ & 27,260 & $3.7 \%$ & 38,730 & $4.4 \%$ & 21,100 & $3.5 \%$ \\
\hline Legal occupations & 5,590 & $0.8 \%$ & 3,800 & $0.5 \%$ & 5,300 & $0.6 \%$ & 3,720 & $0.6 \%$ \\
\hline $\begin{array}{l}\text { Healthcare practitioners and } \\
\text { technical occupations }\end{array}$ & 42,030 & $5.7 \%$ & 44,440 & $6.0 \%$ & 49,740 & $5.7 \%$ & 34,280 & $5.7 \%$ \\
\hline Working Class & & $19.9 \%$ & & $26.9 \%$ & & $26.8 \%$ & & $28.8 \%$ \\
\hline $\begin{array}{l}\text { Construction and extraction } \\
\text { occupations }\end{array}$ & 35,230 & $4.8 \%$ & 32,500 & $4.4 \%$ & 43,170 & $4.9 \%$ & 28,350 & $4.8 \%$ \\
\hline $\begin{array}{l}\text { Installation, maintenance, and } \\
\text { repair occupations }\end{array}$ & 26,750 & $3.6 \%$ & 31,350 & $4.2 \%$ & 40,420 & $4.6 \%$ & 24,560 & $4.1 \%$ \\
\hline Production occupations & 44,820 & $6.1 \%$ & 72,360 & $9.7 \%$ & 66,880 & $7.6 \%$ & 59,230 & $9.9 \%$ \\
\hline $\begin{array}{l}\text { Transportation and material } \\
\text { moving occupations }\end{array}$ & 40,110 & $5.4 \%$ & 63,400 & $8.5 \%$ & 84,540 & $9.7 \%$ & 59,400 & $10.0 \%$ \\
\hline Service Class & & $44.9 \%$ & & $46.2 \%$ & & $47.2 \%$ & & $47.4 \%$ \\
\hline $\begin{array}{l}\text { Healthcare support } \\
\text { occupations }\end{array}$ & 18,100 & $2.5 \%$ & 15,300 & $2.1 \%$ & 18,450 & $2.1 \%$ & 16,470 & $2.8 \%$ \\
\hline $\begin{array}{l}\text { Food preparation and serving } \\
\text { related occupations }\end{array}$ & 56,580 & $7.7 \%$ & 65,140 & $8.8 \%$ & 75,900 & $8.7 \%$ & 49,380 & $8.3 \%$ \\
\hline $\begin{array}{l}\text { Building and grounds } \\
\text { cleaning and maintenance } \\
\text { occupations }\end{array}$ & 23,220 & $3.2 \%$ & 21,090 & $2.8 \%$ & 31,030 & $3.5 \%$ & 18,420 & $3.1 \%$ \\
\hline $\begin{array}{l}\text { Office and administrative } \\
\text { support occupations }\end{array}$ & 118,320 & $16.1 \%$ & 136,230 & $18.3 \%$ & 151,940 & $17.4 \%$ & 105,540 & $17.7 \%$ \\
\hline $\begin{array}{l}\text { Personal care and service } \\
\text { occupations }\end{array}$ & 14,350 & $1.9 \%$ & 12,250 & $1.6 \%$ & 14,830 & $1.7 \%$ & 11,940 & $2.0 \%$ \\
\hline $\begin{array}{l}\text { Protective service } \\
\text { occupations }\end{array}$ & 14,890 & $2.0 \%$ & 14,020 & $1.9 \%$ & 18,470 & $2.1 \%$ & 12,160 & $2.0 \%$ \\
\hline $\begin{array}{l}\text { Sales and related } \\
\text { occupations }\end{array}$ & 76,560 & $10.4 \%$ & 71,450 & $9.6 \%$ & 9,1130 & $10.4 \%$ & 62,900 & $10.5 \%$ \\
\hline $\begin{array}{l}\text { Community and social } \\
\text { services occupations }\end{array}$ & 9,150 & $1.2 \%$ & 8,060 & $1.1 \%$ & 11,080 & $1.3 \%$ & 6,040 & $1.0 \%$ \\
\hline Total & 736,900 & & 743,030 & & 875,540 & & 596,360 & \\
\hline
\end{tabular}


Table 30: Location Quotient Percent Change from 2000 to 2006 and Basic Industries for 2006 Based on Employment by Major Occupational Category for Four MSAs

\begin{tabular}{|c|c|c|c|c|}
\hline Occupational Category & $\begin{array}{l}\text { Raleigh- } \\
\text { Durham }\end{array}$ & Nashville & Indianapolis & Louisville \\
\hline \multicolumn{5}{|l|}{ Super Creative Core } \\
\hline Computer and mathematical occupations & $11.1 \%$ & $13.1 \%$ & $8.4 \%$ & $4.1 \%$ \\
\hline Architecture and engineering occupations & $15.3 \%$ & $3.5 \%$ & $10.5 \%$ & $19.4 \%$ \\
\hline Life, physical, and social science occupations & $-10.8 \%$ & $16.3 \%$ & $-1.2 \%$ & $18.3 \%$ \\
\hline Education, training, and library occupations & $9.4 \%$ & $10.6 \%$ & $5.7 \%$ & $10.2 \%$ \\
\hline $\begin{array}{l}\text { Arts, design, entertainment, sports, and media } \\
\text { occupations }\end{array}$ & $20.0 \%$ & $23.1 \%$ & $-5.0 \%$ & $1.8 \%$ \\
\hline \multicolumn{5}{|l|}{ Creative Professionals } \\
\hline Management occupations & $-5.1 \%$ & $-21.5 \%$ & $7.7 \%$ & $-2.2 \%$ \\
\hline Business and financial operations occupations & $7.4 \%$ & $41.1 \%$ & $12.2 \%$ & $20.0 \%$ \\
\hline Legal occupations & $4.7 \%$ & $32.8 \%$ & $21.2 \%$ & $12.9 \%$ \\
\hline Healthcare practitioners and technical occupations & $2.8 \%$ & $-7.9 \%$ & $-1.5 \%$ & $-1.1 \%$ \\
\hline $\begin{array}{l}\text { Average Change in Relative Concentration for the } \\
\text { Creative Class }\end{array}$ & $6.1 \%$ & $12.3 \%$ & $6.4 \%$ & $9.2 \%$ \\
\hline \multicolumn{5}{|l|}{ Working Class } \\
\hline Construction and extraction occupations & $11.2 \%$ & $20.7 \%$ & $-3.0 \%$ & $0.0 \%$ \\
\hline Installation, maintenance, and repair occupations & $-9.0 \%$ & $-6.7 \%$ & $-9.2 \%$ & $-0.4 \%$ \\
\hline Production occupations & $-16.5 \%$ & $-23.1 \%$ & $5.5 \%$ & $-8.1 \%$ \\
\hline Transportation and material moving occupations & $-8.3 \%$ & $-13.1 \%$ & $-19.4 \%$ & $-9.5 \%$ \\
\hline \multicolumn{5}{|l|}{ Service Class } \\
\hline Healthcare support occupations & $-25.6 \%$ & $-13.3 \%$ & $7.2 \%$ & $-11.3 \%$ \\
\hline Food preparation and serving related occupations & $-11.0 \%$ & $-9.5 \%$ & $-5.4 \%$ & $0.4 \%$ \\
\hline $\begin{array}{l}\text { Building and grounds cleaning and maintenance } \\
\text { occupations }\end{array}$ & $-12.5 \%$ & $-1.9 \%$ & $-15.9 \%$ & $-3.2 \%$ \\
\hline Office and administrative support occupations & $0.3 \%$ & $1.0 \%$ & $4.6 \%$ & $7.6 \%$ \\
\hline Personal care and service occupations & $0.7 \%$ & $31.3 \%$ & $25.3 \%$ & $17.1 \%$ \\
\hline Protective service occupations & $-13.8 \%$ & $-7.6 \%$ & $-8.2 \%$ & $-8.4 \%$ \\
\hline Sales and related occupations & $-4.0 \%$ & $17.4 \%$ & $7.2 \%$ & $-1.2 \%$ \\
\hline Community and social services occupations & $15.2 \%$ & $9.9 \%$ & $-7.4 \%$ & $37.3 \%$ \\
\hline
\end{tabular}

The positive numbers in Table 30 indicate that from 2000 to 2006 the MSA increased

concentration of a given occupation relative to the national concentration, while negative

numbers represent a fall in concentration. The shading represents occupations with

location quotients above 1.00 in 2006.

Raleigh-Durham clearly dominates in the creative class occupations while the

other three MSAs are more concentrated in the working or service classes, although no

MSA is without some concentration of creative class occupations. Management

occupations are concentrated in three of the MSAs and healthcare practitioners and

technical occupations are concentrated in all four. The remaining creative class

occupations are concentrated in only one or two MSAs. 
OES data allow an analysis below the major occupation classification level. I did look at occupational concentrations in the management and healthcare practitioners and technical occupations to determine if specific occupations were driving these results. There were no clear patterns across the MSAs with the exception of Registered Nurse concentrations being above the national percentage in all four MSAs. The summary tables are presented in the data appendix (Tables 43 and 44).

The GMP and percent change in GMP from 2000 to 2005 for these MSAs are presented in Table 31. The strongest growth in GMP occurred in Nashville, followed by Raleigh-Durham. Compared to Table 30 this is clearly inconsistent with creative class concentration.

Table 31: Gross Metropolitan Product 2000, 2005 and Percent Change 00-05 for four MSAs in \$Billions

\begin{tabular}{|r|r|r|r|r|}
\hline & Raleigh- Durham & Nashville & Indianapolis & Louisville \\
\hline GMP 2000 & 52.3 & 51.1 & 62.3 & 43.3 \\
\hline GMP 2005 & 60.2 & 60.3 & 69.1 & 45.7 \\
\hline GMP percent change & $15.2 \%$ & $18.0 \%$ & $10.9 \%$ & $5.6 \%$ \\
\hline
\end{tabular}

\subsection{Summary of Interviews}

Interviews of economic development officials were conducted in five cities. The initial set of questions focused on the perceived role of local government in economic development in these cities, the focus of economic development strategies, and the manner in which economic development success is determined. The intent was to discern whether there were any distinguishable differences in the approach to economic development in these cities. The comments are presented in the order in which the questions were asked and are not meant to reflect the significance of the comments. 


\subsubsection{Louisville, Kentucky}

An economic development official in Louisville stated that “... the local government can help facilitate the infrastructure that needs to be put in place to foster strong economic development. And for me, infrastructure is sort of a broad term. You know it could be, certainly, physical infrastructure; it could be financial infrastructure; and it could also be the infrastructure of a set of policies that are designed to encourage certain types of development to occur..."

A public-private partnership exists between the city and Greater Louisville Inc. (formerly the Louisville Chamber of Commerce) for business attraction and retention activities. The city also has a partnership with a separate not-for-profit Downtown Development Corporation that focuses on the development of the central business district. Louisville has "for the last ten years [been] focusing on logistics and biomedicine, while respecting our traditional core strength, which is manufacturing....and we're beginning to see the bio field and the logistics field interlocking."

When asked about the measurement of success regarding economic development initiatives the official responded, "I would think anybody would argue the two UPS [United Parcel Service] investments of one million [sic $]^{19}$ dollars in this community, each, are wildly successful." Louisville officials also use "private investment in downtown" much of it related to "the number of housing units that are either in construction or in the pipeline." In terms of specific economic development failures Louisville officials offered no specific examples.

\footnotetext{
${ }^{19}$ The UPS investments were billion dollar investments.
} 
Louisville officials mentioned three areas as barriers to the success of economic development projects. The first "is funding...Louisville is very constrained in terms of revenue generation, because it not a home-rule city. Anything that needs to be done, or anything the city wants to do has to be enabled at the state level, which is a real problem for economic development." The second issue was the educational attainment of the workforce. "There are positive trends, but they are twenty year trends, not two year trends, so it takes awhile for [improvement] to occur." Finally, “...the general sense of the community, in terms of lots of things, including economic development, this tends to be a fairly conservative, risk-averse community."

The next area of focus in the interviews was small business development and entrepreneurialism. I was particularly interested in whether Louisville had implemented any type of overall small business, or entrepreneurial, development system similar to that proposed by Lichtenstien and Lyons (2001). One Louisville official emphasized the existence of a retail strategy for small business. "We created this retail strategy largely to facilitate community redevelopment. There are just a lot of sections of our community, and indeed, any large community, that don't have the convenience store, don't have the shoe repair shop, or don't have a dry cleaners, don't have those services close to the neighborhood, and the mayor kind of thinks you should be able to buy a quart of milk or a gallon of milk on the way home. And so we've worked very hard to try to get retail into, particularly, the under-served areas of our community." Louisville has also established a forgivable loan program for businesses in these areas and a micro-loan program as a gap financing program for small business. The official also emphasized that the city has created "as part of [its] program with Greater Louisville, Inc., a program 
that we call High Impact $100 \ldots$ where we focus on 100 of the fastest growing [small] businesses in this community." In addition, Louisville funds forty percent of the operating expenses of the Small Business Development Center and operates the Nia Center in West Louisville "which is a start-up point primarily because of its location for minority businesses." Louisville claims to have implemented the Lichtenstein and Lyons rating system in the Nia Center. Louisville also has the Louisville Medical Center Development Corporation (LMCDC) which is "taking a lead in terms of commercialization of biomedical research that's going on in the university [University of Louisville] and in the hospitals." The LMCDC operates three biomedical research incubators and is working on creating a two-and-one-half block biomedical research park near the downtown medical complex. "And the university has definitely increased, as a priority, its biomedical research and NIH funding."

The series of questions on regionalism was focused on the issue of MSAs versus cities. Again, the unit of analysis in Florida's research was the MSA. The questions were asked to determine if there was a consistent economic development policy in the entire MSA, or whether the cities in question were competing with other locations within the MSA. The official stated that “...we haven't quite figured out the way yet to work together real effectively as a region in economic development. There's still a lot of mistrust and competition, but it's better than it was five years ago and certainly better than it was ten years ago. So it's a progression." There was an admission as well that Louisville Metro ${ }^{20}$ benefits from spillover effects when companies locate in other cities or counties in the MSA.

\footnotetext{
${ }^{20}$ Louisville Metro was the name given to the city of Louisville and Jefferson County after the 2003 merger of city and county government. The Louisville MSA now includes Louisville Metro, 9 other counties in
} 
The officials in Louisville were aware of Florida's research. They indicated that they "do use the creative class mantra sort of as a big part of what we're trying to do downtown." When shown the creativity index rankings from Table 1, they offered several reasons why the rankings might be as they are, i.e. Louisville being the lowest of the four MSAs. The first was the lack of a large "residence-based broad university" although current university objectives call for improvement in this area. The second involved diversity not being a "strong across-the-board value... in terms of pockets of geographic areas." The impact of Research Triangle Park on the Raleigh-Durham MSA, the benefits of merged government in Nashville-Davidson County (merged 1963) and Indianapolis-Marion County (merged 1970), and the investment in athletics in both Nashville and Indianapolis were also mentioned. Nevertheless, the difference in ranking was less important than making progress on creative class types of issues such as the completed, or proposed, developments in the downtown such as Waterfront Park, Fourth Street Live, the proposed arena, and the success of downtown housing. The market for downtown housing is estimated at somewhere between 5,000 and 10,000 units with 3,000 either completed or under construction. Officials indicated that Louisville is finding that people "are attracted to downtown because of the fact that there are lots of other types of people living downtown, as well.” Louisville officials speculated that if the Florida analysis is repeated in 2010 progress will have been made, perhaps not relative to other MSAs, but that is a less important consideration.

Kentucky, and 4 counties in Indiana. 


\subsubsection{Indianapolis, Indiana}

An Indianapolis official stated that “...the role of local government is to make sure you have viable businesses; that you have an appropriate mix of all uses that make a good city, whether that be residential, industrial, commercial; that you make sure that the mix doesn't have negative impacts on any of those three groups of uses; and that you support both new uses coming in, as well as the existing uses that have already been here." Although another official added that "[E]conomic development is, in the broad scheme of things, driven by the private market...[L]ocal and state government can augment and try to counter some of those private forces and try to enhance and redirect, but we are not the lead, nor is our system of government set up to be the lead." Indianapolis supports a not-for-profit organization called the Indy Partnership providing economic assistance to nine counties. Indianapolis Economic Development (IED) is a division within the Indy Partnership focused on Indianapolis and Marion County. These organizations are critical to the business attraction and expansion efforts in Indianapolis. According to officials, Indianapolis has “...five targeted industries: life sciences, advanced manufacturing, logistics and distribution, high technology and automotive related industry."

When asked about measures of success for economic development, the official stated that “...in a real general sense, economic development is a success when a business is open and generating jobs, people are buying and selling goods." In addition, there are specific fulfillment criteria associated with any tax abatements offered to business in Indianapolis. Companies that receive abatements are monitored "on an annual basis to make sure they are in compliance with their commitments and, if they are 
not and they have no way of remediating that situation, we will terminate the tax abatement. And if they're really egregious, we make them pay back the benefits that they have received, especially if they have packed up and moved out of town."

The downtown canal project was offered as a specific instance of economic development success in Indianapolis. This project involved the rehabilitation of the 100year-old canal and surrounding industrial area into a museum, entertainment, residential, and life sciences complex resulting from federal, state, and local government support and considerable private investment. The health science complex is a partnership between Indiana University and Clarion hospital. The economic development failure cited was the United Airlines hub constructed in 1998 and 1999 that was never occupied by United after their bankruptcy in 2000. Big box reuse was cited as a particularly problematic economic development issue.

Consistent with the examples where success has been difficult, Indianapolis discussed control issues from two perspectives. The first was the macro-economic forces that any individual city can't control because "large companies are making decisions to close up or scale back and it really doesn't have that much to do with the local plant." The bankruptcy of United was out of Indianapolis' control. Similarly, the second control issue was with big box redevelopment. The official stated that when large industries or retailers leave, “[W]e, as a city, don't have control of those buildings that just sit there vacant." An official also mentioned the "Indiana-no-place" perception problem that, while improving, is still a barrier in some instances. The officials also mentioned that Indianapolis is not a home-rule city and taxation in Marion County remains somewhat 
fragmented under the Unigov structure created when city and county government merged in 1970.

In terms of small business development, Indianapolis relies on the Indy Partnership to provide small business assistance and advice so there is at least one point of contact. However, no rating system for entrepreneurs is in place. Indianapolis has worked with Community Development Corporations and used federal brownfield remediation funds along with tax increment financing to redevelop aging commercial districts. In addition the Local Initiatives Support Corporation (LISC), the Greater Indianapolis Chamber of Commerce, the Indianapolis Coalition for Neighborhood Development and the city have collaborated to develop a FOCUS (Fostering Commercial Urban Strategies) initiative to foster commercial and retail development along seven commercial corridors in the city. The initiative provides advice and technical assistance and facilitates access to various funding sources for small businesses to locate along these corridors. Indiana University also has a life science incubator called the Emerging Technology Center located in the life sciences complex portion of the canal development. With respect to regional competition, the officials felt that the Indy Partnership's purpose was to foster a sense of regionalism in the MSA. In fact the Partnership has expanded beyond the nine counties in the MSA to include Monroe County (where Indiana University's main campus is located) and Lafayette County (where Purdue University's main campus is located). There is some competition with Hamilton County for the types of industry and people that Indianapolis wishes to attract but there is also a sense that regional growth is good for Indianapolis. Some of that thinking comes from 
the realization that the market area for Indianapolis' professional sports is much larger than Marion County proper.

As far as acting on Florida's advice or in response to the specific creativity index measures, the officials said "[W]e have done a lot of similar things, but I don't think we've done something that we would say we're doing this because of Richard Florida." Efforts to spark downtown development in Indianapolis have spanned four different mayors starting with the "amateur sports capital of the United States" effort in the 1970s to the current mayor's focus on cultural tourism. The Indianapolis Cultural Development Commission was established in 2002 to focus on art of all forms and to signal to people "who make their living through their art, that they could live here."

\subsubsection{Nashville, Tennessee}

The official in Nashville stated that "[T]he best economic strategy to do is to make for an attractive quality of life in the city where people would want to come here and people would want to stay here... The truth of the matter is, the things you would want to do anyway are the best economic development strategy. By that I mean, ... if you had the strongest education system in the southeast, you wouldn't have to spend a dime on economic...on business recruitment."

Nashville has a partnership with the Nashville Chamber of Commerce called Partnership 2010. Nashville is specifically interested in high technology and corporate headquarters and holds out its central location and quality of life as important but they also have a more focused strategy. As the official stated, "Nashville is, in fact, a healthcare center. I don't mean health in the sense of hospitals, although it's that, too. But I mean in the healthcare business, particularly the thing that's called the "for profit" 
or proprietary healthcare business. HCA [Healthcare Corporation of America] kind of started it...and because of all its offshoots and spin-offs...it was very dynamic, very entrepreneurial, very successful healthcare sector. So ...we've looked here in recent years about to--just working on the technology side--it would make sense to target and try to grow more technology that would have the synergy with that particular business." In addition they are focused on music "...there's all sorts of things going on with the technology side of the music [industry], the digital aspects of it."

Nashville concentrates on "job growth, wage growth and then capital investment." In terms of specific projects the official provided the Partnership 2010 publication which lists projects for all nine counties served by the Partnership. No specific failures were provided.

The official did discuss the macro-economic impact on measuring economic success but not so much as a barrier to that success but rather as an external influence that might deflate job growth or investment numbers relative to some objective. No other specific economic development barriers were discussed.

Regarding small business or entrepreneurial development, the official indicated that Nashville "was a pretty reasonably robust entrepreneurial setting...the healthcare industry is very entrepreneurial. But there was a sense in the last year or two that we ought to do more locally." Entrepreneurialism is now a "major component of the [Partnership 2010] strategic plan for the next few years." The Partnership utilizes Fast $\operatorname{Trac} \AA$, an entrepreneurial training system available from the Kaufmann Foundation, as a training tool for entrepreneurs. No rating system for entrepreneurs is in place.

The official's outlook on competition was that "[F]or the most part, as a city like 
Nashville becomes more urbanized, there are certain jobs here--we're really interested in, like, corporate headquarters, you know, high skilled technology jobs...our ability to provide land for even a major factory...it's just less and less available." Such an operation would then go to ring counties. There is some competition with Williamson County for small office space, but "by and large, the kind of jobs we are really interested in...I don't see that we compete that much for these jobs."

With respect to Dr. Florida, the Nashville official could not recall him officially visiting the city. Nevertheless, the official was familiar with the creative class theory and felt that "there's something about it that rings true." The important connection, however, was education. The official stated that "[Creative class theory] is just another way of saying we want to attract a highly-educated work force, or we want to develop a highlyeducated work force where we want to have jobs that require skills and education.”

When I pursued the notion that tolerance was, according to Florida, what distinguishes creative capital from human capital the response was still linked to education. The official stated “...there are something like 90,000 college students within an hour's drive of Nashville" and further "I know intuitively or instinctively or through experience there's a correlation there [between education and tolerance]." When economic development recruitment focuses on "the white collar jobs or corporate headquarters type stuff, ...they want to know about schools for their kids, they want to know, can I bring my executives with me? Are they going to want to come? And they end up choosing Nashville, and we work very hard at that aspect of it. So these quality of life issues, which are related to Florida's notion--tolerance, diversity, those sort of things are... it makes a difference.” 


\subsubsection{Raleigh, North Carolina}

The Raleigh official stated "[T]o me, government has a vital role in economic development. I purely see it as, you know, maintaining and keeping a healthy economy for your city, so I think it's vital that cities are involved in economic development and seek whatever partnerships are necessary to keep the economy strong, healthy and diverse."

The official indicated that in terms of specific economic development attraction strategies, Raleigh is "now considered a major location for corporations to move, particularly in biotech technology-related services..." The Raleigh city government contracts with the Chamber-of-Commerce for business attraction and retention strategies.

In terms of measuring economic development success, the Raleigh official's comments were focused on downtown development and generally a matter of observation although the official stated that the redevelopment of the Favel Street was a "nine million dollar capital investment [that has] now stimulated close to two billion of investment in our downtown." There were no negatives cited, although the new convention center is a case where there was some question about its potential success and "the jury's out."

The official in Raleigh mentioned three economic development barriers. The first two were related--the density of new development and the pace of change. As the official stated, there is a concern on the part of some "about how fast the change is happening and how different downtown is becoming." The third was the lack of an economic development corporation in Raleigh. As a result, all economic development projects must go through city council for approval, which at times slows development. 
The person interviewed in Raleigh was unaware of a specific coordination function for small business or entrepreneurial development. However, North Carolina State University has two initiatives aimed at high-technology business incubation. Their Centennial Campus located in Research Triangle Park is focused on high-technology application in a number of areas (Biotechnology, Advanced Communications Technologies, Life Sciences, Environmental Technologies, Advanced Materials, International Technology Transfer and Trade, and Pre-College Education) ${ }^{21}$ and their Precision Marketing initiative is focused on the non-woven textiles industry.

In the official's opinion, Raleigh does not perceive itself as a competitor with Durham or other cities, or counties, in the MSA. Research Triangle Park and the associated universities seem to be a sufficient draw for business and people that each city can operate with its own focus without competition.

When asked whether Florida's theory had any direct impact on Raleigh's economic development policies, the official stated, "I think the creative class--what is happening is that now when the 20 -somethings and the 30 -somethings are arriving to our city, they are used to a very different type of environment to live in; and so they are pushing, even at RTP, where it's more of a campus approach, that they're hearing from the new people they're attracting, that they're looking for an urban experience. A lot of them are ending up in Raleigh and commuting to RTP because they like urban living, a different type of lifestyle. So I'd have to say the creative class is kind of changing the expectations for housing, for entertainment...I think the creative class is a new market that is changing our downtown."

\footnotetext{
${ }^{21}$ See http://www.raleigh-wake.org/index.cfm?fuseaction=page\& filename=data-real-estate-researchparks.html
} 


\subsubsection{Durham, North Carolina}

Durham officials felt that government's role "is to make sure that you've, when you do your long-range plans, your comprehensive plans, your utility plans, all those great plans that--economic development is included in those plans."

The Durham city government contracts with the city Chamber-of-Commerce for business attraction and retention strategies. The officials indicated that Durham is "very successful in the life sciences sector--biotechnology, bio-pharmaceuticals, and not only do we have a strong life sciences sector, but we're trying to broaden it. We have a huge clinical research organization base, but we're not as large in manufacturing. So we've been working very hard in the last several years to add more manufacturing so we've got a broad-based, more robust, industry cluster. Plus we're developing a new industry cluster in our region...called financial services, and in the last couple of years have been able to attract the global operation center for Credit Suisse, and also attracted a huge operation for Fidelity, and we're very happy to have attracted the operation's headquarters for the American Institute of Certified Public Accountants."

According to the officials, Durham is "looking for things that are capital intense and that create the right type of jobs." In terms of positive projects, Durham has pursued “... area economic development. For instance, they've taken a million square feet of warehouses, and through public-private partnership, have developed now a million square feet of occupied space." The city's efforts were primarily infrastructure focused in terms of roads, communications capabilities and parking, and "they've just started another public-private partnership for another million square feet of space, old tobacco space, that's being adaptively reused." Durham's negative example dealt with a failed small 
business loan program and will be discussed in a later paragraph dealing specifically with small business.

The officials in Durham mentioned that the lack of extensive international flights and direct flights to and from the Raleigh-Durham airport is a barrier for "some projects, particularly headquarters projects." In addition, space availability and terrain inhibit large projects in Durham proper.

The officials indicated that Durham has no overarching coordination of small business programs in Durham. Durham does have small business and micro-enterprise loan programs. The initial small business loan program was cancelled due to malfeasance but has been restructured and is now operating effectively. In addition, officials mentioned that they benefit from the state run First Flight Venture Center, a high-technology incubator facility, and the Council for Entrepreneurial Development, a not-for-profit corporation focused on assisting entrepreneurs. Both facilities are located in Research Triangle Park.

The Durham official's opinion regarding competition within the MSA was quite similar to the position of the Raleigh official. Durham does not perceive itself as a competitor with Raleigh or other cities or counties in the MSA. Once again, Research Triangle Park and the associated universities seem to be a sufficient draw for business and people that each city can operate with its own focus without competition.

When questioned regarding any direct influence from Florida, an official stated, "I don't know if he came here, but Durham, a number of business organizations here, commissioned Dr. Florida to do a study. A lot of our folks felt like what he noted in his regional study was located here in Durham, so they paid him to come back to do a further 
study--follow-up study--and then he came back to announce that Durham was the most creative class community of any community its size...And so we market that, as well. He didn't really give us a lot of suggestions, but we've had other similar types of leaders come here in urban planning and the arts and culture, and we've tried to follow a lot of those recommendations. But, part of it is, we drew up a cultural master plan; we're in the process of implementing that; so we've tried to follow things that are very progressive in nature. The other thing, too, is that the average age of the work force is like...32 now...we have a relatively young population."

\subsection{Criticisms}

The interviews summarized above were with individuals in economic development agencies or chambers-of-commerce. As might be expected, they were all very positive about their cities. I contacted organizations that I felt would offer a different perspective on economic development but had only one response that resulted in an interview. That interview offered legitimate criticism, from the perspective of the person interviewed, on economic development efforts and policies in Louisville. However, without similar criticism from the other cities, summarization of that interview in this dissertation would make it appear that only Louisville's policy choices are debatable. I believe the pursuit of this information is important but leave the issue as an area for further qualitative research.

\subsection{Hypothesis 7 Conclusions}

My hypothesis that economic development officials will be doing things that are creative class oriented but that without an underlying change in economic development 
context, these efforts are unlikely to produce changes in economic growth is fundamentally supported although there are some doubts. Clearly each city is marketing itself based on creative class concepts, although this effort may have started as a qualityof-life initiative prior to the publishing of Florida's work. There are also several common threads--life sciences, biotechnology, downtown revitalization, downtown housing, and the arts. However, referring back to Tables 30 and 31, Nashville has the highest growth in GMP, with an above-national-average concentration in creative class occupations in only three of the nine creative class occupations. Raleigh-Durham with above-nationalaverage concentrations in eight of the nine occupations is second in GMP growth. Raleigh-Durham, Louisville, and Indianapolis are all specifically focused on biotechnology and life sciences related development while Nashville seems more focused on headquarters operations, general health sciences and music. The increase in the location quotients in Table 30 are, for the most part, consistent with each city's focus, but does not seem to translate to short-term GMP growth. Nashville's approach and growth are more closely aligned with its 2000 economic base. Its concentration of artists, business and finance and legal occupations has increased, and it is above the national average in artists and in management occupations (although the relative concentration of management occupations has fallen). This, I believe, supports the economic development context portion of my hypothesis. On the other hand, all four MSAs have increased the relative concentration of creative class occupations, and all four have grown GMP, but the average change in relative creative class concentration is not consistent with each city's change in GMP. Nashville's relative change is the highest at 12.3 percent as is their change in GMP at 18 percent. However, Louisville's relative change in 
concentration is second highest at 9.2 percent while their percent change in GMP is the lowest at 5.6 percent. Indianapolis increased relative concentration 6.4 percent but increased GMP 10.9 percent. And Raleigh-Durham increased relative concentration only 6.1 percent but increased GMP by 15.2 percent. Of course, Raleigh-Durham began the period with the largest creative class concentration which might explain its low growth rate.

The doubts arise because in terms of their stated economic development focus Raleigh-Durham and Indianapolis had above-national-average concentrations in lifescience in both 2000 and 2005 but their concentrations actually fell over that time period. Louisville had an increase in life-science concentration but was not above the national average in either year. Nashville had a strong base in arts, design, entertainment, sports, and media occupations in both years and grew the concentration, but had trends similar to Raleigh-Durham and Indianapolis in management occupations and health sciences. Therefore, Nashville's GMP grew in the face of mixed changes to its creative class economic development focus. The GMP in Raleigh-Durham and Indianapolis grew in spite of reductions to their stated creative class economic development focus, and Louisville's GMP grew consistent with its focus but at the smallest rate. There is clearly some other dynamic at work beyond economic context and economic development focus. Unrelated to my specific hypothesis but of interest is the importance each city attached to education and their partnerships with universities. This may be a key driver, although Nashville, with only one Research I university, outperformed Raleigh-Durham, where there are three, Indianapolis, where there are arguably two (although neither is technically in the Indianapolis MSA), and Louisville with one. 
My notion that economic development competition within an MSA could detract from economic growth in specific cities seems of little concern to these cities. Competition among MSAs is clearly recognized, but competition within MSAs is generally viewed from the perspective that the large city is the real draw in the MSA and that even if companies locate somewhere else in the MSA the city will reap spillover benefits (although Louisville was certainly less positive in this regard but is the only MSA studied that has counties in two states).

Only Louisville had implemented any sort of entrepreneurial rating system although all the MSAs in questions had institutions that facilitated and trained entrepreneurs. The idea that an overall entrepreneurial control and rating system would foster indigenous creativity and result in commercially successful innovation was not evident in the GMP results. This may simply be a timing issue since commercially successful innovation takes time to reach significant scale. It may also simply be that the similarity of the approaches to entrepreneurial development in these MSAs makes entrepreneurial economic contribution indistinguishable. 


\section{CHAPTER 6}

\section{SIGNIFICANCE OF THIS STUDY}

\subsection{Policy Implications}

Florida's concepts have been criticized (Malanga 2004; Li 2005) but to my knowledge no other scholars have attempted to investigate Florida's research and its relationship to economic development context as done in this dissertation. In addition, no comparative analyses of economic development context across time, or across locations, using the Koven and Lyons framework have been undertaken. Nor has the status of the Lichtenstein and Lyons economic development system and its relationship to different economic growth outcomes been studied.

I began this study by questioning whether the creative class could have the positive effect on MSA economies that Florida claims. Creativity is hard to orchestrate, creativity is hard to commercialize, the existing power structure is difficult to modify, and changing culture, especially in the short run, is no easy task. This led me to hypothesize that the creative class percentages were likely unrelated to economic health or economic growth and that while certain elements of the creativity index were likely related to economic health and growth, the creative class percentage portion of the creativity index would not be. As a result of my findings, these hypotheses are rejected in part and confirmed in part. Some of the creativity index elements are important 
predictors of economic health or growth. This analysis, however, is more consistent with the urban literature than anticipated. Human capital and high technology predict current GMP and elements of culture, specifically immigrants in the population and racial tolerance, predict its growth. Where an immigrant lives is to some extent optional, but moving immigrants around is a zero sum game. Growing the immigrant population is a matter of federal policy—-therefore a structural constraint on cities—although clearly important for economic development (Bowles \& Colton 2007). Whether racial tolerance is improving, or how to improve it, is beyond the scope of this dissertation, but all can agree that is not a simple task. The presence of a Research I or II university is important for economic growth but the presence of a Research I or II institution in an MSA is also not likely to change in the short run and tends to be controlled by states and/or institutional administrations rather than cities. The specific research focus may not generate commercial success in the university's city, or, after commercial successes reach productive scale, they may leave for other locations with better access to capital or lower labor costs.

The qualitative research in this dissertation reinforces the notion that economic development practitioners work from common themes. While the cities are pretty much doing the same sorts of things, they are not getting the same results in terms of GMP growth. They have different economic bases which have developed over time and which exert some influence on GMP growth.

The policy implication of this research is that creative class attraction strategies may be inappropriately focused. Attraction of, and the facilitation of upward mobility for, immigrant and minority populations seems more important. These appear to be the 
important subelements of the creativity index for economic growth. In addition, human capital improvement appears more important than creative class concentration. Demographic research by Crouch (2004) and Jordan (2007) indicates that the immigrant and minority populations are important to the economic future of the U. S. and its cities. These populations seem ill served by the existing primary and secondary school system. Coupling my research with demographic research has implications for education in general. Primary and secondary school systems policies can be influenced by local governments and could be refocused to insure that these underserved populations are capable of entering the post-secondary system and contributing in meaningful ways to the economy as the baby-boom generation retires.

In addition, the economic development context appears to be an important starting point for economic development. This, of course, is not new. But the fact that creative class attraction strategies seem to work better in Nashville and Raleigh-Durham than in Indianapolis and Louisville may result from the fact that the strategies were aligned with the basic economic development context in the first place.

Finally, the notion that a region's culture can be changed by adding creative individuals remains debatable. I had hoped to demonstrate through this study that cultural change had to be addressed at a more fundamental level than occupation. I believe I have demonstrated that this is true as far as GMP growth is concerned education and immigration are, I believe, more deeply rooted issues than occupation. However, the cultural change conclusion is less clear. Economic development officials believe that downtown development and urban excitement are important elements of a city's attractiveness. They believe they can attract good jobs by pursuing quality-of-life 
strategies. In the five studied cities this seems to be working. Raleigh-Durham has RTP-it is high-tech--it has an extremely high concentration of the creative class. Nashville is Music City--it has creative energy--it has the highest increase in creative class concentration from 2000 to 2006. Indianapolis and Louisville have weaker creative images. Indianapolis, however, is working to shed its Indiana-no-place image. Louisville admits to a certain amount of conservatism and risk aversion but sees the situation improving. Both Indianapolis and Louisville have added creative class members. Raleigh-Durham and Nashville do not help answer the question because nothing in my interviews establishes what the culture was before quality-of-life initiatives became paramount objectives. Indianapolis and Louisville could, I believe, establish the fact that the cultural change comes first. But my interviews do not clearly establish this fact. Perhaps creative class members initiated the cultural change. The disconnect is that social ills do not improve with added creative class members nor does the city's economy improve commensurate with the change in creative class concentration.

\subsection{Limitations of the Study}

\subsubsection{Timing}

Cultural change may be a generational phenomenon. It is possible that the time frame of this study is simply inadequate to capture the cultural change taking place in MSAs. It is also possible that continual improvement rather than leapfrog improvement is all that MSAs desire, i.e. an improvement in the creativity index rather than an improvement in creativity index rank is all that matters. Only continued time-series analysis will tell. 


\subsubsection{Technical Limitations}

Tabachnick and Fidell (2001, p. 583) refer to the fact that exploratory factor analysis has a "somewhat tarnished" reputation as a scientific tool. Its use in this research was to determine whether three distinct dimensions would emerge from a dataset of occupational, technological and cultural related variables that were consistent with the three T's as presented in Florida's research. The fact that they did not was the only result of interest. This is not completely dispositive of the existence of the three dimensions; a different dataset, collected in a different time frame, could result in a different finding.

The close relationship of education and occupation, high-technology occupations and patents, university research and patents, and education and tolerance raise the questions of the influence of multicollinearity in the various regression models. The stepwise and backward methods were used to minimize this influence. When the standard enter method was used, tolerance, variance inflation factors, collinearity diagnostics and normal plots of residuals were all used as tools to insure that the models were sound.

Conclusions with respect to the analysis of the 49 MSAs with populations over one million are clearly restricted to that dataset and can not be generalized to other MSAs. The qualitative in-depth analysis of five cities likewise can not be generalized to other MSAs although they do add to the policy prescriptions resulting from the quantitative analysis of the full set of MSAs

\subsubsection{Data Limitations}

Homelessness data were missing for some MSAs and have been criticized as both 
undercounting and overcounting the homeless population, depending on the source of the criticism. A more accurate count of the homeless population, or the collection of data from additional MSAs, could alter the finding in this study.

Similarly, the crime rates in various MSAs were constructed from FBI crime statistics that are reported by police jurisdictions. Determining MSA level data required aggregating data from various jurisdictions. Missing data have two possible effects in this situation. Some MSAs had no reports and were excluded from analysis. Other MSAs had data but not from all police jurisdictions in the MSA, these data were analyzed as if they accurately represented the crime in an MSA. A more robust dataset could alter the findings regarding crime.

GMP data for MSAs are derived in top-down fashion from State GDP data by Global Insights, Inc. State GDP data are derived from U.S. GDP by the Bureau of Labor Statistics. The Bureau of Labor Statistics is currently working on developing a bottomsup approach to determining GMP and State GDP but that technique is not yet available. Theoretically, the difference between bottoms-up and top-down GMP data will not be statistically significant, but that remains to be seen and could change the results in this research.

\subsection{Areas for Further Research}

There is a clear set of areas requiring further research. Time series data need to be extended to evaluate whether a cultural change is occurring that has not yet affected the data in this analysis. When bottoms-up GMP data becomes available this research will need confirmation using bottom-up data. 
The gender inequity occupational data need to undergo log linear analysis to determine the extent of horizontal and vertical occupational inequity in creative class occupations. In addition, an income disparity analysis for each MSA could evaluate the argument, consistent with Sassen's (1999) assertion that globalization results in income polarization, that as creative class occupational employment grows the working and service classes earn less. A gender element could be added to such a study to determine the extent to which females are affected differently than males.

Finally, given the empirical results in this study, further analysis of educational systems and immigration policies is warranted to determine whether school systems that produce immigrant high achievers exist, whether the areas retain those graduates, and whether economic and social benefits result. In addition, immigrants often generate economic growth through entrepreneurial activity (Saxenian 2002) and enclave economies (Logan \& Alba 1999). The extent to which education is necessary in these contexts bears further investigation. 


\section{CHAPTER 7}

\section{DATA APPENDIX}

Research questions 1 and 2 explore the validity of the creativity index. Research question 1 explores whether the creativity index does in fact correlate with or predict economic health or economic growth. Research question 2 explores the predictive effects of the subcomponents of the creativity index and whether a measure of human capital is a better predictor of economic growth than the creative class measure. Both questions consider the 276 MSAs for which a creativity index is developed. A common dataset is used and measurement issues are likewise common.

\subsection{Creativity Index}

Florida (2002) develops a composite creativity index which measures and combines the influence of technology, talent and tolerance on metropolitan areas. The index for 276 Metropolitan Statistical Areas is provided in Appendix B of that work. Florida reports several correlations among the elements of the index as shown in Table 31. Table 31 was not presented as a correlation matrix. It merely collects and reports the correlations gleaned from various footnotes in Florida's (2002) work in a tabular format. 
Table 32: Creative Class Variable Correlations

\begin{tabular}{|c|c|c|c|c|c|c|c|}
\hline & $\begin{array}{l}\text { Creative } \\
\text { Class \% }\end{array}$ & $\begin{array}{l}\text { Working } \\
\text { Class } \%\end{array}$ & $\begin{array}{l}\text { Service } \\
\text { Class \% }\end{array}$ & $\begin{array}{l}\text { Melting } \\
\text { Pot } \\
\text { Index }\end{array}$ & $\begin{array}{l}\text { Gay } \\
\text { Index } \\
1990 \\
\end{array}$ & $\begin{array}{l}\text { Gay } \\
\text { Index } \\
2000\end{array}$ & $\begin{array}{l}\text { Bohemian } \\
\text { Index }\end{array}$ \\
\hline Innovation & 0.34 & -0.10 & -0.15 & 0.007 & $0.17 * * *$ & $0.16 * * *$ & \\
\hline $\begin{array}{l}\text { High-tech } \\
\text { industry }\end{array}$ & 0.38 & -0.16 & -0.19 & 0.10 & $0.57 * * *$ & $0.48 * * *$ & $0.38 * * *$ \\
\hline Talent & 0.64 & -0.45 & 0.07 & 0.08 & & & \\
\hline $\begin{array}{l}\text { Population } \\
\text { growth }\end{array}$ & 0.03 & -0.15 & 0.11 & 0.28 & & & $0.28 * * *$ \\
\hline Job growth & & -0.18 & 0.15 & 0.04 & & & $0.23 * * *$ \\
\hline Melting pot & 0.10 & & & & & & \\
\hline Gay 1990 & 0.40 & -0.30 & & & & & \\
\hline Gay 2000 & 0.27 & -0.26 & & & & & \\
\hline
\end{tabular}

Source: The Rise of the Creative Class (Florida, 2002b) Note 7 and 8 from Ch 13 and notes 12, 13, 17, 20, and 27 from Ch 14.

*** Significant at .001. Other items in bold are reported as significant but the specific level of significance is not reported. Items in italics are reported as insignificant. Significance of the other items is not reported.

Table 31 shows that the reported correlation between the creative class percentage and population growth is 0.03 and statistically significant. The correlation between the creative class percentage and job growth is unreported. One might conclude from this that Florida equates economic growth with population growth. This low correlation does not seem consistent with the strength that Florida attributes to the creative class as an economic engine. In Cities and the Creative Class (Florida 2005, p. 24), Florida states that "My theory is concerned primarily with the quality of economic growth, and quality of growth is not reflected in job growth at all, but in the wages and incomes that people make (Emphasis in original).”

In this work, Florida provides quantitative analysis of the impact of talent in 1990 on absolute change in per capita income for large MSAs, but talent is measured in terms of the percentage of the population with a bachelor's degree or higher, the percentage of professional and technical workers and the percentage of scientists and engineers. The correlation is $0.292(\mathrm{p}=0.05)$. The regression analysis of per-capita income change against measures of diversity, high-technology talent and median house value results in a 
statistically significant positive coefficient for talent $(\mathrm{p}=0.05)$ and statistically significant negative coefficient $(\mathrm{p}=0.01)$ for median house value. This talent measure is not equivalent to the creative class measure incorporated into the creativity index, appears to be affected by cost-of-living (using median house value as a surrogate measure for costof-living), and is based on 1990 data.

The individual underlying components of the creativity index are not provided in The Rise of the Creative Class. However, much of the source data are available from secondary sources enabling reconstruction of the components. The following summarizes my reconstruction methodology, where I deviated from Florida (2002), and why.

\subsubsection{Reconstruction of Creativity Index Components}

The Creativity Index is provided for 258 Metropolitan Statistical Areas (MSA) and 18 Consolidated Metropolitan Statistical Areas (CMSA) (Florida 2002). My analyses involving the creativity index utilize comparable geographic units. I am skeptical, however, that economic development efforts are coordinated, or for that matter consistent, across CMSAs (See for instance American Babylon (Self 2003)) which discusses the economic competition between Oakland and San Francisco, both of which are in the San Francisco CMSA). Therefore, I also analyze economic growth using Primary Metropolitan Statistical Areas (PMSA) where possible. There may be inconsistent policies even at this level, but I did not undertake a deeper geographic drilldown for this analysis.

In the 2000 Census, excluding Puerto Rico, there were 258 MSAs, 73 PMSAs, 18 CMSAs and 12 New England County Metropolitan Areas (NECMA). Due to various 
data availability issues, my dataset includes the 258 MSAs and 18 CMSAs but only 58 PMSAs, and 1 NECMA. The reasons for this particular combination of areas are as follows:

\subsubsection{Data Sources for the Reconstruction}

\subsection{The Occupational Employment Survey}

The Occupational Employment Survey (OES) data from the U. S. Bureau of Labor Statistics are provided at the MSA/PMSA level. U. S. Bureau of Labor Statistics. 2000 Metropolitan Area Cross-industry Estimates, downloadable from http://www.bls.gov/oes/oes_dl.htm was used develop super creative core, creative professional, working class and service class percentages for each MSA by dividing classification by total employment for an MSA/PMSA. PMSA data were aggregated to form CMSA data. The percent creative class is the percent super creative core plus the percent creative professionals. There was, however, one issue with these data. The OES reports employment for Sales and Related Occupations (SRO). Florida includes only high end sales in the creative class. The occupational subclassifications of SRO that constitute "high end" are not straightforward. Using data at the national level, I assigned SRO occupational subclassifications that exceeded the national annual mean salary to the creative class and those below to the service class. Secondly, I was interested in the annual mean salary by class. To develop this I averaged the means of the occupations in the class. The simplest example is the working class. It includes four occupational classifications (construction, production, installation, and transportation), and each has an annual mean earnings figure. I averaged these four means to calculate the annual mean earnings for the class. I used the same process for the other classes. The creative class 
includes the super creative core occupations and the creative professional occupations including the subclassifications of the Sales and Related Occupations that were assigned to the creative class. The service class includes service class occupations and the sub classifications of the Sales and Related Occupations that were assigned to the service class.

\subsection{Gross Metropolitan Product}

Gross Metropolitan Product data are available online from the U. S. Conference of Mayors at http://www.usmayors.org/metroeconomies/0703/metroecon_appendix_0703.pdf for 1993 through 2003 data. Revised data for 2001 through 2004 is available at http://www.usmayors.org/74thWinterMeeting/metroeconreport January2006.pdf and for 2002 to 2005 at http://www.usmayors.org/74thWinterMeeting/metroeconreport_January2007.pdf. GMP per capita in 2000 is the measure I used to operationalize economic strength and is the author's calculation based on GMP and population data from the Census 2000, Summary File 1, Table P1 Total Population. The growth in GMP from 2000 to 2004, and from 2000 to 2005 , were used to operationalize economic growth. The initial 2000 GMP data were consistent with the U.S. Census Bureau MSA definitions as of June 1999 and were provided at the MSA/PMSA level with the exception of Boston (only the Manchester-Nashua PMSA is reported separately) and New York (where New Haven, $\mathrm{CT}$ is reported separately, but not its underlying PMSAs). GMP percent change from 2000 to 2004 and from 2000 to 2005 are the author's calculations. In January 2006 Global Insights, Inc. provided the GMP data consistent with the U. S. Census Bureau 
MSA definitions as of December 2006. Two previously defined MSAs were redefined as micropolitan areas (Enid, OK and Jamestown, NY). No attempt was made to retrieve data for these two MSAs. Several other MSAs or PMSAs were absorbed into newly defined MSAs. For instance in the 1999 definitions the Hamilton, OH PMSA was in the Cincinnati, OH CMSA. Now the Cincinnati, OH MSA includes the counties in the former Hamilton PMSA and no separate MSA exists for Hamilton so no GMP data is available for Hamilton. The changes from 1999 were evaluated based on counties and resulted in several previous MSAs without GMP data for 2004 or 2005. As a result, the number of analyzed units changes from 2000 to 2004 and 2005.

\subsection{The Milken Tech Pole Index}

The Milken tech pole index results from multiplying the high-tech percentage of national real output for an area by the high-tech location quotient for that same area. Data are available on line from the Milken Institute: America's High Tech Economy. Milken Institute. Available at http://www.milkeninstitute.org/pdf/hightech metros.pdf. The data required to aggregate the PMSAs to CMSAs were unavailable. The percentage of national real output for PMSAs is additive. However, the CMSA location quotient requires recalculation using the underlying PMSA employment data and the rationale used by the Milken Institute for determining what constitutes high-tech employment. The specific tech pole measures for CMSAs used to develop the 2000 Creativity Index was graciously provided by Kevin Stolarick (Carnegie Melon University).

\subsection{Patents}

Patent information was obtained from the United States Patent Grants by State, County, and Metropolitan Area (Utility Patents, 1990 - 1999). April 2000. Office for 
Patent and Trademark Information. U.S. Patent and Trademark Office, Washington, DC. These data are used to compute patent growth for an MSA from 1990 to 1999. The data are available at the MSA/PMSA level with the exception of the New England area where NECMAs are used.

\subsection{Census 2000 Sources}

\subsection{Melting Pot Index}

Summary File 3, Table P22. Year of Entry for the Foreign Born Population. This data allows the development of a location quotient for the foreign born population in a region referred to as the melting pot index.

\subsection{Gay Index}

Number of households with an unmarried male, or female householder with a same-sex partner: Summary File 4, Table PCT22. Households By Presence Of Nonrelatives. These data are used to form a location quotient for the percentage of households with an unmarried male, or female householder with a same-sex partner. This measure is referred to as the Gay and Lesbian Index. It undercounts the total gay and lesbian population but is the measure used by Florida in the development of the creativity index.

\subsection{Bohemian Index}

The Bohemian Index represents the relative concentration of individuals in artistic occupations. I developed the Bohemian Index from the Bureau of Labor Statistics Occupation Employment Survey by determining the percentage of employment in occupational sub-classifications that matched the labels provided by Florida (Florida 
2002, Appendix A, p. 333) for the Nation and for each MSA. The Bohemian Index is a location quotient derived from these percentages.

\subsection{Tolerance Index}

I deviated from the Florida variables in the construction of the Tolerance Index. According to Florida (2002), he developed a segregation index for all minority groups by evaluating the census tracts in each MSA/CMSA. Notes to the Census 2000 report Housing Patterns - Appendix B http://www.census.gov/hhes/www/housing/housing_patterns/gettable_msa.html cites literature indicating that the GINI index is a better measure of segregation than the segregation index. GINI indices were obtained from the web site. GINI indices were averaged across all races for each MSA/CMSA. This "average" segregation number is then subtracted from one to determine the Tolerance Index.

\subsection{GMP per capita}

GMP data were divided by total population for the year 2000 from the Total Population by MSA, CMSA, PMSA: Summary File 1, Table P1- Total Population.

\subsection{Educational Attainment}

Data from Summary File 3, Table P37. Sex by Educational Attainment for the Population 25+ Years were used to calculate the percentage of the population over 25 in the United States with a bachelor's degree or higher. A similar percentage was developed for each MSA and CMSA. The MSA/CMSA percentage divided by the National percentage provides a location quotient for educational attainment. 


\subsubsection{New Haven and Boston Special Considerations}

For most of the NECMAs, there is a corresponding MSA (although the specific geographic areas and populations differ). In these cases I combined the NECMA patent data and other MSA data into single dataset records for the MSAs—-for instance, the dataset record for the Bangor, Maine MSA includes patent data for the Bangor NECMA and all other data for the Bangor MSA.

The New Haven, CT and Boston, MA areas presented special difficulties. In addition to the patent and GMP issues above, the Milken Tech Pole index is provided for MSA/PMSAs with the exception of Boston, MA. (this appears to be provided for the Boston CMSA based on population). As a result, my dataset includes only one record for the Boston CMSA with patent data from the NECMA, the sum of the GMP data from Boston and Manchester-Nashua, and all other PMSA data aggregated to the CMSA level or taken directly from census data at the CMSA level. This eliminates 10 PMSAs.

GMP data are provided for the PMSAs in the New York CMSA with the exception of the Bridgeport, Danbury, New-Haven, Stamford-Norwalk and Waterbury, CT PMSAs. There is a single GMP entry for New Haven. These same areas are also involved in the New Haven, CT NECMA. My dataset includes one record for the New Haven NECMA which includes the patent data for the NECMA, the GMP for New Haven and all other data aggregated from the five PMSAs. This replaces 5 PMSAs with one NECMA. This single record was then aggregated with the other PMSAs in the New York CMSA to form the record for the New York CMSA.

\subsubsection{Comparison of Reconstruction to Original Data}

Florida (2002, Appendix B) reports the class percentages used in the construction 
of the creativity index. However, I used the percentages I developed from the OES data, in part to replicate Florida's results, to specify the method for separating the SRO classification into creative and service classes and, to develop percentages for the PMSAs. Table 33 shows that my results for MSAs and CMSAs are quite close to Florida's.

Table 33: Descriptive Statistics for the Creative Class Percentages

\begin{tabular}{|l|l|l|l|l|l|l|l|l|l|l|}
\hline & $\mathrm{N}$ & Range & Min & Max & Mean & $\begin{array}{l}\text { Std. } \\
\text { Error }\end{array}$ & $\begin{array}{l}\text { Std. } \\
\text { Dev. }\end{array}$ & $\begin{array}{l}\text { Vari- } \\
\text { ance }\end{array}$ & $\begin{array}{l}\text { Skew- } \\
\text { ness } \\
\text { t Stat }\end{array}$ & $\begin{array}{l}\text { Kurtosis } \\
\text { t Stat }\end{array}$ \\
\hline $\begin{array}{l}\text { percent } \\
\text { creative } \\
\text { class MSAs } \\
\& \text { CMSAs }\end{array}$ & 276 & 0.227 & 0.170 & 0.397 & 0.279 & 0.002 & 0.041 & 0.002 & 1.256 & 1.275 \\
\hline $\begin{array}{l}\text { Florida's } \\
\text { percentages } \\
\text { of the } \\
\begin{array}{l}\text { Creative } \\
\text { Class }\end{array}\end{array}$ & 276 & 0.227 & 0.172 & 0.398 & 0.277 & 0.002 & 0.042 & 0.002 & 2.560 & 0.960 \\
\hline $\begin{array}{l}\text { percent } \\
\text { creative } \\
\text { class MSAs } \\
\& \text { PMSAs }\end{array}$ & 318 & 0.258 & 0.170 & 0.428 & 0.282 & 0.002 & 0.043 & 0.002 & 2.791 & 2.621 \\
\hline
\end{tabular}

Source: Author's percentages developed from U. S. Bureau of Labor Statistics 2000 Occupational Employment Survey. Florida's percentages from Florida (2002), Appendix B 


\subsection{Sources for Other Variables in This Dissertation}

\subsubsection{Climate Variables}

Data and definitions downloaded were from http://diegopuga.org/data/sprawl/ .

Pronouns in the following three definitions refer to the original researchers (Burchfield, Overman, Puga \& Turner 2006).

cooling_dd: Mean cooling degree-days. Our weather variables are calculated from the climatic normals for individual weather stations 1961-1990 contained in the Climate Atlas of the United States. Cooling degrees on a given day are zero if the average temperature is below $65^{\circ} \mathrm{F}$ (about $18^{\circ} \mathrm{C}$ ) and the degrees by which the average temperature exceeds $65^{\circ} \mathrm{F}$ otherwise. Mean annual cooling degree days are computed by summing cooling degrees over all days in a year. We computed metropolitan area mean cooling degree days by averaging climatic normals over all reporting weather stations in each metropolitan area. For the four metropolitan areas that did not contain a reporting station, we averaged data from weather stations within 30 kilometers of the metropolitan area.

Heating_dd: Mean heating degree-days. Mean annual heating degree days are similarly calculated by summing degrees below $65^{\circ} \mathrm{F}$ over all days in a year. Again, we computed metropolitan area mean heating degree days by averaging climatic normals over all reporting weather stations in each metropolitan area. For the four metropolitan areas that did not contain a reporting station, we averaged data from weather stations within 30 kilometers of the metropolitan area.

Ruggedness_msa: Terrain ruggedness index in MSA $(\mathbf{m}$.$) . We use the$ same the national elevation grid providing the elevation in meters of points 90 meters apart as for $\square$ levate_range_fringe. Using these data, we calculate the terrain ruggedness index originally devised by Riley, DeGloria and Elliot (1999) to quantify topographic heterogeneity that can act either as concealment for prey or stalking cover for predators in wildlife habitats. Let $e_{r, c}$ denote elevation at the point located in row $r$ and column $c$ of a grid of elevation points. Then the terrain ruggedness index of Riley, DeGloria and Elliot (1999) at that point is calculated as $\sum_{i=r-1}^{i=r+1} \sum_{j=c-1}{ }^{j=c+1}\left(e_{i, j}-e_{r, c}\right)^{2}$. The variable used in the regression is the average terrain ruggedness index of the urban fringe in each metropolitan area. The ruggedness_msa measure is the same as ruggedness_fringe, but for the entire metropolitan area. 


\subsubsection{Community Culture Variables}

7.2.2.1. Poverty: Summary File 3, Table P87. Poverty Status In 1999 By Age [17] Universe: Population for whom poverty status is determined.

7.2.2.2. Crime: Index of Crime by Metropolitan Statistical Area, 2002. Crimes per 100,000 Population. http://www.fbi.gov/ucr/cius 02/html/web/offreported/02table06WXYZ.html and calculation by author. The 2002 data were used as representative of the period under study.

7.2.2.3. Homelessness: Homeless population: Emergency and Transitional Shelter Population: 2000. Census 2000 Special Reports. Issued October 2001. Poverty: http://factfinder.census.gov/servlet.

7.2.2.4. Home ownership for the year 2000: State and Metropolitan Area Data Book2006, Table B-7 available at http://www.census.gov/compendia/smadb/SMADBmetro.html

7.2.2.5. Voting participation: U. S. 2000 Presidential Election Results by County available from http://spa.american.edu/ccps/pages.php?ID=12

7.2.2.6. Young single migration: http://www.census.gov/population/cen2000/phc$\underline{\mathrm{t} 34 / \mathrm{tab} 02 . \mathrm{xls}}$

7.2.2.7. Association index: This index was calculated using Census 2000 Table P50. Sex By Occupation For The Employed Civilian Population 16 Years And Over and the formula for the association index (Charles \& Grusky 2004, p. 42) as follows:

$$
A=\sqrt{1 / J \times \sum_{j=1}^{J}\left(\ln \left(F_{j} / M_{j}\right)-\left[1 / J \times \sum_{j=1}^{J} \ln \left(F_{j} / M_{j}\right)\right]\right)^{2}}
$$

Where $\mathrm{J}=$ the total occupations measured, $\mathrm{F}_{\mathrm{j}}=$ Female employment in occupation $\mathrm{j}$, and $\mathrm{M}_{\mathrm{j}}=$ Male employment in occupation $\mathrm{j}$.

\subsection{Correlation Matrices for the Linear Regressions in Research Question 2}

These matrices are shown in tables 34 and 35.

\subsubsection{Data Checks for Regressions in Research Question 2}

All variables were tested for the assumption of normality. Several were positively skewed. The skewed variables were logarithmically transformed (Tabachnick \& Fidell 2001). 
I did not pre-screen the data for outliers. Rather, I used the casewise diagnostic function in SPSS using a threshold of three standard deviations and eliminated the outliers from consideration. The number of outliers in any given regression are discussed as findings are presented.

\subsubsection{Correlation Matrix for Context Variables}

This matrix is shown in Tables 38 through 40 . 


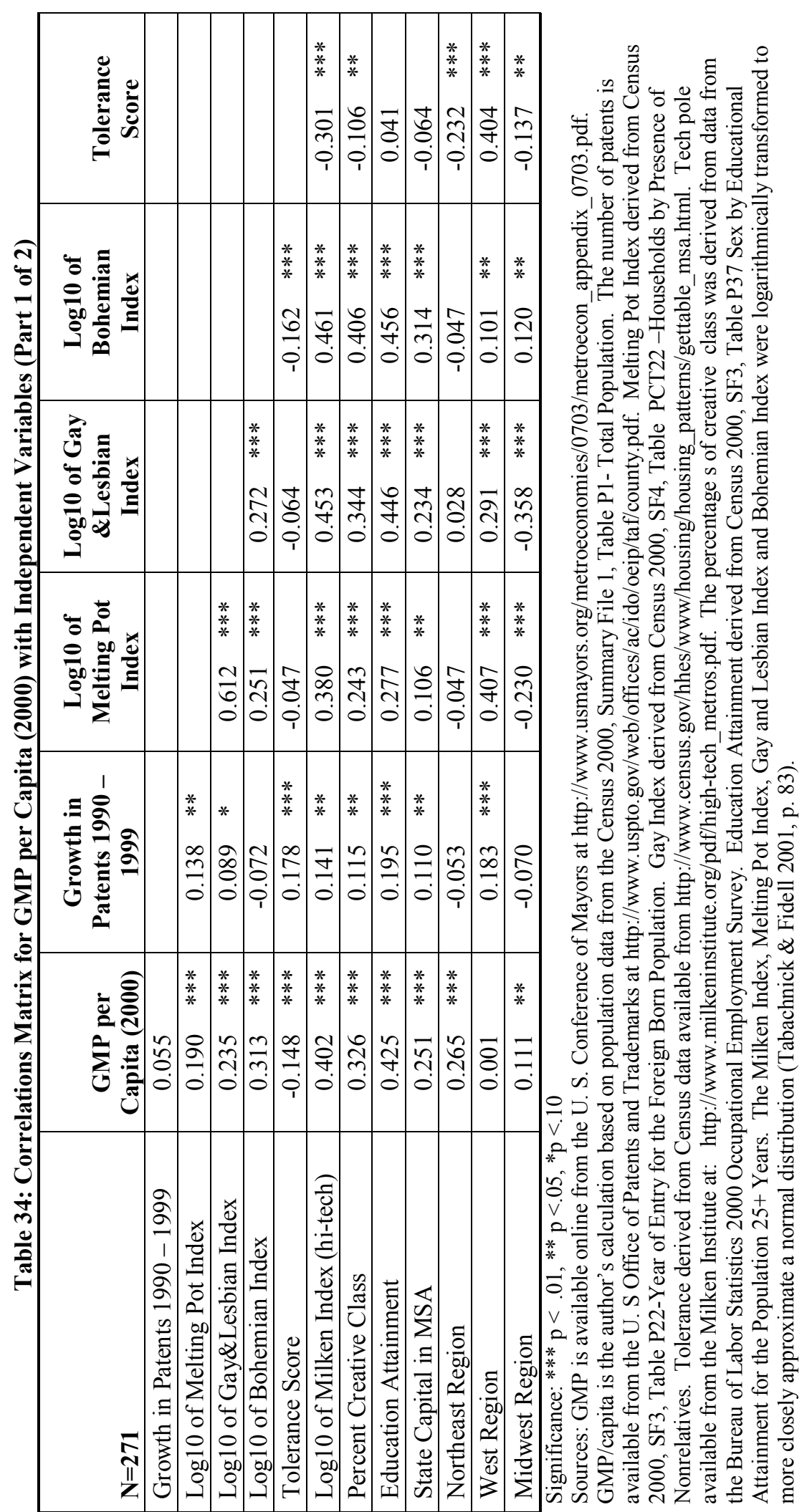




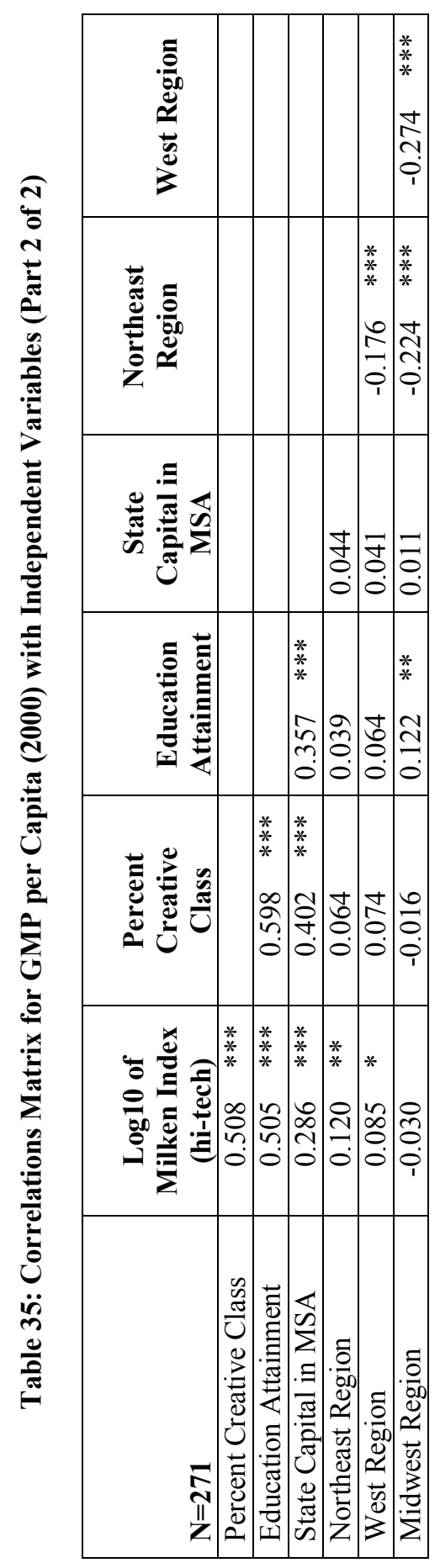




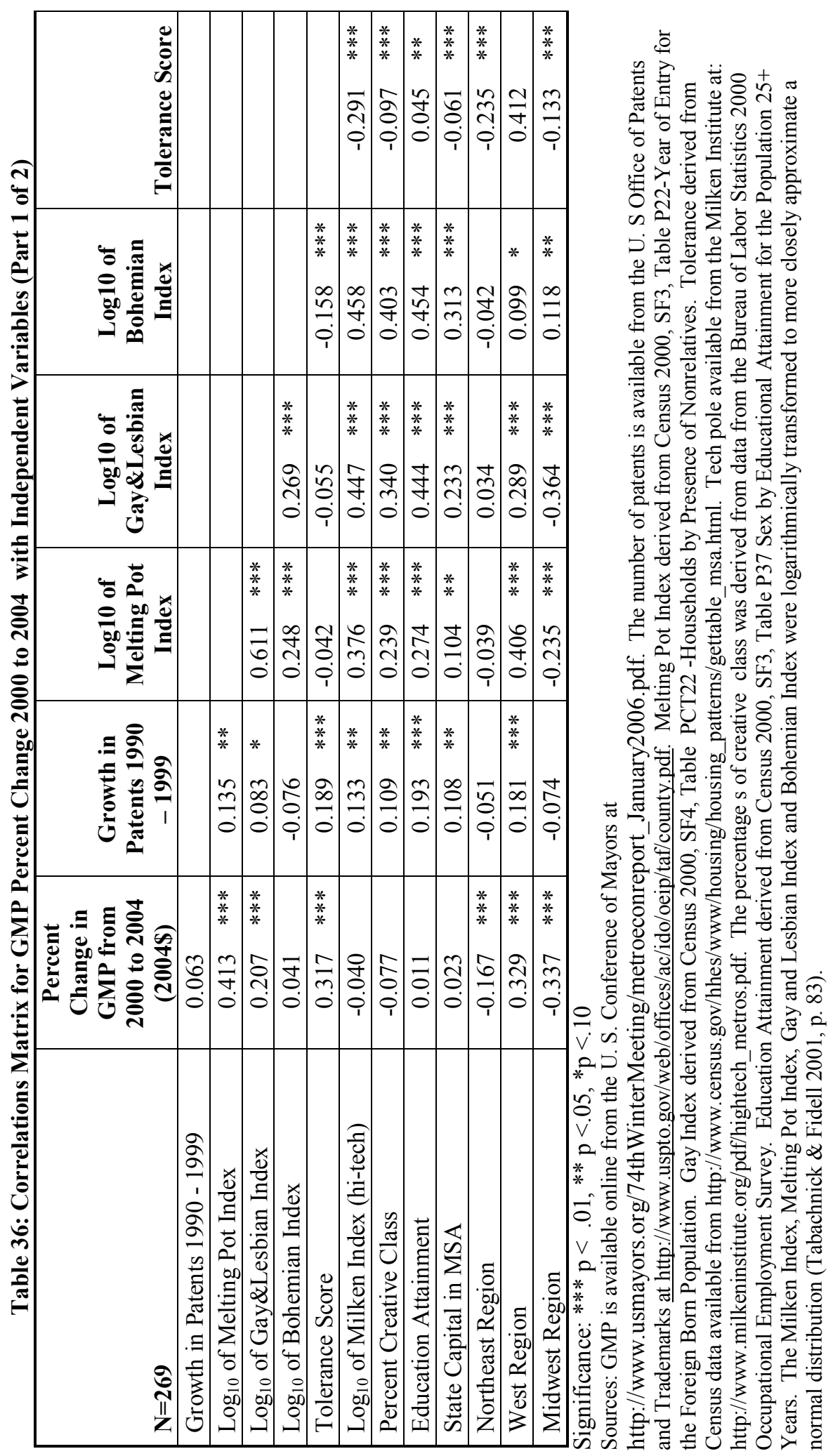




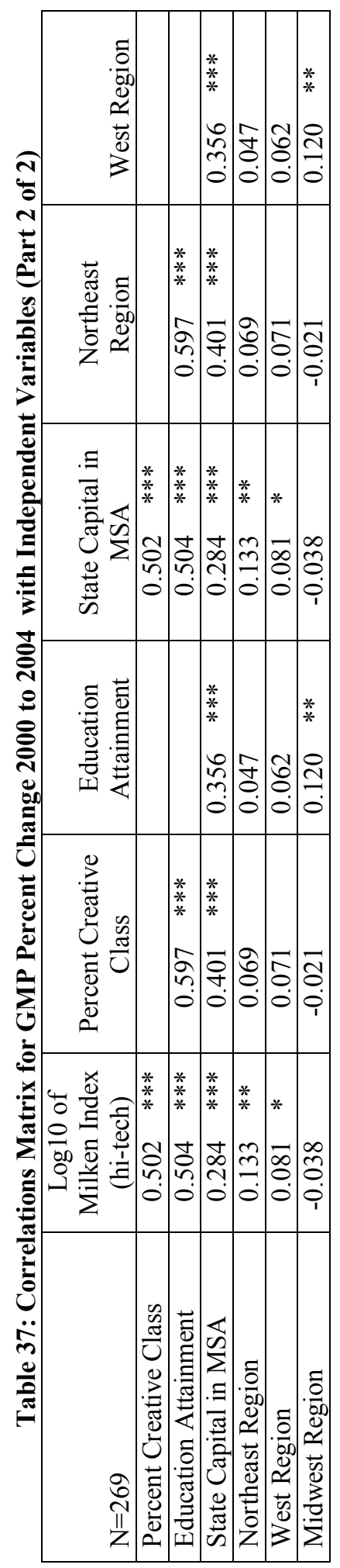




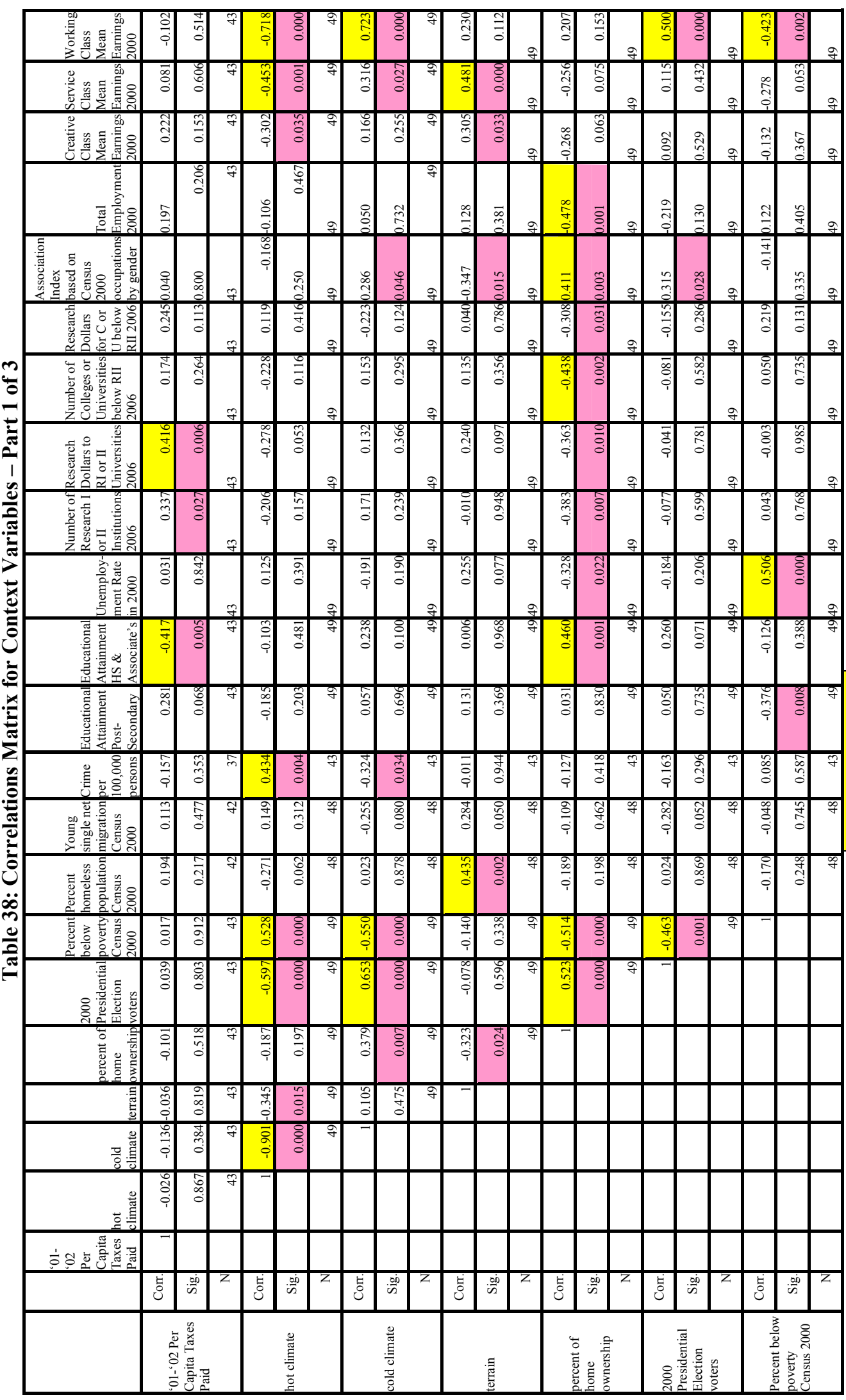




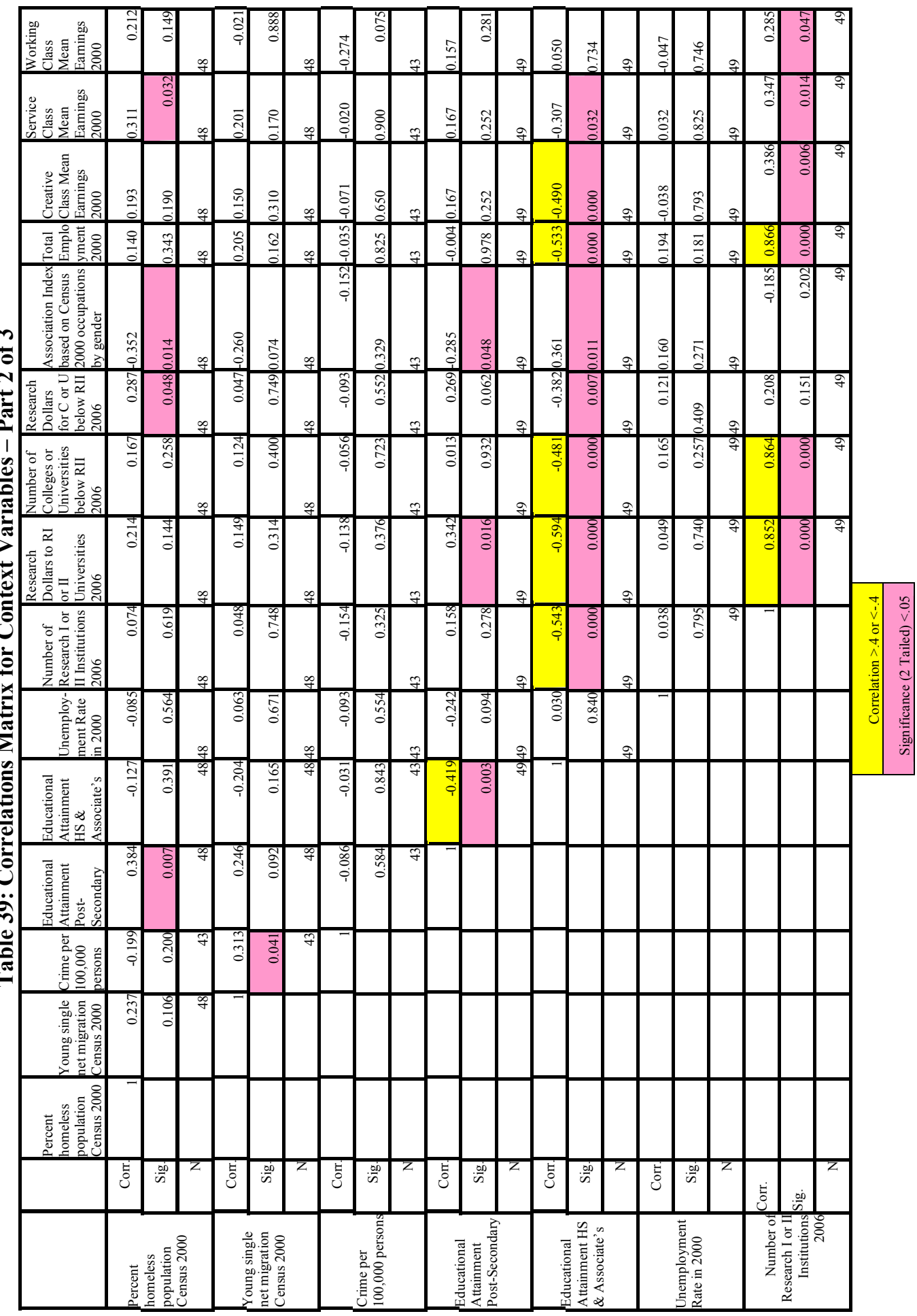




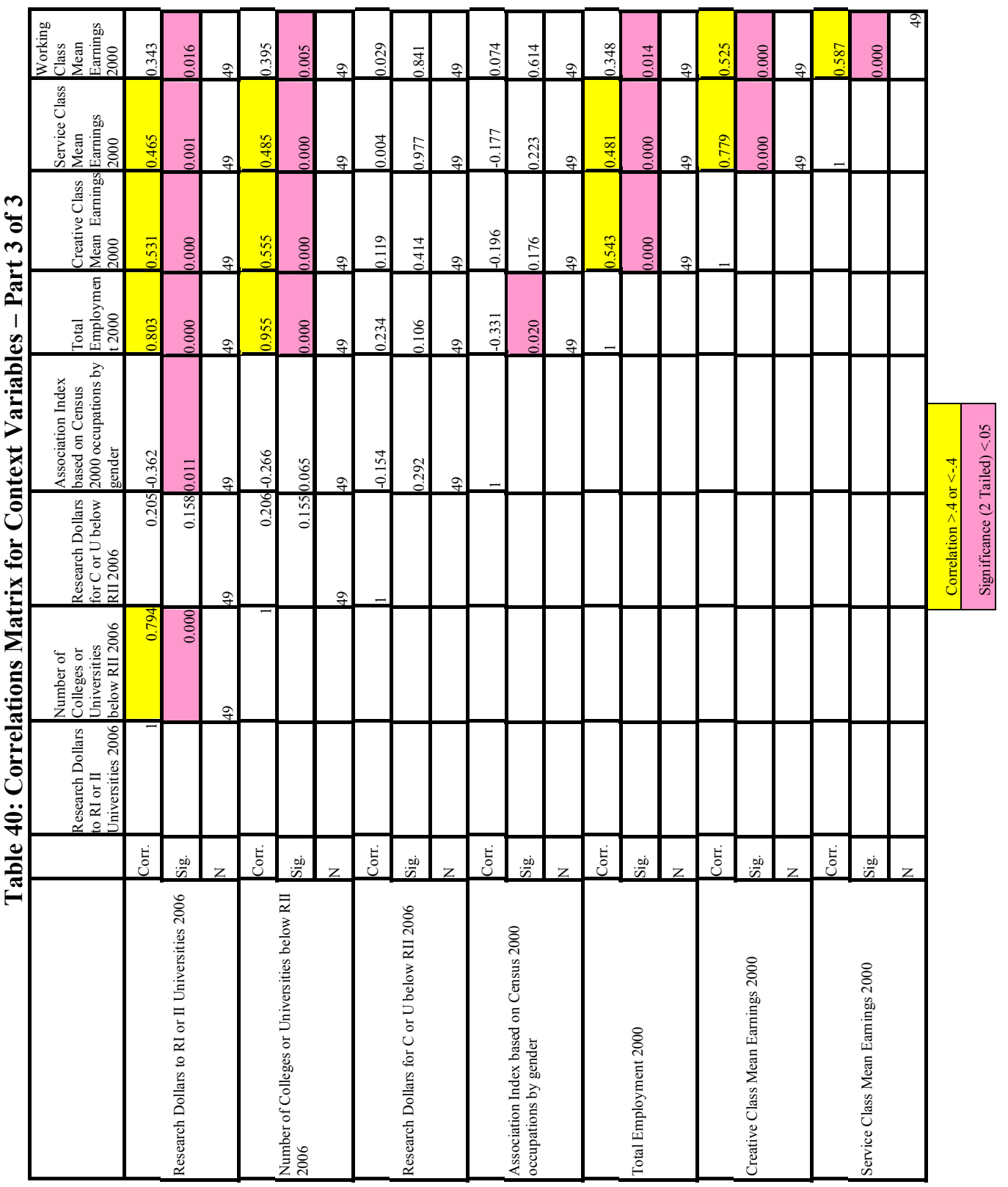

ले 


\subsubsection{Regression Results for Contextual Variables with Creativity Index Subcomponents}

Tables 41 and 42 show the output of SPSS for the regression analyses of relevant context variables and creativity index subcomponent variables as discussed in section 4.2.5.

Table 41: Regression Results for GMP per Capita in 2000 vs. Significant Context Variables and Creativity Index Tolerance Subcomponents

\begin{tabular}{|l|r|r|r|r|r|}
\hline & \multicolumn{1}{|l|}{ Unstandardized Coefficients } & \multicolumn{1}{c|}{$\begin{array}{l}\text { Soeff. } \\
\text { Cond }\end{array}$} & \multicolumn{1}{c|}{$\mathrm{t}$} & \multicolumn{1}{c|}{ Sig. } \\
\hline & \multicolumn{1}{|c|}{$\mathrm{B}$} & \multicolumn{1}{c|}{ Std. Error } & \multicolumn{1}{c|}{ Beta } & & \\
\hline (Constant) & $26,962.299$ & $25,849.793$ & & 1.043 & 0.304 \\
\hline Hot climate & -2.293 & 1.755 & -0.461 & -1.306 & 0.199 \\
\hline Cold climate & -0.639 & 0.905 & -0.272 & -0.706 & 0.485 \\
\hline Percent of home ownership & 444.973 & 201.095 & 0.410 & 2.213 & 0.033 \\
\hline Educational Attainment HS \& Associate's & $-16,038.989$ & $11,021.825$ & -0.246 & -1.455 & 0.154 \\
\hline $\begin{array}{l}\text { Association Index based on Census 2000 } \\
\text { occupations by gender }\end{array}$ & $-3,928.306$ & $3,413.072$ & -0.211 & -1.151 & 0.257 \\
\hline Working Class Mean 2000 & 0.558 & 0.380 & 0.304 & 1.470 & 0.150 \\
\hline Melting Pot Index & 500.934 & $1,705.722$ & 0.067 & 0.294 & 0.771 \\
\hline Gay Index & 745.597 & $4,385.262$ & 0.039 & 0.170 & 0.866 \\
\hline Tolerance Index & $7,775.564$ & $12,222.886$ & 0.095 & 0.636 & 0.528 \\
\hline Bohemian Index & 50.825 & $1,582.783$ & 0.005 & 0.032 & 0.975 \\
\hline
\end{tabular}

a Dependent Variable: GMP per capita for 2000

Table 42: Regression Results for GMP Percent Change from 2000 to 2004 vs. Significant Context Variables and Creativity Index Tolerance Subcomponents

\begin{tabular}{|c|c|c|c|c|c|}
\hline & \multicolumn{2}{|c|}{ Unstandardized Coefficients } & \multirow{2}{*}{$\begin{array}{c}\text { Stand. } \\
\text { Coeff. } \\
\text { Beta }\end{array}$} & \multirow[t]{2}{*}{$\mathrm{t}$} & \multirow[t]{2}{*}{ Sig. } \\
\hline & $\mathrm{B}$ & Std. Error & & & \\
\hline (Constant) & 0.098 & 0.067 & & 1.462 & 0.154 \\
\hline 2001-2002 Taxes Paid & 0.000 & 0.000 & 0.341 & 1.620 & 0.116 \\
\hline Hot climate & 0.000 & 0.000 & 0.211 & 1.177 & 0.248 \\
\hline Percent homeless population Census 2000 & 0.115 & 0.157 & 0.143 & 0.731 & 0.470 \\
\hline $\begin{array}{l}\text { Number of Colleges or Universities below RII } \\
2003 / 4\end{array}$ & 0.002 & 0.001 & 0.684 & 1.762 & 0.088 \\
\hline Research Dollars for C or U below RII 2004 & 0.000 & 0.000 & -0.264 & -1.718 & 0.096 \\
\hline Total Employment 2000 & 0.000 & 0.000 & -1.502 & -3.339 & 0.002 \\
\hline Melting Pot Index & 0.059 & 0.020 & 0.724 & 2.889 & 0.007 \\
\hline Gay Index & -0.019 & 0.049 & -0.091 & -0.397 & 0.695 \\
\hline Tolerance Index & -0.075 & 0.155 & -0.075 & -0.484 & 0.632 \\
\hline Bohemian Index & 0.031 & 0.019 & 0.260 & 1.692 & 0.101 \\
\hline
\end{tabular}

a Dependent Variable: GMP percent change 2000 to 2004 


\subsection{Occupational Employment Data}

Bureau of Labor Statistics Occupational Employment Survey data were used to construct location quotients for occupations in the management and healthcare practitioner occupations. The results are shown in Tables 43 and 44 respectively.

Table 43: Location Quotients for Management Occupations for Four MSAs

\begin{tabular}{|l|l|l|l|l|}
\hline & Indianapolis & Louisville & Nashville & $\begin{array}{l}\text { Raleigh- } \\
\text { Durham }\end{array}$ \\
\hline Chief Executives & 0.83 & 1.60 & 1.35 & 0.19 \\
\hline General and Operations Managers & 0.77 & 0.93 & 1.06 & 0.98 \\
\hline Legislators & 0.83 & 0.34 & 0.67 & 0.00 \\
\hline Advertising and Promotions Managers & 0.73 & 0.93 & 1.19 & 0.83 \\
\hline Marketing Managers & 0.88 & 1.05 & 0.74 & 1.06 \\
\hline Sales Managers & 1.06 & 0.86 & 0.99 & 0.92 \\
\hline Public Relations Managers & 1.37 & 1.09 & 0.92 & 1.05 \\
\hline Administrative Services Managers & 0.79 & 0.72 & 1.46 & 0.42 \\
\hline Computer and Information Systems Managers & 1.13 & 0.81 & 0.90 & 1.42 \\
\hline Financial Managers & 0.77 & 1.06 & 1.08 & 0.96 \\
\hline Human Resources Managers & 1.01 & 1.19 & 1.10 & 0.82 \\
\hline Industrial Production Managers & 1.06 & 1.25 & 0.58 & 0.81 \\
\hline Purchasing Managers & 0.91 & 1.00 & 1.22 & 1.14 \\
\hline Transportation, Storage, and Distribution & 1.47 & 1.31 & 0.74 & 0.49 \\
\hline Managers & 1.37 & 0.86 & 0.97 & 1.62 \\
\hline Construction Managers & & & & \\
\hline Education Administrators, Preschool and Child \\
Care Center/Program & 0.72 & 0.80 & 1.09 & 1.33 \\
\hline Education Administrators, Elementary and & & 0.85 & \\
\hline Secondary School & 0.85 & 0.00 & 0.55 & 1.27 \\
\hline Education Administrators, Postsecondary & 0.00 & 0.46 & 0.59 & 1.05 \\
\hline Engineering Managers & 0.82 & 0.52 & 0.47 & 1.31 \\
\hline Food Service Managers & 1.02 & 1.60 & 0.95 & 1.03 \\
\hline Funeral Directors & 0.00 & 0.91 & 0.68 & 0.52 \\
\hline Gaming Managers & 0.00 & 0.00 & 0.00 & 0.00 \\
\hline Lodging Managers & 0.85 & 0.60 & 0.68 & 1.19 \\
\hline Medical and Health Services Managers & 1.24 & 1.12 & 0.81 & 0.76 \\
\hline Natural Sciences Managers & 0.00 & 0.27 & 0.15 & 3.19 \\
\hline Postmasters and Mail Superintendents & 0.39 & 0.78 & 0.36 & 0.00 \\
\hline Property, Real Estate, and Community & 0.91 & 0.90 & 0.92 & 0.37 \\
\hline Association Managers & 0.68 & 0.74 & 0.95 & 0.98 \\
\hline Social and Community Service Managers & & & & \\
\hline & & & & \\
\hline
\end{tabular}


Table 44: Location Quotients for Healthcare Practitioner Occupations in Four MSAs

\begin{tabular}{|c|c|c|c|c|}
\hline & Indianapolis & Louisville & Nashville & \begin{tabular}{|l} 
Raleigh- \\
Durham \\
\end{tabular} \\
\hline Chiropractors & 0.00 & 0.00 & 0.00 & 0.00 \\
\hline Dentists & 1.04 & 0.00 & & 0.95 \\
\hline Dietitians and Nutritionists & 1.22 & 1.45 & 0.83 & 1.02 \\
\hline Optometrists & 2.06 & 1.41 & 0.32 & 1.11 \\
\hline Pharmacists & 1.06 & 0.94 & 0.88 & 1.00 \\
\hline Anesthesiologists & 0.00 & 0.60 & 0.00 & 0.00 \\
\hline Family and General Practitioners & 0.89 & 0.64 & 0.36 & 1.11 \\
\hline Internists, General & 0.00 & 0.95 & 0.65 & 0.40 \\
\hline Obstetricians and Gynecologists & 0.62 & 1.07 & 0.00 & 0.00 \\
\hline Pediatricians, General & 0.00 & 1.25 & 0.00 & 0.00 \\
\hline Psychiatrists & 0.62 & 0.49 & 0.00 & 0.00 \\
\hline Surgeons & 0.83 & 1.20 & 0.00 & 0.00 \\
\hline Physician Assistants & 0.42 & 0.25 & 0.72 & 1.53 \\
\hline Podiatrists & 0.00 & 0.00 & 0.00 & 0.00 \\
\hline Registered Nurses & 1.01 & 1.09 & 1.11 & 1.31 \\
\hline Audiologists & 0.00 & 0.00 & 0.00 & 0.71 \\
\hline Occupational Therapists & 1.43 & 1.18 & 0.73 & 1.15 \\
\hline Physical Therapists & 1.15 & 0.99 & 0.91 & 1.21 \\
\hline Radiation Therapists & 1.36 & 0.98 & 0.88 & 0.00 \\
\hline Recreational Therapists & 0.58 & 5.16 & 0.59 & 0.56 \\
\hline Respiratory Therapists & 1.61 & 0.00 & 1.12 & 0.50 \\
\hline Speech-Language Pathologists & 0.89 & 1.12 & 0.89 & 1.13 \\
\hline Veterinarians & 0.89 & 0.97 & 0.79 & 1.98 \\
\hline Medical and Clinical Laboratory Technologists & 1.25 & 1.04 & 0.96 & 0.60 \\
\hline Medical and Clinical Laboratory Technicians & 1.41 & 0.58 & 1.65 & 1.05 \\
\hline Dental Hygienists & 1.18 & 0.72 & 0.60 & 1.05 \\
\hline Cardiovascular Technologists and Technicians & 0.70 & 1.92 & 0.54 & 0.75 \\
\hline Diagnostic Medical Sonographers & 0.81 & 0.81 & 0.85 & 1.09 \\
\hline Nuclear Medicine Technologists & 1.01 & 1.15 & 1.23 & 0.00 \\
\hline Radiologic Technologists and Technicians & 0.95 & 1.21 & 1.29 & 1.02 \\
\hline Emergency Medical Technicians and Paramedics & 0.80 & 0.90 & 0.90 & 0.92 \\
\hline Dietetic Technicians & 1.31 & 0.82 & 2.06 & 0.55 \\
\hline Pharmacy Technicians & 1.16 & 1.12 & 1.11 & 0.98 \\
\hline Psychiatric Technicians & 0.00 & 0.00 & 0.00 & 0.00 \\
\hline Respiratory Therapy Technicians & 1.26 & 1.39 & 0.84 & 0.00 \\
\hline Surgical Technologists & 1.12 & 1.24 & 1.79 & 0.46 \\
\hline Veterinary Technologists and Technicians & 0.88 & 0.81 & 0.81 & 1.44 \\
\hline Licensed Practical and Licensed Vocational Nurses & 0.99 & 1.10 & 1.33 & 0.59 \\
\hline Medical Records and Health Information Technicians & 0.92 & 1.06 & 0.99 & 0.47 \\
\hline Opticians, Dispensing & 1.23 & 0.74 & 0.72 & 0.68 \\
\hline Orthotists and Prosthetists & 0.00 & 0.00 & 0.00 & 0.00 \\
\hline Occupational Health and Safety Specialists and Technicians & 1.14 & 0.58 & 0.39 & 1.33 \\
\hline Athletic Trainers & 1.26 & 0.78 & 0.92 & 0.00 \\
\hline
\end{tabular}




\section{REFERENCES}

\subsection{References}

Acs, Z. J. (2002). Innovation and the Growth of Cities. Northampton, MA: Edward Elgar Publishing, Ltd.

Amabile, T. M. (1983). The Social Psychology of Creativity. New York: Springer-Verlag.

Banfield, E. C. (1974). The Unheavenly City Revisited. Prospect Heights, IL: Waveland Press, Inc.

Blakely, E. J. \& Bradshaw, T. K. (2002). Planning Local Economic Development: Theory and Practice ( $3^{\text {rd }}$ ed.). Thousand Oaks, Ca: Sage Publications.

Bowles, J. \& Colton, C. (2007). A World of Opportunity. Report from the Center for an Urban Future. http://www.nycfuture.org/images_pdfs/pdfs/IE-final.pdf

Brookings Institution Center on Urban \& Metropolitan Policy. (2002). Beyond Merger: A Competitive Vision for the Regional City of Louisville. Washington, DC: Brookings Institution.

Burchfield, M., Overman, H. G., Puga, D., \& Turner, M. A. (2006). Causes Of Sprawl: A Portrait From Space. Quarterly Journal of Economics. Vol. 121, No. 2, pp. 587-633.

Charles, M. \& Grusky, D. B. (2004). Occupational Ghettos: the Worldwide Segregation of Men and Women. Stanford, CA: Stanford University Press.

Clark, T. N. (ed.). (1994). Urban Innovation: Creative Strategies for Turbulent Times.

Thousand Oaks, CA: Sage Publications, Inc.

Clark, T. N. (2004). Urban Amenities: Lakes, Opera, and Juice Bars: Do they Drive Development? In Clark, T. N. (ed.) The City as Entertainment Machine. Boston: Elsevier.

Coomes, P. \& Kornstein, B. (2004). Kentucky's Economic Competitiveness

A Call for Modernization of the State's Fiscal Policies. Research Report for the chambers of commerce of Northern Kentucky, Lexington and Louisville. December.

Creative Cities Report. (2005). Available online at http://www.greaterlouisvilleproject.org/2005report/intro.htm 
Crouch, R. (2004). Rules for a New Demographic Ballgame. Museum News. May/June, pp. 43-45 and 64-66.

Elazar. D. J. (1998). Political Science, Geography, and the Spatial Dimension of Politics. Conference Paper for the Conference on Geopolitics and Globalization in a Post-Modern World, 25-30 January 1998, Haifa University, Haifa and Ben-Gurion University, Beersheva, Israel

Fagan, K. (2003). Shame of the City. San Francisco Chronicle. Five part series on homelessness in San Francisco. http://www.sfgate.com/cgibin/article.cgi?f=/c/a/2003/12/01/MNGJ43BL3O6.DTL

Fisher, P. S. \& Peters, A. H. (1998). Industrial Incentives: Competition Among American States and Cities. Kalamazoo, MI: W.E. Upjohn Institute for Employment Research.

Fitzgerald, J. \& Leigh, N. G. (2002). Economic Revitalization: Cases and Strategies for City and Suburb. Thousand Oaks, CA: Sage Publications.

Florida, R. (2002a). (hardcover ed.) The Rise of the Creative Class. New York: Basic Books, A Member of the Perseus Books Group

Florida, R. (2002b). (softcover ed.) The Rise of the Creative Class. New York: Basic Books, A Member of the Perseus Books Group.

Florida, R. (2004). Response to Edward Glaeser's review of The Rise of the Creative Class. Found on line at: http//www.creativeclass.org/acrobat/ResponsetoGlaeser.pdf. Accessed May 1, 2006

Florida, R. (2005a). Cities and the Creative Class. New York: Routledge.

Florida, R. (2005b). The Flight of the Creative Class. New York: HarperCollins Publishers.

Florida, R. (2005c). Response to the [Review of the book Cities and the Creative Class]. Journal of the American Planning Association. Vol. 71, No. 2, pp 208-220.

Gates, G. J. \& Ost, J. (2004). The Gay and Lesbian Atlas. Washington, DC: Urban Institute Press.

Glaeser, E. (2004). Review of Richard Florida's The Rise of the Creative Class. Found on line at www.creative cities.org/acrobat/GlaeserReview.pdf. Accessed on May 1, 2006

Hall, P. (1998). Cities in Civilization. New York: Pantheon Books.

Hall, P. (2000). Creative Cities and Economic Development. Urban Studies. Vol. 37, No. 4, pp. 639-649.

Howkins, J. (2001). The Creative Economy: How People Make Money from Ideas. New York: The Penguin Press. 
Inglehart, R. (1990). Culture Shift in Advanced Industrial Society. Princeton, NJ: Princeton University Press.

Inglehart, R. (1997). Modernization and Postmodernization: Cultural, Economic, and Political Change in 43 Societies. Princeton, NJ: Princeton University Press.

International City/County Management Association. (2005). Economic development Survey. Available on line at http://www.icma.org/upload/bc/attach/\{34A39D05-637E-4BA6-9D9FBB9EEDD48AB7\} ed2004web.pdf

Jacobs, J. (1961). The Death and Life of Great American Cities. New York: Vintage Books.

Jacobs, J. (1984). Cities and the Wealth of Nations. New York: Vintage Books.

Jordan, M. (2007). Boomers' Good Life Tied to Better Life for Immigrants. Wall Street Journal. Vol. CCXLIX, No. 106, May 7, p. A2.

Kaufman, J. C. \& Baer, J. (eds.). (2005) Creativity Across Domains: Faces of the Muse. Mahwah, NJ: Lawrence Erlbaum Associates, Publishers.

Kotkin, J. \& Seigel, F. (2004). Paths to Prosperity. American Enterprise. July/August, 32-5

Koven, S. G. \& Lyons, T. S. (2003) Economic Development: Strategies for State and Local Practice. International City/County Management Association (ICMA).

Landry, C. (2000). The Creative City: A Toolkit for Urban Innovators. London: Earthscan.

Lang, R.. (2005). From the Review Editors. [Review of the book Cities and the Creative Class]. Journal of the American Planning Association. Vol. 71, No. 2, pp 203-217.

Li, S. (2005). High Tech Spatial Concentration: Human Capital, Agglomeration Economies, Location Theories and Creative Cities. Doctoral dissertation, University of Louisville. Louisville, Kentucky. http://etd.louisville.edu/data/UofL0106d2005.pdf

Lichtenstein, G. A. \& Lyons, T. S. (1996) . Incubating New Enterprises: A Guide to Successful Practice. The Aspen Institute.

Lichtenstein, G. A. \& Lyons, T. S. (2001). The Entrepreneurial Development System: Transforming Business Talent and Community Economics. Economic Development Quarterly, Vol. 15, No. 1, pp. 3-20.

Lichtenstein, G. A., Lyons, T. S. \& Kutzhanova, N. (2004). Building Entrepreneurial Communities: The Appropriate Role of Enterprise Development Activities. Journal of Community Development Society. Vol. 35, No. 1, pp. 1-20. 
Logan, J. R. \& Alba, R. (1999). Minority Niches and Immigrant Enclaves in New York and Los Angeles: Trends and Impacts. In F. Bean and S. Rose-Bell (Eds.), Immigration and Opportunity (pp. 172-193). New York: Russell Sage.

Logan, J. R. \& Molotch, H. L. (1987). Urban Fortunes: The Political Economy of Place. Berkeley, CA: University of California Press.

Malanga, S. (2004). The Curse of the Creative Class. City Journal. Winter. Downloaded from http://www.city-journal.org/printable.php?id=1203.

Markley, D. M. (2004) Rural Economic Development: A Focus on Entrepreneurship. Conference presentation to the Rural Policy Academy, National Conference of State Legislatures, Salt Lake City, Utah. July 19.

McCracken, G. (1988). The Long Interview. Newbury Park: Sage Publications.

Mintzberg, H. \& Quinn, J. B. (1996) The Strategy Process: Concepts, Contexts and Cases. $\left(3^{\text {rd }}\right.$ ed.) New Jersey: Prentice Hall

Negrey, C. \& Rausch, S. (2004). Creativity, Class, and Gender: Comparing Women and Men in the Creative Economy. Revision of a paper presented at the annual meeting of the Urban Affairs Association, Washington, DC.

Peck, J. (2005). Struggling with the Creative Class. International Journal of Urban and Regional Research. Vol. 29, No. 4, pp. 740-770.

Peterson, P. E. (1981). City Limits. Chicago: University of Chicago Press.

Rausch, S. \& Negrey, C. (2006). Does the Creative Engine Run? A Consideration of the Effect of Creative Class on Economic Strength and Growth. Journal of Urban Affairs. Vol. 28, No. 5, pp. 473-489.

Ray, M. \& Myers, R. (1986). Creativity In Business. New York: Doubleday and Co., Inc.

Rubin, H. J. \& Rubin, I. S. (1995). Qualitative Interviewing: The Art of Hearing Data. Thousand Oaks, CA: Sage Publications.

Sampson, D. A. (2003) Entrepreneurship in a Growing Economy. Conference presentation. Main Streets of Tomorrow: Growing and Financing Rural Entrepreneurs. Center for the Study of Rural America. Kansas City, Missouri. April 28-29.

Sassen, S. (1999). The Global City. Princeton: Princeton University Press.

Savitch, H. V. \& Kantor, P. (2002). Cities in the International Marketplace. Princeton and Oxford: Princeton University Press.

Saxenian, A. (2002). Silicon Valley's New Immigrant High-Growth Entrepreneurs. Economic Development Quarterly. Vol. 16, No. 1, pp. 20-31. 
Scott, A. J. (2006) Creative Cities: Conceptual Issues and Policy Questions. Journal of Urban Affairs. Vol. 28, No. 1, pp. 1-17.

Self, R. O. (2003). American Babylon: Race and the Struggle for Postwar Oakland. Princeton and Oxford: Princeton University Press.

Simon, W. H. (2001). The Community Economic Development Movement: Law Business and the New Social Policy. Durham: Duke University Press

Stone, C. N. \& Sanders, H. (eds.) (1987). The Politics of Urban Development. Lawrence: University of Kansas Press.

Swanstrom, T. (1988). Semisovereign Cities: The Politics of Urban Development. Polity., Vol. 21, No. 1 (Autumn), pp. 83-110.

Tabachnick, B. \& Fidell, L. S. (2001). Using Multivariate Statistics, Fourth Edition. Boston: Allyn and Bacon.

Thomas, J. M. \& Darnton, J. (2006). Social Diversity and Economic Development in the Metropolis. Journal of Planning Literature. Vol 21, No. 2 (November): 1-16.

Williamson, T., Imbroscio, D. \& Alperovitz, G. (2003). Making a Place for Community. New York: Routledge

\subsection{Data Sources}

\subsubsection{Bureau of Labor Statistics Sources}

2000 Metropolitan Area Occupational Employment Survey: U. S. Bureau of Labor Statistics. 2000 Metropolitan Area Cross-industry Estimates. Downloadable from http://www.bls.gov/oes/oes_dl.htm\#2006

2006 Metropolitan Area Occupational Employment Survey: U. S. Bureau of Labor Statistics. 2006 Metropolitan Area Cross-industry Estimates. Downloadable from

http://www.bls.gov/oes/oes_dl.htm\#2006

Unemployment rates for 2000 through 2005 by MSA were downloaded from the Bureau of Labor Statistics at http://www.bls.gov/lau/home.htm\#data.

\subsubsection{Census Bureau Sources}

Educational Attainment: Summary File 3, Table P37. Sex by Educational Attainment for the Population 25+ Years. 
Finances of County Governments: 2002 available at http://www.census.gov/prod/2005pubs/gc02x43.pdf.

Foreign Born population: Summary File 3, Table P22. Year of Entry for the Foreign Born Population.

Homelessness: Homeless population: Emergency and Transitional Shelter Population: 2000. Census 2000 Special Reports. Issued October 2001. Poverty: http://www.census.gov/prod/2001pubs/censr01-2.pdf.

Home ownership for the year 2000: State and Metropolitan Area Data Book - 2006, Table B-7 available at http://www.census.gov/compendia/smadb/SMADBmetro.html

Notes to the Census 2000 report Housing Patterns - Appendix B http://www.census.gov/hhes/www/housing/housing_patterns/gettable_msa.html

Number of households with an unmarried male, or female householder with a same-sex partner: Summary File 4, Table PCT22. Households By Presence Of Nonrelatives.

Poverty: Summary File 3, Table P87. Poverty Status In 1999 By Age [17] - Universe: Population for whom poverty status is determined.

Sex By Occupation For The Employed Civilian Population 16 Years and Over. Census 2000 Table P50.

Total Population by MSA, CMSA, PMSA: Summary File 1, Table P1- Total Population. This data were used to compute the GMP per capita by MSA/CMSA.

Young single migration: http://www.census.gov/population/cen2000/phc-t34/tab02.xls

\subsubsection{Other Sources}

Crime: Crime per 100,000 Population: Crime Rates per 100,000 Population: http://www.fbi.gov/ucr/cius_02/html/web/offreported/02-table06WXYZ.html and calculation by author.

Gross Metropolitan Product: GMP is available online from the U. S. Conference of Mayors at http://www.usmayors.org/metroeconomies/0703/metroecon_appendix 0703.pdf for 1993 through 2003 data. Revised data for 2001 through 2004 are available at: http://www.usmayors.org/74thWinterMeeting/metroeconreport_January2006.pdf. Revised data for 2002 through 2005 are available at: http://www.usmayors.org/metroeconomies/0107/GMPreport.pdf.

Patents: United States Patent Grants by State, County, and Metropolitan Area (Utility Patents, 1990 - 1999). April 2000. Office for Patent and Trademark Information. U.S. Patent and Trademark Office, Washington, DC. 
Research funding granted colleges and universities: National Science Foundation. Downloaded from the NSF website at:

http://www.nsf.gov/statistics/nsf07318/tables/tab27.xls

School rankings: The Carnegie Foundation for the Advancement of Teaching (access from http://www.carnegiefoundation.org/classifications/index.asp?key=783)

The Milken tech pole index results from multiplying the high-tech percentage of national real output for an area by the high-tech location quotient for that same area. Data are available on line from the Milken Institute: America's High Tech Economy. Milken Institute. Available at http://www.milkeninstitute.org/pdf/hightech_metros.pdf.

Voting participation: U. S. 2000 Presidential Election Results by County available from http://spa.american.edu/ccps/pages.php?ID=12 


\title{
CURRICULUM VITA
}

\section{Stephen D. Rausch}

5500 Highlander Court

Greenville, Indiana 47124

(502)931-1543 (C) (812)923-8447 (H)

E-Mail: sdrausch@sbcglobal.net (home)

Soraus01@gwise.louisville.edu (school)

\section{$E D \cup C A T I O N$}

\author{
Bellarmine College \\ 1967 to 1971 \\ Louisville, Kentucky \\ BS Mathematics, magna cum Laude \\ Indiana University SouthEast \\ 1992 to 1996 \\ New Albany, Indiana \\ Master of Business Administration, Outstanding MBA Student 1996 \\ University of Louisville \\ 2003 to Present \\ Louisville, Kentucky \\ Doctoral Student in School of Urban and Public Affairs
}

Graduate Assistantship - Spring 2003 - Investigating the Incidence of Predatory Lending in Jefferson county, Kentucky - Report Published by Dr. Steven Bourassa February 2004.

Graduate Assistantship - Fall 2003/Spring 2004 - Teaching Assistant for Urban Sociology taught by Dr. Cynthia Negrey and research assistance on gender distinctions in the creative economy - coauthored paper presented at the 2004 Urban Affairs Association Annual Meeting.

Graduate Assistantship - Fall 2004/Spring 2005 - Taught Urban Sociology in Fall 2004 and provided research assistance to Dr. Cynthia Negrey on a general critique of Dr. Richard Florida's book on the creative class coauthored paper presented at the 2005 Urban Affairs Association Annual Meeting.

Graduate Assistantship - Fall 2005/Spring 2006 - Taught Urban Sociology in Fall 2005 and provided research assistance to Dr. Cynthia Negrey on a reevaluation of progressive versus booster cities originally done by Dr. David Rosdil concentrating the gender effects of boosterism versus progressivism. coauthored paper presented at the 2006 Urban Affairs Association Annual Meeting.

Doctoral candidate in the Department of Urban and Public Affairs (anticipated completion August 2007)

TE A C H I N G

Indiana University SouthEast New Albany, Indiana $\quad$ Spring and Summer 2007

Spring - Taught two sessions of D300 International Business and K201 Introduction to Excel and Access.

Summer - taught Marketing Foundations D304 
University of Louisville Louisville, Kentucky

Taught Economic Development (PLAN626/PADM645/POLS603/UPA640)

Louisville, Ky Sister Cities program adopted Juijiang, China as a sister City in 2004. In 2007

Juijiang sent a delegation of 7 government officials to Louisville to research and learn U.S. policy

and strategy. Co-taught Policy Analysis (April), Urban Budgeting and Finance (June) and

Research Methods (July) with a Chinese Graduate Student.

Indiana University SouthEast New Albany, Indiana Fall 2006

Taught two sessions of D300 International Business

University of Louisville Louisville, Kentucky

Fall 2005

Louisville, Ky Sister Cities program adopted Juijiang, China as a sister City in 2004. In 2005

Juijiang sent a delegation of 10 government officials to Louisville to research and learn U.S. policy

and strategy. Co-taught Research Methods and Urban Budgeting and Finance with a Chinese

Graduate Student.

University of Louisville Louisville, Kentucky

Fall 2004 and Fall 2005

Taught Urban Sociology (SOC 305)

University of Louisville Louisville, Kentucky

Fall 2002 and Spring 2003

Teaching Assistant for Urban Sociology course (SOC 305) -- Involved evaluating undergraduate student homework exercises and teaching one session on Economic Development

Indiana University SouthEast New Albany, Indiana 2000 to 2002

Adjunct Professor for eleven semesters (including 3 summer sessions) for

\section{E280 Applied Statistics for Business and Economics}

The course is basically separated into three sections. The objective of the first section is to enable the student to collect and summarize data; understand sampling; present summarized data in tables and charts; and utilize PHSTAT (A MicroSoft EXCEL add-in) to create descriptive statistics and various charts including the histogram. The objectives of the second section are to understand probability, learn the arithmetic associated with probabilities and apply probability concepts to decision making problems. Finally the objectives of the last section are to apply probability concepts to collected data to understand point and interval estimation and hypothesis testing and to solve problems using PHSTAT.

\section{S E R V I C E}

Served as president of the School of Urban and Public Affairs PhD student association for the 2004/2005 academic year.

Served as treasurer of the Graduate Student Council and as a graduate student senator in the Student government Association for the 2005/2006 academic year. Also served as the graduate student representative on the Faculty Senate subcommittee for library administration.

2005/2006 Jefferson County Public Schools academic year - participated in the "Every1Reads" tutoring program -- a program aimed at improving the reading skills of students reading below grade level. Two hours per week tutoring a $1^{\text {st }}$ grade reading student.

Elected to serve as treasurer of the GSC and graduate student senator for the academic year of 2006/2007 continued to serve on the Library subcommittee of the Faculty Senate. 


\section{$P \cup B L I C A T I O N S$}

Rausch, S. and Negrey, C. (2006). Does the Creative Engine Run? A Consideration of the Effect of Creative Class on Economic Strength and Growth. Journal of Urban Affairs, 28(5), 473-489.

Two other papers have been co-authored with Dr. Cynthia Negrey and have been presented at the Urban Affairs Association Annual meetings (2004 and 2006) and have been submitted to journals for publication.

\section{PR OFESSION A L EXPERIE N C E}

BellSouth Telecommunications, Inc.

Louisville, Kentucky

RETIRED

OCTOBER 1, 2002

MANAGER - REgulatory

November, 1987 to October, 2002

\section{Docket Management}

Developed strategies for accomplishing policy objectives in Kentucky on major regulatory issues, such as incentive regulation, intraLATA competition and price regulation. Also directed dockets dealing with the implementation of the Telecommunication Act of 1996 including arbitration proceedings, universal service considerations, access reform and interLATA relief.

\section{$\underline{\text { Regulatory Proceedings before the Kentucky Public Service Commission }}$}

- Critique written testimony, advise witnesses, develop lines of cross examination for opposition witnesses and oversee case logistics.

- Write and give sworn testimony in regulatory proceedings

Tariffs and Related Issues

Evaluate tariff filing packages for accuracy and consistency with policy objectives including market research, econometric studies, cost studies, priceouts and tariff language. File tariffs with the Commission and provide necessary support to secure approval. Specific areas: Intrastate access, intraLATA toll (including Kentucky Information Highway), operator and public coin services

Systems Manager - Marketing

SEPTEMBER, 1985 - NOVEMBER 1987

Supervised development of technical solutions for large business customers and development of specific customer rate proposals. Assisted in sales presentations to customers. Acted as liaison between sales force and network organizations.

\section{Manager - Network Administration \\ May, 1971 - September 1985}

Held various positions of increasing responsibility including both line supervision and staff assignments and a two year temporary assignment with AT\&T in Basking Ridge, New Jersey to write and conduct pilot training on the Network Management module of the Engineering and Administration Data Acquisition System. The Network Administration function involves the study of network usage, evaluating the provision of adequate network capacity and provision of customer specific software instructions to computer based switching systems.

\section{R E E R E C E S}

Available on Request 